\title{
Full-mouth treatment modalities (within 24 hours) for chronic periodontitis in adults (Review)
}

Eberhard J, Jepsen S, Jervøe-Storm PM, Needleman I, Worthington HV

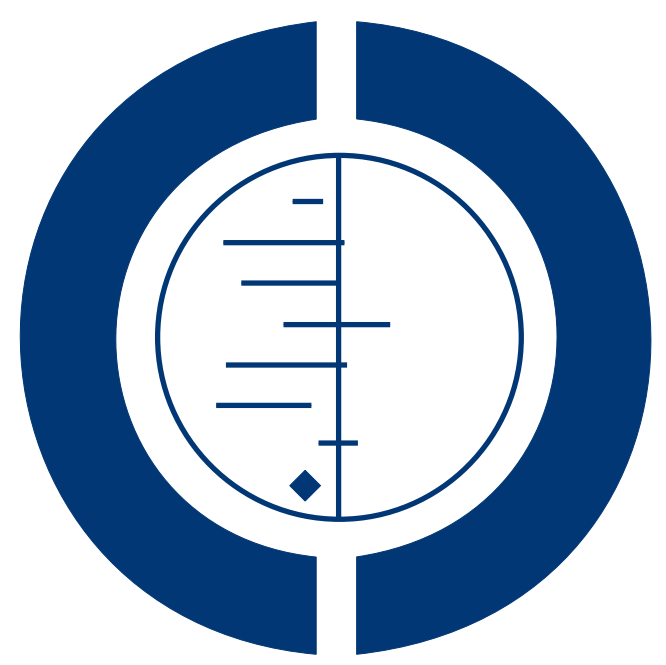

\section{THE COCHRANE COLLABORATION $^{\circledR}$}

This is a reprint of a Cochrane review, prepared and maintained by The Cochrane Collaboration and published in The Cochrane Library 2015, Issue 4

http://www.thecochranelibrary.com

\section{WILEY}

Full-mouth treatment modalities (within 24 hours) for chronic periodontitis in adults (Review)

Copyright $\odot 2015$ The Cochrane Collaboration. Published by John Wiley \& Sons, Ltd. 
TABLE OF CONTENTS

HEADER

ABSTRACT

PLAIN LANGUAGE SUMMARY . . . . . . . . . . . . . . . . . . . . . . . . . . . . . . . . . . . . .

SUMMARY OF FINDINGS FOR THE MAIN COMPARISON . . . . . . . . . . . . . . . . . . . . . . . 4

BACKGROUND . . . . . . . . . . . . . . . . . . . . . . . . . . . . . . . . . . . . 6

OBJECTIVES . . . . . . . . . . . . . . . . . . . . . . . . . . . . . . . . . . . . . . . . . . .

METHODS . . . . . . . . . . . . . . . . . . . . . . . . . . . . . . . . . . . . . . 6

RESULTS . . . . . . . . . . . . . . . . . . . . . . . . . . . . . . . . . . . . . . . 9

Figure 1. . . . . . . . . . . . . . . . . . . . . . . . . . . . . . . . . . . . . 10

Figure 2. . . . . . . . . . . . . . . . . . . . . . . . . . . . . . . . . . . . . . 12

Figure 3. . . . . . . . . . . . . . . . . . . . . . . . . . . . . . . . . . . . . . 13

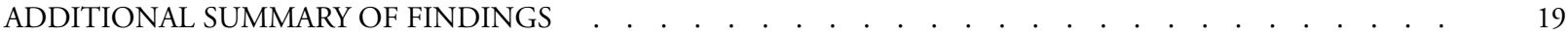

DISCUSSION . . . . . . . . . . . . . . . . . . . . . . . . . . . . . . . . . . . . . . . . . . .

AUTHORS' CONCLUSIONS . . . . . . . . . . . . . . . . . . . . . . . . . . . . . . . . . . . . . . . . .

ACKNOWLEDGEMENTS . . . . . . . . . . . . . . . . . . . . . . . . . . . . . . . . . 25

REFERENCES . . . . . . . . . . . . . . . . . . . . . . . . . . . . . . . . . . . . . 25

CHARACTERISTICS OF STUDIES . . . . . . . . . . . . . . . . . . . . . . . . . . . . . . . . . . . . . . . .

DATA AND ANALYSES . . . . . . . . . . . . . . . . . . . . . . . . . . . . . . . . . . . . . . . . . . . . . . . 48

Analysis 1.1. Comparison 1 FMS versus control, Outcome 1 Change in PPD: whole mouth, single-rooted teeth and multirooted teeth. . . . . . . . . . . . . . . . . . . . . . . . . . . . . . . . . . . 49

Analysis 1.2. Comparison 1 FMS versus control, Outcome 2 Change in CAL: whole mouth, single- and multi-rooted teeth.

Analysis 1.3. Comparison 1 FMS versus control, Outcome 3 Change in BOP: whole mouth, single- and multi-rooted teeth.

Analysis 2.1. Comparison 2 FMD versus control, Outcome 1 Change in PPD: whole mouth, single- and multi-rooted teeth.

Analysis 2.2. Comparison 2 FMD versus control, Outcome 2 Change in CAL: whole mouth, single- and multi-rooted teeth. .

Analysis 2.3. Comparison 2 FMD versus control, Outcome 3 Change in BOP: whole mouth, single- and multi-rooted teeth.

Analysis 3.1. Comparison 3 FMS versus FMD, Outcome 1 Change in PPD: whole mouth, single- and multi-rooted teeth.

Analysis 3.2. Comparison 3 FMS versus FMD, Outcome 2 Change in CAL: whole mouth, single- and multi-rooted teeth.

Analysis 3.3. Comparison 3 FMS versus FMD, Outcome 3 Change in BOP: whole mouth, single- and multi-rooted teeth.

ADDITIONAL TABLES ........ . . . . . . . . . . . . . . . . . . . . . 57

APPENDICES . . . . . . . . . . . . . . . . . . . . . . . . . . . . . . . . 66

WHAT'S NEW . . . . . . . . . . . . . . . . . . . . . . . . . . . . . . . . . . . . . 69

HISTORY . . . . . . . . . . . . . . . . . . . . . . . . . . . . . . . . . . . . . . . . 69

CONTRIBUTIONS OF AUTHORS . . . . . . . . . . . . . . . . . . . . . . . . . . . . . . . . . . . . . . . 69

DECLARATIONS OF INTEREST . . . . . . . . . . . . . . . . . . . . . . . . . . . . . . . . . . . . 70

SOURCES OF SUPPORT . . . . . . . . . . . . . . . . . . . . . . . . . . . . . . . . . . . 70

DIFFERENCES BETWEEN PROTOCOL AND REVIEW _. . . . . . . . . . . . . . . . . . . . . . . . . 70

NOTES . . . . . . . . . . . . . . . . . . . . . . . . . . . . . . . . . . . . . . 71

INDEX TERMS . . . . . . . . . . . . . . . . . . . . . . . . . . . . . . . . . . . 71

Full-mouth treatment modalities (within 24 hours) for chronic periodontitis in adults (Review)

Copyright $\odot 2015$ The Cochrane Collaboration. Published by John Wiley \& Sons, Ltd. 


\title{
[Intervention Review] \\ Full-mouth treatment modalities (within 24 hours) for chronic periodontitis in adults
}

\author{
Joerg Eberhard ${ }^{1}$, Sören Jepsen ${ }^{2}$, Pia-Merete Jervøe-Storm ${ }^{2}$, Ian Needleman ${ }^{3}$, Helen V Worthington ${ }^{4}$ \\ ${ }^{1}$ Prosthetic Dentistry and Biomaterials Science, Hannover Medical School, Hannover, Germany. ${ }^{2}$ Department of Periodontology, \\ Operative and Preventive Dentistry, University Hospital Bonn, Bonn, Germany. ${ }^{3}$ Unit of Periodontology and International Centre for \\ Evidence-Based Oral Healthcare, UCL Eastman Dental Institute, London, UK. ${ }^{4}$ Cochrane Oral Health Group, School of Dentistry, \\ The University of Manchester, Manchester, UK
}

Contact address: Joerg Eberhard, Prosthetic Dentistry and Biomaterials Science, Hannover Medical School, Carl-Neuberg-Straße 1, Hannover, 30625, Germany. eberhard.joerg@mh-hannover.de.

Editorial group: Cochrane Oral Health Group.

Publication status and date: New search for studies and content updated (no change to conclusions), published in Issue 4, 2015.

Review content assessed as up-to-date: 26 March 2015.

Citation: Eberhard J, Jepsen S, Jervøe-Storm PM, Needleman I, Worthington HV. Full-mouth treatment modalities (within 24 hours) for chronic periodontitis in adults. Cochrane Database of Systematic Reviews 2015, Issue 4. Art. No.: CD004622. DOI: 10.1002/14651858.CD004622.pub3.

Copyright (C) 2015 The Cochrane Collaboration. Published by John Wiley \& Sons, Ltd.

\begin{abstract}
A B S T R A C T
Background

Periodontitis is chronic inflammation that causes damage to the soft tissues and bones supporting the teeth. Mild to moderate periodontitis affects up to $50 \%$ of adults. Conventional treatment is quadrant scaling and root planing. In an attempt to enhance treatment outcomes, alternative protocols for anti-infective periodontal therapy have been introduced: full-mouth scaling (FMS) and full-mouth disinfection (FMD), which is scaling plus use of an antiseptic. This review updates our previous review of full-mouth treatment modalities, which was published in 2008.
\end{abstract}

\section{Objectives}

To evaluate the clinical effects of 1) full-mouth scaling (over 24 hours) or 2) full-mouth disinfection (over 24 hours) for the treatment of chronic periodontitis compared to conventional quadrant scaling and root planing (over a series of visits at least one week apart). A secondary objective was to evaluate whether there was a difference in clinical effect between full-mouth disinfection and full-mouth scaling.

\section{Search methods}

The following electronic databases were searched: the Cochrane Oral Health Group Trials Register (to 26 March 2015), the Cochrane Central Register of Controlled Trials (CENTRAL; The Cochrane Library 2015, Issue 2), MEDLINE via OVID (1946 to 26 March 2015), EMBASE via OVID (1980 to 26 March 2015) and CINAHL via EBSCO (1937 to 26 March 2015). We searched the US National Institutes of Health Trials Register (ClinicalTrials.gov) and the WHO International Clinical Trials Registry Platform for ongoing studies. There were no restrictions regarding language or date of publication in the searches of the electronic databases. We scanned reference lists from relevant articles and contacted the authors of eligible studies to identify trials and obtain additional information.

Full-mouth treatment modalities (within 24 hours) for chronic periodontitis in adults (Review)

Copyright (๑) 2015 The Cochrane Collaboration. Published by John Wiley \& Sons, Ltd. 


\section{Selection criteria}

We included randomised controlled trials (RCTs) with at least three months of follow-up that evaluated full-mouth scaling and root planing within 24 hours with adjunctive use of an antiseptic such as chlorhexidine (FMD) or without the use of antiseptic (FMS), compared to conventional quadrant scaling and root planing (control). Participants had a clinical diagnosis of chronic periodontitis according to the International Classification of Periodontal Diseases. We excluded studies of people with aggressive periodontitis, systemic disorders or who were taking antibiotics.

\section{Data collection and analysis}

Several review authors independently conducted data extraction and risk of bias assessment (which focused on method of randomisation, allocation concealment, blinding of examiners and completeness of follow-up). Our primary outcome was tooth loss and secondary outcomes were change in probing pocket depth (PPD), bleeding on probing (BOP) and probing attachment (i.e. clinical attachment level; CAL), and adverse events. We followed the methodological guidelines of The Cochrane Collaboration.

\section{Main results}

We included 12 trials, which recruited 389 participants. No studies assessed the primary outcome tooth loss.

Ten trials compared FMS and control; three of these were assessed as being at high risk of bias, three as unclear risk and four as low risk. There was no evidence for a benefit for FMS over the control for change in probing pocket depth (PPD), gain in probing attachment (i.e. clinical attachment level; CAL) or bleeding on probing (BOP). The difference in changes between FMS and control for whole mouth PPD at three to four months was $0.01 \mathrm{~mm}$ higher $(95 \% \mathrm{CI}-0.17$ to 0.19 , three trials, 82 participants). There was no evidence of heterogeneity. The difference in changes for CAL was $0.02 \mathrm{~mm}$ lower ( $95 \% \mathrm{CI}-0.26$ to 0.22 , three trials, 82 participants), and the difference in change in BOP was 2.86 per cent of sites lower (95\% CI -7.65 to 1.93, four trials, 120 participants).

We included six trials in the meta-analyses comparing FMD and control, with two trials assessed as being at high risk of bias, one as low and three as unclear. The analyses did not indicate a benefit for FMD over the control for PPD, CAL or BOP. The difference in changes for whole-mouth PPD between FMD and control at three to four months was $0.13 \mathrm{~mm}$ higher (95\% CI -0.09 to 0.34, two trials, 44 participants). There was no evidence of heterogeneity. The difference in changes for CAL was $0.04 \mathrm{~mm}$ higher $(95 \% \mathrm{CI}-0.25$ to 0.33 , two trials, 44 participants) and the difference in change in BOP being 12.59 higher for FMD (95\% CI -8.58 to 33.77 , three trials, 68 participants).

Three trials were included in the analyses comparing FMS and FMD. The mean difference in PPD change at three to four months was $0.11 \mathrm{~mm}$ lower (-0.34 to 0.12 , two trials, 45 participants) indicating no evidence of a difference between the two interventions. There was a difference in the gain in CAL at three to four months $(-0.25 \mathrm{~mm}, 95 \% \mathrm{CI}-0.42$ to -0.07 , two trials, 45 participants $)$, favouring FMD but this was not found at six to eight months. There was no evidence for a difference between FMS and FMD for BOP (-1.59, $95 \%$ CI -9.97 to 6.80 , two trials, 45 participants).

Analyses were conducted for different teeth types (single- or multi-rooted) and for teeth with different levels of probing depth at baseline, for PPD, CAL and BOP. There was insufficient evidence of a benefit for either FMS or FMD.

Harms and adverse events were reported in eight studies. The most important harm identified was an increased body temperature after FMS or FMD treatments.

We assessed the quality of the evidence for each comparison and outcome as 'low' because of design limitations leading to risk of bias and because of the small number of trials and participants, which led to imprecision in the effect estimates.

\section{Authors' conclusions}

The inclusion of five additional RCTs in this updated review comparing the clinical effects of conventional mechanical treatment with FMS and FMD approaches for the treatment of chronic periodontitis has not changed the conclusions of the original review. From the twelve included trials there is no clear evidence that FMS or FMD provide additional benefit compared to conventional scaling and root planing. In practice, the decision to select one approach to non-surgical periodontal therapy over another should include patient preference and the convenience of the treatment schedule.

\section{PLAIN LANGUAGE S UMMARY}

Treating all teeth (full mouth) within 24 hours for chronic gum disease (periodontitis) in adults

Full-mouth treatment modalities (within 24 hours) for chronic periodontitis in adults (Review)

Copyright $\odot 2015$ The Cochrane Collaboration. Published by John Wiley \& Sons, Ltd. 


\section{Review question}

Long lasting (chronic) gum disease causes damage to the gums and soft tissue structures around teeth. This review seeks to evaluate the effectiveness of full-mouth treatments carried out within 24 hours compared to the more conventional treatment of partial mouth scaling and root planing (SRP) usually done over a number of weeks. The treatments being reviewed are full-mouth scaling (FMS) and full-mouth disinfection (FMD). A secondary aim was to establish if there was a difference in effectiveness between FMS and FMD. This review updates our previous review published in 2008.

\section{Background}

Gum disease or periodontitis is a chronic inflammatory disease that causes damage to the soft tissue and bone around the teeth. Mild periodontitis is common in adults with severe periodontitis occurring in up to $20 \%$ of the population. Non-surgical treatments based on the mechanical removal of bacteria from infected root surfaces are used in order to arrest and control the loss of the bone and tissue that support the tooth in adults suffering from chronic gum disease. These treatments can be carried out in a different area of the mouth in separate sessions over a period of several weeks (SRP), which is the conventional method, or alternatively, can be done within 24 hours in one or two sessions, which is termed 'full-mouth scaling' (FMS). When an antiseptic agent (such as chlorhexidine for example) is added to the full-mouth scaling the intervention is called 'full-mouth disinfection' (FMD). The rationale for full-mouth approaches is that they may reduce the likelihood of re-infection in already treated sites.

\section{Study characteristics}

This review, carried out within the Cochrane Oral Health Group, is an update of one we published in 2008 and the evidence is current up to March 2015. We identified another five relevant studies for inclusion in this review and therefore this review includes 12 studies, which involved 389 participants. There is one Chinese study awaiting classification. Participants in the included studies were aged between 27 and 78 years, and there were roughly the same number of men and women involved.

The studies we included had to be randomised controlled trials with at least three months of follow-up that evaluated full-mouth scaling and root planing within 24 hours. Both FMS and FMD were compared to conventional quadrant scaling and root planing, which was the control group. Participants had to have a clinical diagnosis of chronic periodontitis according to the International Classification of Periodontal Diseases. We excluded studies of people with aggressive periodontitis, systemic disorders or who were taking antibiotics.

\section{Key results}

Treatment effects of FMS and FMD compared to conventional scaling and root planing (SRP) are modest and there are no clear implications for periodontal care. Harms and adverse events were reported in eight studies. The most important harm identified was an increased body temperature after FMS or FMD treatments. In practice, the decision to select one approach to non-surgical periodontal therapy over another can include patient preference and the convenience of the treatment schedule.

\section{Quality of the evidence}

The quality of the evidence is low for all treatment comparisons and outcomes. This is due to the small number of studies and participants involved and limitations in the study designs. Future research is likely to change findings. 


\section{SUMMARY OF FINDINGSFOR THE MAIN COMPARISON [Explanation]}

\section{FMS versus control for the treatment of adult chronic periodontitis}

Patient or population: adults with chronic periodontitis

Settings: university dental departments

Intervention: FMS versus control

\begin{tabular}{|c|c|c|c|c|c|c|}
\hline \multirow[t]{3}{*}{ Outcomes } & \multicolumn{2}{|c|}{ Illustrative comparative risks* (95\% CI) } & \multirow{3}{*}{$\begin{array}{l}\text { Relative effect } \\
\text { (95\% CI) }\end{array}$} & \multirow{3}{*}{$\begin{array}{l}\text { No of Participants } \\
\text { (studies) }\end{array}$} & \multirow{3}{*}{$\begin{array}{l}\text { Quality of the evidence } \\
\text { (GRADE) }\end{array}$} & \multirow[t]{3}{*}{ Comments } \\
\hline & Assumed risk & Corresponding risk & & & & \\
\hline & Control & FMS versus control & & & & \\
\hline Tooth loss & & & & & & $\begin{array}{l}\text { Not reported in any of the } \\
\text { trials. }\end{array}$ \\
\hline $\begin{array}{l}\text { Change in PPD; single- } \\
\text { and multi-rooted teeth - } \\
\text { Whole mouth } \\
\text { Follow-up: } 3-4 \text { months }\end{array}$ & $\begin{array}{l}\text { The mean change in PPD; } \\
\text { single- and multi-rooted } \\
\text { teeth - whole mouth } \\
\text { ranged across control } \\
\text { groups from } \\
\mathbf{0 . 6 9} \text { to } 2.51 \mathrm{~mm}\end{array}$ & $\begin{array}{l}\text { The mean change in PPD; } \\
\text { single- and multi-rooted } \\
\text { teeth - whole mouth in the } \\
\text { intervention groups was } \\
\mathbf{0 . 0 1} \text { higher } \\
(0.17 \text { lower to } 0.19 \\
\text { higher) }\end{array}$ & & $\begin{array}{l}82 \\
\text { (3 studies) }\end{array}$ & $\begin{array}{l}\oplus \oplus \oplus \bigcirc \\
\mathbf{l}_{\mathbf{0}} \mathbf{w}^{1}\end{array}$ & $\begin{array}{l}\text { Similar result was found } \\
\text { for the longer follow-up of } \\
6 \text { to } 8 \text { months } \\
\text { Subgroup analyses were } \\
\text { undertaken for 1) single- } \\
\text { and multi-rooted teeth } \\
\text { separately, and 2) for } \\
\text { teeth with initial moderate } \\
(5-6 \mathrm{~mm} \text { ) or high (> } 6 \\
\text { mm) levels of PPD } \\
\text { There was no consistent } \\
\text { evidence of a benefit for } \\
\text { FMS. }\end{array}$ \\
\hline
\end{tabular}

Change in CAL; single- The mean change in CAL; The mean change in CAL; and multi-rooted teeth - single- and multi-rooted single- and multi-rooted Whole mouth

Follow-up: 3-4 months teeth - whole mouth teeth - whole mouth in the ranged across control intervention groups was groups from

0.81 to $1.87 \mathrm{~mm}$
(3 studies)

\section{$\oplus \oplus \oplus \bigcirc$}

low

Similar result was found for the longer follow-up of 6 to 8 months

Subgroup analyses were undertaken for 1) singleand multi-rooted teeth 
higher)

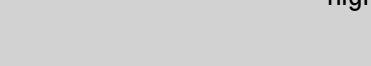

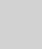

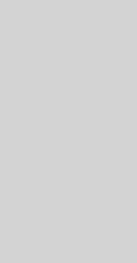

Change in BOP; single- The mean change in BOP; The mean change in BOP

and multi-rooted teeth - single- and multi-rooted single- and multi-rooted

Whole mouth teeth - whole mouth teeth - whole mouth in the

Follow-up: 3-4 months ranged across control intervention groups was groups from 2.86 lower 18 to 49.4 percent

\section{(7.65 lower to 1.93}

higher) separately, and 2) for teeth with initial moderate $(5-6 \mathrm{~mm})$ or high $(>6$ $\mathrm{mm}$ ) levels of PPD

There was no consistent evidence of a benefit for FMS.

\section{0}

(4 studies) $\oplus \oplus \oplus \bigcirc$

low $^{2}$
Similar result was found for the longer follow-up of 6 to 8 months

Subgroup analyses were undertaken for 1) singleand multi-rooted teeth separately, and 2) for teeth with initial moderate $(5-6 \mathrm{~mm})$ or high $(>6$ $\mathrm{mm}$ ) levels of PPD

There was no consistent evidence of a benefit for FMS.

*The basis for the assumed risk (e.g. the median control group risk across studies) is provided in footnotes. The corresponding risk (and its $95 \%$ confidence interval) is based on the assumed risk in the comparison group and the relative effect of the intervention (and its $95 \% \mathrm{Cl}$ ).

Cl: confidence interval; FMS: full mouth scaling; PPD: probing pocket depth; CAL: clinical attachment level; BOP: bleeding on probing (BOP)

\section{GRADE Working Group grades of evidence}

High quality: Further research is very unlikely to change our confidence in the estimate of effect.

Moderate quality: Further research is likely to have an important impact on our confidence in the estimate of effect and may change the estimate.

Low quality: Further research is very likely to have an important impact on our confidence in the estimate of effect and is likely to change the estimate.

Very low quality: We are very uncertain about the estimate.

${ }^{1}$ One trial at high, one at unclear and one at low risk of bias. Small number of studies and participants. Downgraded two levels for design limitations and imprecision.

2 One trial at high, two at unclear and one at low risk of bias. Small number of studies and participants. Downgraded two levels for design limitations and imprecision. 


\section{B A C K G R O U N D}

\section{Description of the condition}

Periodontitis is a chronic inflammatory disease affecting the tissues surrounding the teeth characterised by a progressive loss of the alveolar bone. Periodontitis is caused by microorganisms that adhere to and grow on the tooth surfaces. Some $5 \%$ to $20 \%$ of the population suffer from severe, generalised periodontitis, though mild to moderate periodontitis affects the majority of adults (AAP 2005; Oliver 1991).

Periodontitis is seen as resulting from a complex interplay of bacterial infection and host response, modified by behavioural and systemic risk factors. In people with periodontitis, key pathogens such as Aggregatibacter actinomycetemcomitans, Porphyromonas gingivalis and Prevotella intermedia have been found to colonise nearly all niches in the oral cavity, such as the tongue, the mucosa, the saliva and the tonsils (Beikler 2004). Translocation of these pathogens may occur rapidly and a recently instrumented deep pocket might be re-colonised from remaining untreated pockets or from other intraoral niches before a less pathogenic ecosystem can be established.

\section{Description of the intervention}

Conventional treatment involves scaling and root planing (SRP), which is done at several appointments over a period of weeks. There is considerable evidence to support SRP as an effective procedure for the treatment of infectious periodontal diseases (Heitz-Mayfield 2002; Van der Weijden 2002). However, based on the risk of re-colonisation hypothesis, a full-mouth disinfection (FMD) approach, which consists of SRP of all pockets in two visits within 24 hours, in combination with adjunctive chlorhexidine treatments of all oral niches, has been proposed (Quirynen 2006). This was first evaluated in a series of studies by the same research group (Bollen 1998; Mongardini 1999; Vandekerckhove 1996). A later report indicated that this full-mouth treatment approach resulted in superior clinical outcomes and microbiological effects than conventional quadrant SRP (control), irrespective of the adjunctive use of chlorhexidine (Quirynen 2000). More recent studies from other research centres, however, failed to demonstrate an advantage of full-mouth scaling within 24 hours versus the control regimen (Apatzidou 2004; Del Peloso 2008; Jervøe-Storm 2006; Knöfler 2007; Koshy 2005; Loggner Graff 2009; Swierkot 2009; Wennström 2005; Zanatta 2006; Zijnge 2010).

\section{How the intervention might work}

It is thought that the comprehensive reduction of bacteria from several oral niches by application of antiseptics within 24 hours will reduce the re-colonisation of already treated sites leading to reductions of probing pocket depth and bleeding on probing, and gains in clinical attachment.

\section{Why it is important to do this review}

This is an update of a Cochrane review published in 2008 (Eberhard 2008a). Three other systematic reviews (Eberhard 2008b; Farman 2008; Lang 2008) have been conducted to assess the evidence for full-mouth treatment modalities. A review article was published by the advocates of the full-mouth treatment concept (Teughels 2009), which disagreed with the results of these reviews. Our review update includes the most recent studies on this topic and ensures the evidence base for this important clinical question is up to date.

\section{O B JE C T IVES}

To evaluate the clinical effects of 1 ) full-mouth scaling (over 24 hours) or 2) full-mouth disinfection (over 24 hours) for the treatment of chronic periodontitis compared to conventional quadrant scaling and root planing (over a series of visits at least one week apart). A secondary objective was to evaluate whether there was a difference in clinical effect between full-mouth disinfection and full-mouth scaling.

\section{METHODS}

\section{Criteria for considering studies for this review}

\section{Types of studies}

Randomised controlled clinical trials (RCTs) with at least three months follow-up.

\section{Types of participants}

People with a clinical diagnosis of chronic periodontitis based on the International Classification of Periodontal Diseases (Armitage 1999). We did not include studies of people with aggressive periodontitis. Studies including only participants with systemic disorders were also excluded, as were studies including participants taking antibiotics. 


\section{Types of interventions}

1. Full-mouth scaling (FMS), comprising scaling and root planing of all quadrants within 24 hours

2. Full-mouth disinfection (FMD), comprising scaling and root planing of all quadrants within 24 hours along with adjunctive antiseptic treatments (such as chlorhexidine), which could include rinsing, pocket irrigation, spraying of the tonsils and tongue brushing

3. Quadrant scaling and root planing (control), comprising SRP of each quadrant at a separate session, each session separated by an interval of at least one week

The comparisons were: FMS versus control, FMD versus control and FMS versus FMD.

\section{Types of outcome measures}

\section{Primary outcomes}

- Tooth loss

- Change in probing pocket depth after three to four months and six to eight months

\section{Secondary outcomes}

- Change in clinical attachment level after three to four months and six to eight months

- Change in bleeding on probing after three to four months and six to eight months

- Adverse events

\section{Search methods for identification of studies}

\section{Electronic searches}

For the identification of studies for this review, we developed detailed search strategies for each database searched. These were based on the search strategy developed for MEDLINE (OVID) (Appendix 1) but revised appropriately for each database. The search strategy used a combination of controlled vocabulary and free text terms.

We searched the following electronic databases:

- The Cochrane Oral Health Group Trials Register (to 26 March 2015) (Appendix 2)

- The Cochrane Central Register of Controlled Trials (CENTRAL) (The Cochrane Library 2015, Issue 2) (Appendix 3)

- MEDLINE via OVID (1946 to 26 March 2015)

(Appendix 1)

- EMBASE via OVID (1980 to 26 March 2015) (Appendix

4)

- CINAHL via EBSCO (1937 to 26 March 2015) (Appendix 5)
A filter to limit the search to RCTs was not used as the yield was low. There were no restrictions on language or date of publication in the searches of the electronic databases.

\section{Searching other resources}

Incomplete information and ambiguous data were researched further by contacting the author and/or researcher responsible for the study directly. For unpublished material, the conference proceedings of the International Association for Dental Research (IADR), American Academy of Periodontology (AAP) and European Federation of Periodontology (EFP) were searched up to February 2014. Relevant 'in press' manuscripts were sought from Journal of Clinical Periodontology, Journal of Periodontology, Journal of Dental Research and Journal of Periodontal Research and by contact with the journal editors.

The following journals were handsearched:

- Journal of Periodontology (1980 to 5 February 2014)

- Journal of Clinical Periodontology (1980 to 5 February 2014)

- Journal of Periodontal Research (1980 to 5 February 2014)

We searched the following databases for ongoing trials (see Appendix 6 for the search strategy):

- US National Institutes of Health Trials Register (http:// clinicaltrials.gov) (to 26 March 2015)

- The WHO Clinical Trials Registry Platform (http:// apps.who.int/trialsearch/default.aspx) (to 26 March 2015)

\section{Data collection and analysis}

\section{Selection of studies}

Titles and abstracts were downloaded to EndNote 9 software. Two review authors (JE and SJ) carried out the selection of papers and decisions about eligibility independently, in duplicate. Any disagreements were resolved by discussion. Data extraction and data entry into a computer were carried out by four review authors (PS, HW, JE and SJ). We recorded reasons for studies that were rejected at full-text stage in Characteristics of excluded studies tables.

\section{Data extraction and management}

We extracted the following data:

- General study characteristics: year of the study, country of origin, authors, funding, university/private practice based

- Specific trial characteristics: population, diagnosis of chronic periodontitis, gender, age, severity of periodontal disease, inclusion and exclusion criteria not already stated

- Primary outcomes: probing depth (after three months if available, otherwise the nearest assessment time point evaluation) 
- Secondary outcomes: attachment level and bleeding on probing before and after different treatment modalities (after three months if available, otherwise the nearest assessment time point evaluation)

\section{Assessment of risk of bias in included studies}

The methodological quality of included studies was assessed mainly using the risk of bias components shown to affect study outcomes including method of randomisation, allocation concealment and blinding of examiners. Completeness of outcome reporting, selective outcome reporting and other potential threats to validity were also examined. Risk of bias was used in sensitivity analyses to test the robustness of the conclusions but was not used to exclude studies qualifying for the review. We used the definitions of risk of bias categories from the Cochrane Handbook for Systematic Reviews of Interventions (Higgins 2011) (see Appendix 7).

To examine overall risk of bias for each study, we used all the domains of risk of bias. If all domains were at low risk, the study was deemed to be at low risk of bias. If any domains had an unclear risk then the study was classed as having an unclear risk of bias; however, if one or more domains were assessed as being at a high risk of bias, then so was the study.

\section{Measures of treatment effect}

We used change scores for the secondary outcomes as this is how the data were generally presented in these trials. If only post scores or covariance adjusted means were presented, these were included and a subgroup analysis was conducted for the different outcome measures. For continuous outcomes, we used mean differences (MD) and 95\% confidence intervals (CI) to summarise the data for each group. For dichotomous outcomes, the estimates of effect of an intervention were expressed as risk ratios together with $95 \%$ CI.

\section{Unit of analysis issues}

Whole mouth, single-rooted teeth and multi-rooted teeth outcomes were the basis for data analysis, and we calculated means for all the primary and secondary outcomes. We did not feel that trials with a split-mouth or cross-over design were appropriate for this review due to potential carryover effects.

\section{Dealing with missing data}

We calculated missing standard deviations using the methods in Higgins 2011.

\section{Assessment of heterogeneity}

Prior to each meta analysis, we assessed heterogeneity by inspection of a graphical display of the estimated treatment effects from trials, along with Cochran's test for heterogeneity, and $\mathrm{I}^{2}$ statistics.

\section{Assessment of reporting biases}

We gave consideration to the different types of reporting bias that might have been present in this review. If there had been more than 10 studies included in a meta-analysis, we would have created a funnel plot to detect possible publication bias, although an asymmetrical funnel plot may be due to other factors. However, no single comparison of the present review included more than 10 studies.

\section{Data synthesis}

Where there were studies of similar comparisons reporting the same outcome measures, we performed a meta-analysis. We combined risk ratios for dichotomous data, and mean differences for continuous data, using the random-effects model.

We categorised teeth into the following groups for the meta-analysis, as these categories are thought to have clinical relevance: whole mouth (all teeth), teeth that had moderate pocket depth at baseline, teeth that had deep pocket depth at baseline. These analyses were repeated for single-rooted and multi-rooted teeth separately for all outcomes, and for two outcome assessment times: three to four months and six to eight months after treatment. Based on current treatment concepts we categorised the pocket depth of 4 to $6 \mathrm{~mm}$ as moderate and $7 \mathrm{~mm}$ or more as deep. This is described in more detail for each study in the results section.

\section{Subgroup analysis and investigation of heterogeneity}

We conducted subgroup analyses for different outcome measures (post, change, covariance adjusted). The following factors were recorded to assess the clinical heterogeneity of outcomes across studies:

- Plaque levels

- Time allowed for treatment

- Age of patients

- Initial probing depth

- Smoking status

- Risk of bias

There were insufficient studies in any one comparison to investigate any clinical heterogeneity.

\section{Sensitivity analysis}

We conducted sensitivity analyses by analysing only studies assessed as having low risk of bias, and by excluding unpublished literature. 


\section{RE S U L T S}

\section{Description of studies}

\section{Results of the search}

Two review authors (from JE, SJ and HV) screened 370 titles and abstracts and rejected 345. The full text was obtained for 25 potentially eligible articles. Of these, 10 studies (11 articles) were excluded and one, in Chinese, awaits assessment. We included 12 trials (reported in 13 articles) (Figure 1). The 12 included trials were Apatzidou 2004; Del Peloso 2008; Jervøe-Storm 2006; Knöfler 2007; Koshy 2005; Mongardini 1999; Quirynen 2006; Swierkot 2009; Vandekerckhove 1996; Wennström 2005; Zanatta 2006; and Zijnge 2010. The Mongardini 1999 trial was reported in two articles; one of the articles (Quirynen 2000) included a third group (described as FRp group) that was not randomised and therefore is not part of this review. 
Figure I. Study flow diagram

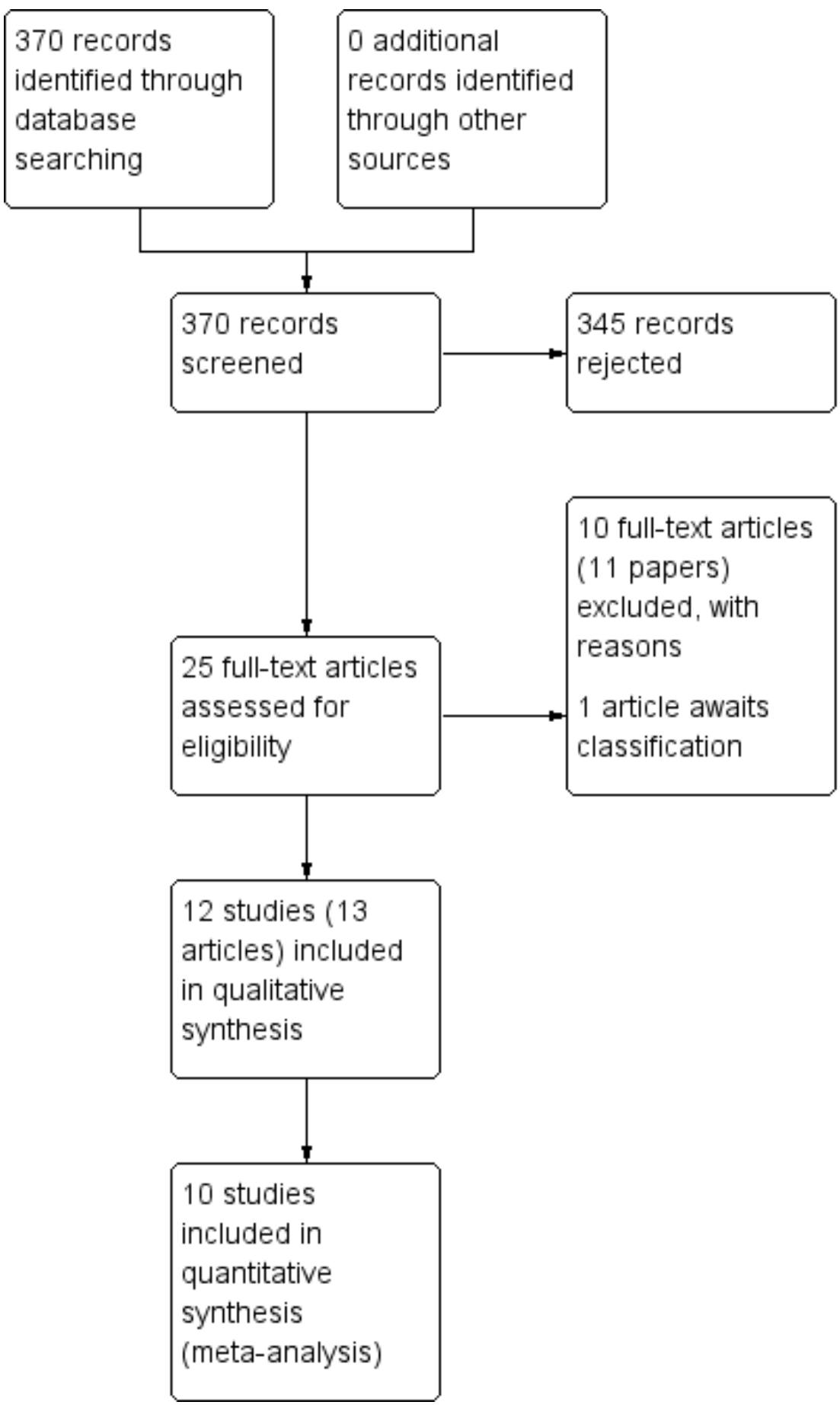




\section{Included studies}

\section{Design}

Nine of the included studies were conducted in Europe, two in Brazil (Del Peloso 2008; Zanatta 2006) and one in Japan (Koshy 2005). They were all parallel group trials of between 3 and 12 months duration.

\section{Participants}

In total, 389 patients were treated in the 12 included studies. They were all adults with chronic periodontitis, aged 23 to 75 years (one study did not specify the age range (Jervøe-Storm 2006)). Three of the studies involved non-smokers (Del Peloso 2008; Koshy 2005; Zijnge 2010); seven studies involved a mix of smokers and non-smokers; and two studies were unclear about smoking status (Knöfler 2007; Zanatta 2006). The number of patients enrolled in the included studies ranged from 10 to 85 . Seven trials had no drop-outs and the other trials had drop-outs ranging from $3 \%$ to $18 \%$.

\section{Interventions}

Four studies included more than one comparison. The comparisons included in the trials were:

- FMS versus control (10 trials): Apatzidou 2004; Del Peloso 2008; Jervøe-Storm 2006; Knöfler 2007; Koshy 2005; Quirynen 2006; Swierkot 2009; Wennström 2005; Zanatta 2006; Zijnge 2010

- FMD versus control (6 trials): Koshy 2005; Mongardini 1999; Quirynen 2006; Swierkot 2009; Vandekerckhove 1996; Zanatta 2006

- FMS versus FMD (4 trials): Koshy 2005; Quirynen 2006; Swierkot 2009; Zanatta 2006

\section{Outcomes}

None of the studies measured tooth loss.

Eight studies (Apatzidou 2004; Del Peloso 2008; Koshy 2005; Mongardini 1999; Swierkot 2009; Vandekerckhove 1996; Wennström 2005; Zijnge 2010) reported information about adverse events or patient-reported outcomes (see Table 1).

Ten studies provided whole-mouth data, with two studies only providing partial-mouth scores (Knöfler 2007; Quirynen 2006). Ten studies provided full information on the primary outcome 'change in probing pocket depth' (PPD), as well as on the secondary outcomes 'change in attachment loss' (CAL) and 'change in bleeding on probing' (BOP). One study reported only PPD and
BOP (Zijnge 2010); another reported only PPD (Vandekerckhove 1996). All studies provided change scores and we were able to use these in all analyses.

Seven studies provided data for the comparison of single- and multi-rooted teeth between FMS and control three or four (in the following, designated as 3/4) months after baseline (Del Peloso 2008; Jervøe-Storm 2006; Quirynen 2006; Swierkot 2009; Wennström 2005; Zanatta 2006; Zijnge 2010). Six studies provided these data after six or eight (in the following, designated as 6/8) months (Apatzidou 2004; Jervøe-Storm 2006; Knöfler 2007; Koshy 2005; Quirynen 2006; Swierkot 2009). There were two studies performing retreatment after three months (Del Peloso 2008; Wennström 2005), and another after six months (Knöfler 2007). These three studies were included in the meta-analysis, but only data measured before retreatment were used for the comparisons.

Five studies provided data for the comparison between FMD and control 3/4 months after baseline (Mongardini 1999; Quirynen 2006; Swierkot 2009; Vandekerckhove 1996; Zanatta 2006); five studies showed such data after 6/8 months (Koshy 2005; Mongardini 1999; Quirynen 2006; Swierkot 2009; Vandekerckhove 1996). Four studies compared the three different treatment modalities after 3/4 and 6/8 months (Koshy 2005; Quirynen 2006; Swierkot 2009; Zanatta 2006). Five studies separated the data into the subcategories 'single-rooted' or 'multirooted' teeth in terms of PPD (Koshy 2005; Mongardini 1999; Quirynen 2006; Swierkot 2009; Vandekerckhove 1996).

With regard to 'moderate' pocket depth, one study defined this as 4 to $5.5 \mathrm{~mm}$ (Quirynen 2006); three studies defined it as 4 to $6 \mathrm{~mm}$ (Knöfler 2007; Swierkot 2009; Zijnge 2010); one study defined it as $6 \mathrm{~mm}$ or less (Del Peloso 2008); while seven studies classified pocket depths of 5 to $6 \mathrm{~mm}$ as moderate (Apatzidou 2004; Jervøe-Storm 2006; Koshy 2005; Mongardini 1999; Vandekerckhove 1996; Wennström 2005; Zanatta 2006). Eleven studies defined 'deep' pockets as being $7 \mathrm{~mm}$ or more (Apatzidou 2004; Del Peloso 2008; Jervøe-Storm 2006; Knöfler 2007; Koshy 2005; Mongardini 1999; Swierkot 2009; Vandekerckhove 1996; Wennström 2005; Zanatta 2006; Zijnge 2010) and one study defined deep pockets as $6 \mathrm{~mm}$ or deeper (Quirynen 2006). Three studies provided data from the first quadrant only (Mongardini 1999; Quirynen 2006; Vandekerckhove 1996); another study included only premolars and molars (Knöfler 2007); the other eight studies generated the data from the whole mouth (Apatzidou 2004; Del Peloso 2008; Jervøe-Storm 2006; Koshy 2005; Swierkot 2009; Wennström 2005; Zanatta 2006; Zijnge 2010).

\section{Excluded studies}


We excluded 10 studies for the reasons below (see Characteristics of excluded studies).

- Type of disease (aggressive periodontitis, data not split regarding classification of periodontitis) (Bollen 1998)

- Intervention after 24 hours (Eren 2002)

- No control group (Jothi 2009)

- Retreatment of patients prior to outcome assessment at six months (Loggner Graff 2009)

- Length of follow-up was less than three months (Quirynen 1995)

- Several retreatments prior to outcome assessment at 18 months (Tomasi 2006)

- Participants in all arms received chlorhexidine rinse (Preus 2013)

- Immunological study, lack of clinical data (Ushida 2008)

- Data only available as figures; no reply from authors to request for supplemental data (Meulman 2013)

- 4-6 week follow-up data only (Serrano 2011)

\section{Risk of bias in included studies}

The risk of bias for each domain for each study is summarised in Figure 2 and Figure 3.

Figure 2. Risk of bias graph: review authors' judgements about each risk of bias item presented as percentages across all included studies

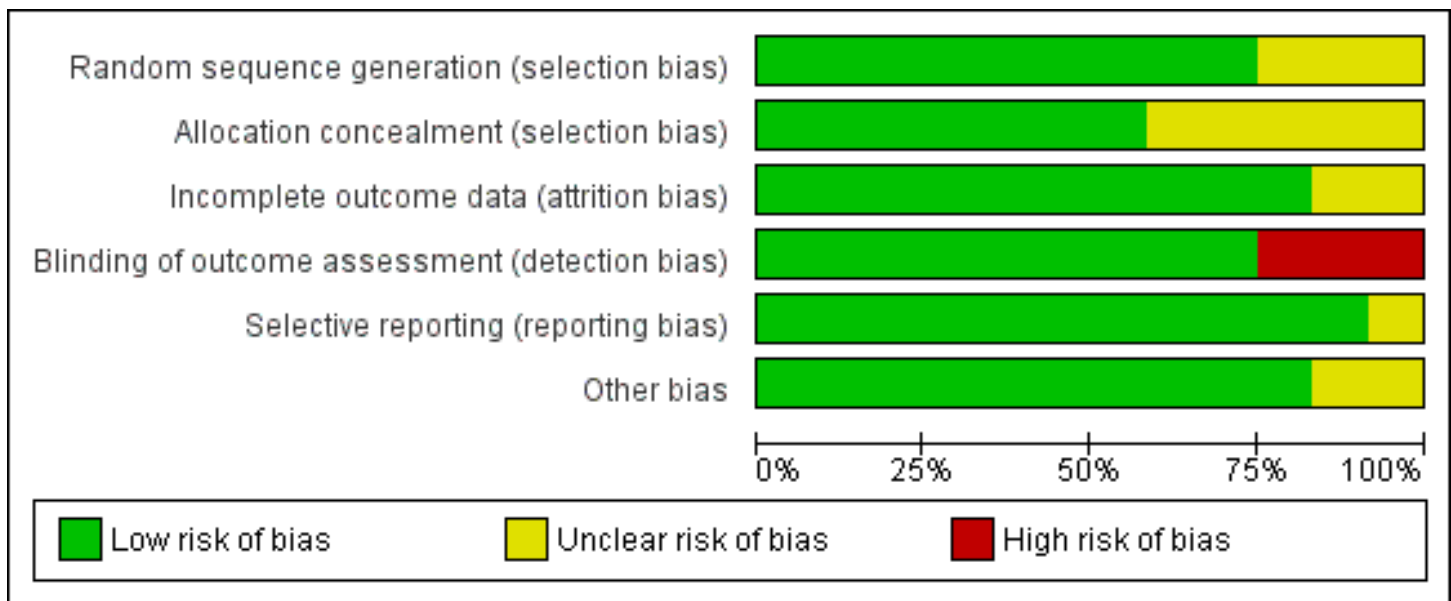

Full-mouth treatment modalities (within 24 hours) for chronic periodontitis in adults (Review) 
Figure 3. Risk of bias summary: review authors' judgements about each risk of bias item for each included study

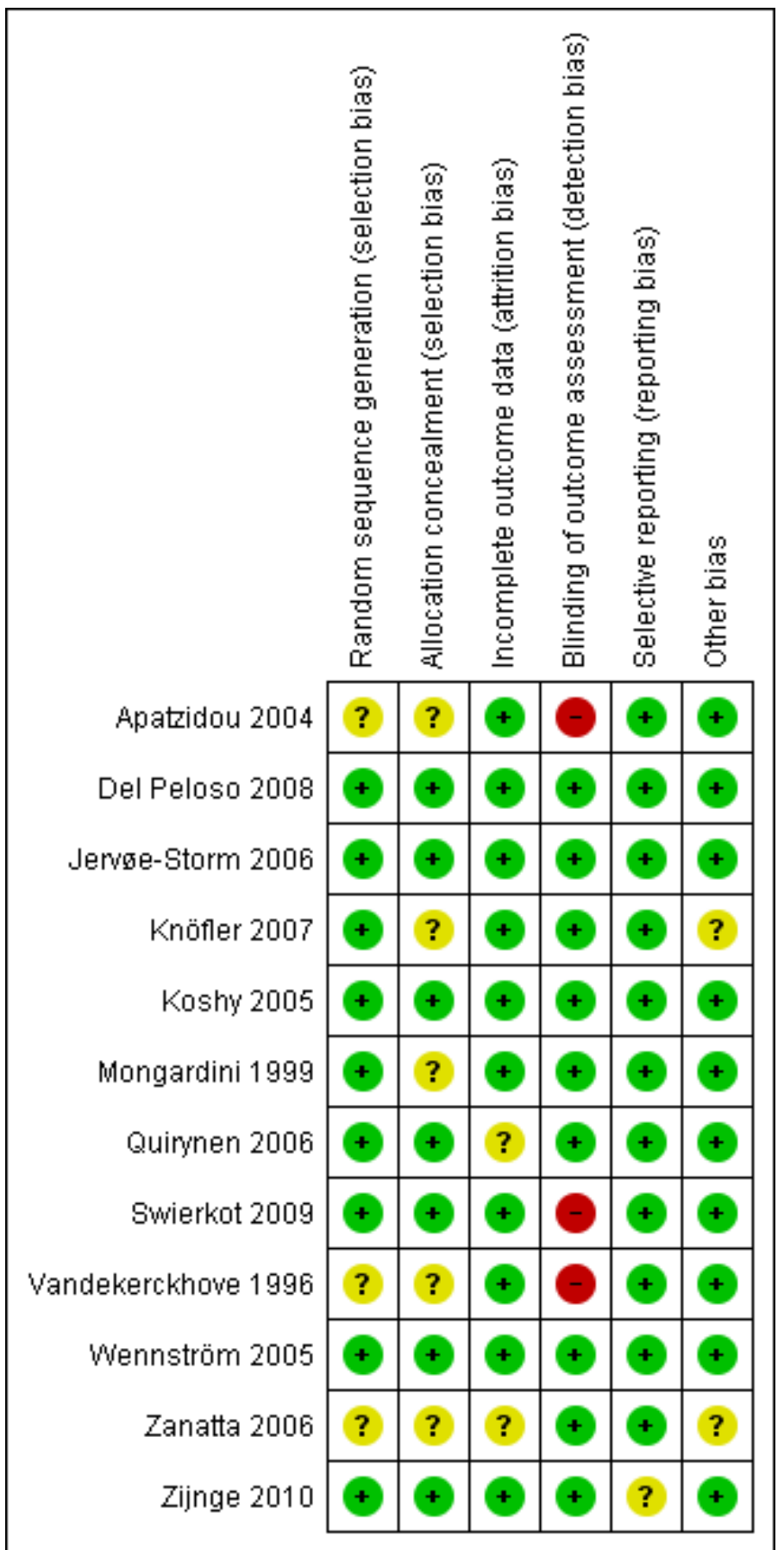

Full-mouth treatment modalities (within 24 hours) for chronic periodontitis in adults (Review)

Copyright $\odot 2015$ The Cochrane Collaboration. Published by John Wiley \& Sons, Ltd. 


\section{Allocation}

Six of the 12 trials described the method of randomisation, which was performed with the aid of a computer (Del Peloso 2008; Jervøe-Storm 2006; Koshy 2005; Quirynen 2006; Wennström 2005; Zijnge 2010). In three trials, the method of randomisation was a coin toss (Knöfler 2007; Mongardini 1999; Swierkot 2009). In three trials the method of randomisation was uncertain or not stated (Apatzidou 2004; Vandekerckhove 1996; Zanatta 2006). Seven trial reports provided adequate information about allocation concealment (Del Peloso 2008; Jervøe-Storm 2006; Koshy 2005; Quirynen 2006; Swierkot 2009; Wennström 2005; Zijnge 2010).

\section{Blinding}

The outcome assessor was blinded to the treatment groups in nine trials, and not blinded with a high risk of bias in three trials (Apatzidou 2004; Swierkot 2009; Vandekerckhove 1996).

\section{Incomplete outcome data}

The completeness of follow-up (the number of subjects who were entered into the study and subsequently finished it) was described adequately in 10 of the 12 trials (Apatzidou 2004; Del Peloso 2008; Jervøe-Storm 2006; Knöfler 2007; Koshy 2005; Mongardini 1999; Swierkot 2009; Vandekerckhove 1996; Wennström 2005; Zijnge 2010). Timing or reason for drop-out was not described in two studies, which were therefore considered to be at unclear risk of attrition bias (Quirynen 2006; Zanatta 2006).

\section{Selective reporting}

One study did not report CAL (Zijnge 2010), therefore risk of selective reporting was unclear for this study.

\section{Other potential sources of bias}

In two studies, the baseline balance for smoking was unclear and therefore they were assessed as having an unclear risk of bias ( Knöfler 2007; Zanatta 2006).

\section{Overall risk of bias}

Based on all domains, three studies were assessed as being at high risk of bias (Apatzidou 2004; Swierkot 2009; Vandekerckhove 1996) and four as low (Del Peloso 2008; Jervøe-Storm 2006; Koshy 2005; Wennström 2005), with the remaining five being assessed as unclear.

\section{Effects of interventions}

See: Summary of findings for the main comparison FMS versus control for the treatment of adult chronic periodontitis; Summary of findings 2 FMD versus control for the treatment of adult chronic periodontitis; Summary of findings 3 FMS versus FMD for the treatment of adult chronic periodontitis

\section{FMS versus control}

\section{Tooth loss}

None of the studies reported on the primary outcome - tooth loss.

\section{Change in probing pocket depth (PPD)}

Whole-mouth data are shown in a forest plot (Analysis 1.1) and other data in Table 2.

Three studies (one at high, one at unclear and one at low risk of bias) compared whole-mouth scores in single- and multi-rooted teeth after 3/4 months (Swierkot 2009; Wennström 2005; Zanatta 2006). There was no statistically significant difference between FMS and control for whole-mouth scores $(\mathrm{P}$ value $=0.90$, mean difference (MD) $0.01 \mathrm{~mm}, 95 \%$ confidence interval (CI) -0.17 to $0.19 ; \mathrm{Chi}^{2}=0.08,2$ degrees of freedom $(\mathrm{df}), \mathrm{P}_{\text {het }}=0.69, \mathrm{I}^{2}$ $=0 \%$ ). Four studies (two at high, one at unclear and one at low risk of bias) compared whole-mouth scores in single- and multirooted teeth after 6/8 months (Apatzidou 2004; Knöfler 2007; Koshy 2005; Swierkot 2009). There was no statistically significant difference between FMS and control for whole-mouth scores (P value $=0.73$, MD $0.03 \mathrm{~mm}, 95 \% \mathrm{CI}-0.12$ to $0.17 ; \mathrm{Chi}^{2}=2.34$, $\left.3 \mathrm{df}, \mathrm{P}_{\text {het }}=0.50, \mathrm{I}^{2}=0 \%\right)$.

We included six studies (one at high, two at unclear and three at low risk of bias) in the meta-analysis for moderate (five studies) and deep (six studies) pockets in single- and multi-rooted teeth after 3/4 months (Del Peloso 2008; Jervøe-Storm 2006; Swierkot 2009; Wennström 2005; Zanatta 2006; Zijnge 2010) (Table 2). There was no significant difference between FMS and control for the moderate pockets $(5$ to $6 \mathrm{~mm})(\mathrm{P}$ value $=0.46, \mathrm{MD}-0.05$ $\mathrm{mm}, 95 \% \mathrm{CI}-0.19$ to 0.09 ; $\mathrm{Chi}^{2}=0.8,5 \mathrm{df}, \mathrm{P}_{\text {het }}=0.94, \mathrm{I}^{2}=$ $0 \%)$ or deep pockets $(>6 \mathrm{~mm})(\mathrm{P}$ value $=0.69, \mathrm{MD}-0.05 \mathrm{~mm}$, $95 \%$ CI -0.31 to $\left.0.21 ; \mathrm{Chi}^{2}=3.89,5 \mathrm{df}, \mathrm{P}_{\text {het }}=0.57, \mathrm{I}^{2}=0 \%\right)$. We included four studies (one at high, one at unclear and two at low risk of bias) in the meta-analysis for moderate (three studies) and deep pockets (three studies) in single- and multi-rooted teeth after 6/8 months (Apatzidou 2004; Jervøe-Storm 2006; Knöfler 2007; Swierkot 2009) (Table 2). There was no significant difference between FMS and control for the moderate pockets ( 5 to 6 $\mathrm{mm})(\mathrm{P}$ value $=0.23, \mathrm{MD}-0.13 \mathrm{~mm}, 95 \% \mathrm{CI}-0.35$ to 0.08 ; Chi 
$\left.{ }^{2}=0.18,2 \mathrm{df}, \mathrm{P}_{\text {het }}=0.91, \mathrm{I}^{2}=0 \%\right)$. The same was found for the deep pockets $(>6 \mathrm{~mm})(\mathrm{P}$ value $=1.00, \mathrm{MD} 0.00 \mathrm{~mm}, 95 \% \mathrm{CI}$ 0.48 to $\left.0.48 ; \mathrm{Chi}^{2}=0.41,2 \mathrm{df}, \mathrm{P}_{\text {het }}=0.81, \mathrm{I}^{2}=0 \%\right)$.

\section{Single-rooted teeth (Table 2)}

One study at high risk of bias was included for single-rooted teeth alone after 3/4 months (Swierkot 2009). There was a significant difference for moderate pockets ( $\mathrm{P}=0.0002$, mean difference 0.63 $\mathrm{mm}, 95 \%$ CI 0.29 to 0.97 ); data for deep pockets were not available. We included three studies (one at high, one at unclear and one at low risk of bias) in the meta-analysis for single-rooted teeth alone after 6/8 months (Koshy 2005; Quirynen 2006; Swierkot 2009). There was no significant difference for moderate (P value $=0.06, \mathrm{MD} 0.16 \mathrm{~mm}, 95 \% \mathrm{CI}-0.01$ to $0.32 ; \mathrm{Chi}^{2}=0.24,2 \mathrm{df}$, $\left.\mathrm{P}_{\text {het }}=0.89, \mathrm{I}^{2}=0 \%\right)$ or deep pockets $(\mathrm{P}$ value $=0.27, \mathrm{MD} 0.26$ $\mathrm{mm}, 95 \% \mathrm{CI}-0.21$ to $0.73 ; \mathrm{Chi}^{2}=0.21,1 \mathrm{df}, \mathrm{P}_{\text {het }}=0.64, \mathrm{I}^{2}=$ $0 \%)$.

\section{Multi-rooted teeth (Table 2)}

The same three studies provided data for multi-rooted teeth. One study at high risk of bias, was included for multi-rooted teeth alone after 3/4 months (Swierkot 2009). There was a significant difference for moderate pockets in favour of FMS (P value $=0.0008$, MD $1.00 \mathrm{~mm}, 95 \%$ CI 0.41 to 1.59 ); data for deep pockets were not available. We included three studies (one at high, one at unclear and one at low risk of bias) in the meta-analysis for multirooted teeth alone after 6/8 months (Koshy 2005; Quirynen 2006; Swierkot 2009). There was no significant difference for moderate $\left(\mathrm{P}\right.$ value $=0.24, \mathrm{MD} 0.21 \mathrm{~mm}, 95 \% \mathrm{CI}-0.14$ to $0.55 ; \mathrm{Chi}^{2}=$ $5.60,2 \mathrm{df}, \mathrm{P}_{\text {het }}=0.06, \mathrm{I}^{2}=64 \%$ ) or deep pockets ( $\mathrm{P}$ value $=0.42$, MD $0.18 \mathrm{~mm}, 95 \% \mathrm{CI}-0.26 \mathrm{~mm}$ to $0.62 \mathrm{~mm} ; \mathrm{Chi}^{2}=0.65,1$ df, $\left.\mathrm{P}_{\text {het }}=0.42, \mathrm{I}^{2}=0 \%\right)$.

\section{Sensitivity analysis}

A sensitivity analysis was undertaken for low risk trials only for PPD at 6/8 months; the MD was 0.12 (-0.32 to 0.56 ; one trial), which is consistent with the overall finding of no evidence of a difference.

\section{Clinical attachment level (CAL)}

Whole-mouth data are shown in a forest plot (Analysis 1.2) and other data in Table 3.

We included three studies in the meta-analysis for whole-mouth scores in single- and multi-rooted teeth after 3/4 months (Swierkot 2009; Wennström 2005; Zanatta 2006), one at high, one at unclear and one at low risk of bias. We included five studies in the meta-analysis for moderate and deep pockets in single- and multirooted teeth (Del Peloso 2008; Jervøe-Storm 2006; Swierkot 2009;
Wennström 2005; Zanatta 2006). No significant differences between FMS and control were found for whole-mouth $(\mathrm{P}$ value $=$ 0.86, MD -0.02 mm), moderate pockets $(P=0.85$, MD $0.02 \mathrm{~mm}$ ) or deep pockets $(\mathrm{P}$ value $=0.57, \mathrm{MD} 0.09 \mathrm{~mm}$ ). There was no evidence of heterogeneity for the moderate or deep pockets, but some evidence for whole-mouth recording. We included four studies in the meta-analysis for whole-mouth scores in single- and multirooted teeth after 6/8 months (Apatzidou 2004; Knöfler 2007; Koshy 2005; Swierkot 2009), two at high, one at unclear and one at low risk of bias. Five studies were included in the meta-analysis for moderate and deep pockets in single- and multi-rooted teeth (Apatzidou 2004; Jervøe-Storm 2006; Knöfler 2007; Quirynen 2006; Swierkot 2009). No significant differences between FMS and control were found for whole-mouth $(\mathrm{P}$ value $=0.53, \mathrm{MD}$ $0.05 \mathrm{~mm}$ ), moderate pockets $(\mathrm{P}=0.40$, MD $0.09 \mathrm{~mm}$ ) or deep pockets ( $\mathrm{P}=0.89$, MD $0.05 \mathrm{~mm}$ ). There was no evidence of heterogeneity for the moderate pockets, but some evidence for wholemouth and deep pocket recordings.

\section{Single and multi-rooted teeth (Table 3)}

Only two studies (one at high and one at low risk of bias) provided data after 3/4 and 6/8 months for single-rooted and multi-rooted teeth alone (Koshy 2005; Swierkot 2009). A significant difference was observed for single-rooted teeth $(\mathrm{P}$ value $=0.05$, MD 0.41 $\mathrm{mm})$ and multi-rooted teeth $(P$ value $=0.0009, \mathrm{MD} 1.11 \mathrm{~mm})$ at $3 / 4$ months for moderate pockets in favour of FMS.

\section{Bleeding on probing (BOP)}

Whole-mouth data are shown in a forest plot (Analysis 1.3) and other data in Table 4.

We included five studies in the meta-analysis after 3/4 months for single- and multi-rooted teeth combined (Jervøe-Storm 2006; Swierkot 2009; Wennström 2005; Zanatta 2006; Zijnge 2010), one at high, two at unclear and two at low risk of bias. There was no significant difference between FMS and control for the whole-mouth evaluation ( $\mathrm{P}$ value $=0.24, \mathrm{MD}-2.86 \%$ ), , moderate pockets $(\mathrm{P}$ value $=0.48, \mathrm{MD}-8.05 \%)$ or deep pockets ( $\mathrm{P}$ value $=0.93, \mathrm{MD}-0.33 \%)$. There was no evidence of heterogeneity between the trials. We included five studies in the meta-analysis after $6 / 8$ months for single- and multi-rooted teeth combined (Apatzidou 2004; Jervøe-Storm 2006; Knöfler 2007; Koshy 2005; Swierkot 2009), two at high, one at unclear and two at low risk of bias. There was no significant difference between FMS and control for the whole-mouth evaluation $(\mathrm{P}=0.59$, mean difference $1.98 \%$ ), moderate pockets (P value $=0.41, \mathrm{MD}-4.94 \%$ ) or deep pockets $(\mathrm{P}$ value $=0.06, \mathrm{MD} 10.22 \%)$. There was no evidence of heterogeneity for the moderate pockets, but some evidence for whole-mouth recording. 


\section{Single and multi-rooted teeth (Table 4)}

Only two studies (Quirynen 2006; Swierkot 2009), with high and unclear risk of bias, provided data after $3 / 4$ and $6 / 8$ months for single-rooted teeth alone. No significant differences for moderate $(\mathrm{P}=0.42, \mathrm{MD} 3.06 \%)$ and deep $(\mathrm{P}=0.63, \mathrm{MD} 4.00 \%)$ pockets after $6 / 8$ months were found. The same two studies provided data after 3/4 and 6/8 months for multi-rooted teeth; only one significant difference was found in favour of FMS, which was for moderate pockets after $3 / 4$ months $(\mathrm{P}<0.00001$, mean difference $7.00 \%)$.

It must be stated that whole-mouth evaluation was defined differently among the studies. In five studies, evaluation was carried out on all pockets (Apatzidou 2004; Koshy 2005; Swierkot 2009; Wennström 2005; Zanatta 2006); one study evaluated only pockets initially $>3 \mathrm{~mm}$ (Zijnge 2010); one study evaluated only pockets initially $>5 \mathrm{~mm}$ (Jervøe-Storm 2006); one study evaluated only premolars and molars (Knöfler 2007; one study only reported results in the subcategories single- or multi-rooted teeth (Quirynen 2006); and one study evaluated only pockets of the upper right quadrant (Vandekerckhove 1996).

\section{FMD versus control}

\section{Tooth loss}

None of the studies reported on the primary outcome - tooth loss.

\section{PPD}

Whole-mouth data are shown in a forest plot (Analysis 2.1) and other data in Table 5.

Two studies (one at high and one at unclear risk of bias) compared whole-mouth scores in single- and multi-rooted teeth after 3/4 months (Swierkot 2009; Zanatta 2006). There was no statistically significant difference between FMD and control for whole-mouth scores $(\mathrm{P}$ value $=0.25, \mathrm{MD} 0.13 \mathrm{~mm}, 95 \% \mathrm{CI}-0.09$ to 0.34 ; Chi $2=0.46,1 \mathrm{df}, \mathrm{P}_{\text {het }}=0.50, \mathrm{I}^{2}=0 \%$ ). Two studies (one at high and one at low risk of bias) made the same comparison after $6 / 8$ months (Koshy 2005; Swierkot 2009). There was no statistically significant difference between FMD and control for whole-mouth scorings ( $\mathrm{P}$ value $=0.41, \mathrm{MD} 0.14 \mathrm{~mm}, 95 \% \mathrm{CI}-0.19$ to 0.46 ; $\mathrm{Chi}^{2}=0.89,1 \mathrm{df}, \mathrm{P}_{\text {het }}=0.35, \mathrm{I}^{2}=0 \%$ ).

One study at unclear risk of bias was included for moderate pockets in single- and multi-rooted teeth after 3/4 months (Zanatta 2006). There was no significant difference between FMD and control for the moderate pockets ( 5 to $6 \mathrm{~mm})(\mathrm{P}$ value $=0.45, \mathrm{MD}-0.12$ $\mathrm{mm}$ ). For deep pockets the meta-analysis of two studies (Swierkot 2009; Zanatta 2006) with high and unclear risk of bias showed a significant difference in favour of the control treatment $(\mathrm{P}$ value $=$ $0.04, \mathrm{MD}-0.56 \mathrm{~mm}, 95 \% \mathrm{CI}-1.10$ to -0.03 ; $\mathrm{Chi}^{2}=1.40,1 \mathrm{df}$, $\left.\mathrm{P}_{\text {het }}=0.24, \mathrm{I}^{2}=29 \%\right)$.
Only one study at high risk of bias was included for moderate and deep pockets in single- and multi-rooted teeth after 6/8 months ( Swierkot 2009). There was no significant difference between FMD and control for the moderate $(\mathrm{P}$ value $=0.41, \mathrm{MD} 0.14 \mathrm{~mm}, 95 \%$ $\mathrm{CI}-0.19$ to 0.46 ) and the deep pockets ( $\mathrm{P}$ value $=0.47$, MD -0.14 $\mathrm{mm}, 95 \% \mathrm{CI}-0.52$ to 0.24 ).

\section{Single-rooted teeth (Table 5)}

We included three studies (Mongardini 1999; Swierkot 2009; Vandekerckhove 1996), two at high and one at unclear risk of bias, in the meta-analysis for single-rooted teeth alone after 3/4 months. No significant differences were found for moderate ( $\mathrm{P}$ $=0.52$, mean difference $-0.28 \mathrm{~mm})$ or deep pockets $(\mathrm{P}=0.15$, mean difference $1.28 \mathrm{~mm}$ ) with a high degree of heterogeneity. We included five studies (Koshy 2005; Mongardini 1999; Quirynen 2006; Swierkot 2009; Vandekerckhove 1996), two at high, one at unclear and two at low risk of bias, in the meta-analysis after $6 / 8$ months for single rooted teeth alone. There were significant differences in favour of FMD for moderate $(\mathrm{P}$ value $=0.006, \mathrm{MD}$ $0.41 \mathrm{~mm}, 95 \%$ CI 0.11 to 0.70 ; $\mathrm{Chi}^{2}=13.13,4 \mathrm{df}, \mathrm{P}_{\text {het }}=0.01$, $\left.\mathrm{I}^{2}=70 \%\right)$ and deep pockets $(\mathrm{P}$ value $=0.05$, MD $0.78 \mathrm{~mm}, 95 \%$ $\mathrm{CI}-0.01$ to 1.57 ; $\mathrm{Chi}^{2}=9.41,3 \mathrm{df}, \mathrm{P}_{\text {het }}=0.03, \mathrm{I}^{2}=67 \%$ ) with a high degree of heterogeneity.

\section{Multi-rooted teeth (Table 5)}

The same three studies provided data for multi-rooted teeth. After 3/4 months there was no significant difference for moderate pockets, but we found a significant difference for deep pockets (two studies (Mongardini 1999; Vandekerckhove 1996); P value $=0.003, \mathrm{MD} 1.28 \mathrm{~mm}, 95 \% \mathrm{CI} 0.44$ to $2.11 \mathrm{Chi}^{2}=0.01,1 \mathrm{df}$, $\left.\mathrm{P}_{\text {het }}=0.92, \mathrm{I}^{2}=0 \%\right)$ in favour of FMD. We included five studies (Koshy 2005; Mongardini 1999; Quirynen 2006; Swierkot 2009; Vandekerckhove 1996), two at high, one at unclear and two at low risk of bias, in the meta-analysis for multi-rooted teeth alone after $6 / 8$ months. There was no significant difference for moderate $(\mathrm{P}$ value $=0.21, \mathrm{MD} 0.21 \mathrm{~mm}, 95 \% \mathrm{CI}-0.12$ to $0.53 ; \mathrm{Chi}^{2}=10.56$, $\left.4 \mathrm{df}, \mathrm{P}_{\text {het }}=0.03, \mathrm{I}^{2}=62 \%\right)$ or deep pockets $(\mathrm{P}$ value $=0.16, \mathrm{MD}$ $0.56 \mathrm{~mm}, 95 \% \mathrm{CI}-0.23$ to $1.34, \mathrm{Chi}^{2}=8.52,3 \mathrm{df}, \mathrm{P}_{\text {het }}=0.04$, $\left.\mathrm{I}^{2}=56 \%\right)$.

\section{Sensitivity analysis}

We undertook a sensitivity analysis for low risk of bias trials only for change in PPD at $6 / 8$ months. The MD was $0.23(-0.15$ to 0.61 ; one trial), which is consistent with the overall finding of no evidence of a difference.

\section{CAL}

Whole-mouth data are shown in a forest plot (Analysis 2.2) and other data in Table 6. 
We included two studies in the meta-analysis for whole-mouth scores in single- and multi-rooted teeth after 3/4 months (Swierkot 2009; Zanatta 2006), one at high and one at unclear risk of bias. One study was included for moderate (Zanatta 2006) and two for deep pockets in single- and multi-rooted teeth (Swierkot 2009; Zanatta 2006). We did not find any significant differences between FMD and control for whole mouth ( $\mathrm{P}$ value $=0.79$, mean difference $0.04 \mathrm{~mm})$, moderate pockets $(\mathrm{P}$ value $=0.37$, mean difference $0.18 \mathrm{~mm}$ ) or deep pockets $(\mathrm{P}=0.42$, mean difference $0.39 \mathrm{~mm}$ ). There was evidence of heterogeneity in the deep pockets data. We included two studies in the meta-analysis for wholemouth scores in single- and multi-rooted teeth after 6/8 months (Koshy 2005; Swierkot 2009), one at high and one at low risk of bias. No studies provided data for moderate pockets and only one study was included for deep pockets in single- and multi-rooted teeth (Swierkot 2009). No significant differences between FMD and control were found for whole mouth $(\mathrm{P}$ value $=0.77, \mathrm{MD}$ $0.03 \mathrm{~mm}$ ) or deep pockets (P value $=0.20, \mathrm{MD}-0.16 \mathrm{~mm}$ ). There was no evidence of heterogeneity.

\section{Single-rooted teeth (Table 6)}

Two studies (Mongardini 1999; Swierkot 2009), at high and unclear risk of bias, provided data after 3/4 months for single-rooted teeth alone. A significant difference was only observed for deep pockets in favour of FMD (P value = 0.001, MD $1.90 \mathrm{~mm} ; 95 \%$ CI 0.73 to 3.07). Three studies (Koshy 2005; Mongardini 1999; Swierkot 2009), one at high, one at unclear and one at low risk of bias, provided data after $6 / 8$ months for single-rooted teeth alone. A significant difference was observed for moderate pockets in favour of FMD (P value $=0.05$, MD $0.14 \mathrm{~mm}$; 95\% CI 0.00 to 0.28$)$.

\section{Multi-rooted teeth (Table 6)}

Two studies (Mongardini 1999; Swierkot 2009) with high and unclear risk of bias provided data after $3 / 4$ months for multi-rooted teeth. A significant difference was observed for deep pockets in favour of FMD ( $\mathrm{P}=0.02$, MD $1.30 \mathrm{~mm}$; $95 \% \mathrm{CI} 0.20$ to 2.40 ). Three studies (Koshy 2005; Mongardini 1999; Swierkot 2009), one at high, one unclear and one at low risk of bias, provided data after 6/8 months for multi-rooted teeth. No significant difference was found for moderate $(\mathrm{P}$ value $=0.43, \mathrm{MD} 0.12 \mathrm{~mm}$; $95 \% \mathrm{CI}$ -0.17 to 0.41 ) or deep pockets ( $\mathrm{P}=0.57$, MD $0.52 \mathrm{~mm}$; $95 \% \mathrm{CI}$ -1.30 to 2.34 ), with high risk of heterogeneity.

\section{BOP}

Whole-mouth data are shown in a forest plot (Analysis 2.3) and other data in Table 7.

We included three studies in the meta-analysis after 3/4 months for single- and multi-rooted teeth combined (Mongardini 1999; Swierkot 2009; Zanatta 2006), one at high and two at unclear risk of bias. There was no significant difference between FMD and control for the whole-mouth evaluation (P value $=0.24, \mathrm{MD}$ $12.59 \%, 95 \%$ CI $-8.58 \%$ to $33.77 \%$ ) or deep pockets (P value $=0.14, \mathrm{MD}-5.00 \%, 95 \% \mathrm{CI}-11.70 \%$ to $1.70 \%)$; no data were available for moderate pockets. We included three studies in the meta-analysis after $6 / 8$ months for single- and multi-rooted teeth combined (Koshy 2005; Mongardini 1999; Swierkot 2009), one at high, one at unclear and one at low risk of bias. There was no significant difference between FMD and control for the wholemouth evaluation $(\mathrm{P}$ value $=0.14, \mathrm{MD} 12.56 \%$, 95\% CI $-4.01 \%$ to $29.13 \%$ ) or deep pockets (P value $=0.69, \mathrm{MD} 2.00 \%, 95 \% \mathrm{CI}$ $-7.83 \%$ to $11.83 \%$ ); no data were provided for moderate pockets. There was evidence of heterogeneity for the whole-mouth findings.

\section{Single-rooted teeth (Table 7)}

Only one study (Swierkot 2009), at high risk of bias, provided data after 3/4 months for single-rooted teeth alone. A significant difference for moderate pockets was found in favour of FMD ( $P$ value $=0.001, \mathrm{MD} 5.00 \%$, 95\% CI $1.97 \%$ to $8.03 \%$ ); no data were available for deep pockets. Two studies (Quirynen 2006; Swierkot 2009), one at high and one at unclear risk of bias, provided data after $6 / 8$ months for single-rooted teeth. A significant difference for moderate pockets was found in favour of FMD ( $\mathrm{P}$ value $=$ $0.001, \mathrm{MD} 4.83 \%$, 95\% CI $1.86 \%$ to $7.80 \%$; $\mathrm{Chi}^{2}=0.28,1 \mathrm{df}$, $\left.\mathrm{P}=0.60, \mathrm{I}^{2}=0 \%\right)$. For deep pockets, no significant difference was found (P value $=0.09$, MD $14.00 \%, 95 \%$ CI $-2.17 \%$ to $30.17 \%$ ).

\section{Multi-rooted teeth (Table 7)}

Only one study (Swierkot 2009), at high risk of bias, provided data after 3/4 months for multi-rooted teeth. A significant difference for moderate pockets was found in favour of FMD (P value $=0.02$, MD $2.00 \%$, 95\% CI $0.38 \%$ to $3.62 \%$ ). No data were available for deep pockets. Two studies (Quirynen 2006; Swierkot 2009), one at high and one at unclear risk of bias, provided data after $6 / 8$ months for multi-rooted teeth. No significant difference for moderate (P value $=0.13$, MD $8.72 \%, 95 \% \mathrm{CI}-2.61 \%$ to $20.06 \%)$ or deep pockets was found $(\mathrm{P}$ value $=0.36, \mathrm{MD}-8.00 \%, 95 \% \mathrm{CI}-25.00 \%$ to $9.00 \%)$.

\section{FMS versus FMD}

\section{FMS versus FMD: tooth loss}

None of the studies reported on the primary outcome - tooth loss.

\section{FMS versus FMD: PPD}

Whole-mouth data are shown in a forest plot (Analysis 3.1) and other data in Table 8. 
Two studies (Swierkot 2009; Zanatta 2006), one at high and one at unclear risk of bias, compared whole-mouth scores in singleand multi-rooted teeth after 3/4 months. There was no significant difference between FMS and FMD for whole-mouth scores (P value $=0.37, \mathrm{MD}-0.11 \mathrm{~mm}, 95 \% \mathrm{CI}-0.34$ to 0.12 ). Two studies (Koshy 2005; Swierkot 2009), one at high and one at low risk of bias, made the same comparison after $6 / 8$ months. There was no statistically significant difference between FMS and FMD for whole-mouth scores $(\mathrm{P}$ value $=0.97, \mathrm{MD} 0.00 \mathrm{~mm}, 95 \% \mathrm{CI}-$ 0.28 to 0.29 ).

We included two studies (Swierkot 2009; Zanatta 2006), one at high and one at unclear risk of bias, in the meta-analysis for moderate pockets in single- and multi-rooted teeth after 3/4 months. There was no significant difference between FMS and FMD for the moderate pockets $(\mathrm{P}$ value $=0.44, \mathrm{MD}-0.13 \mathrm{~mm}, 95 \% \mathrm{CI}$ 0.46 to 0.20 ; Zanatta 2006). For deep pockets, the meta-analysis of two studies (Swierkot 2009; Zanatta 2006) showed no significant difference $(\mathrm{P}$ value $=0.15, \mathrm{MD} 0.95 \mathrm{~mm}, 95 \% \mathrm{CI}-0.33$ to 2.23).

Only one study at high risk of bias was included in the analysis for deep pockets in single- and multi-rooted teeth after $6 / 8$ months (Swierkot 2009). There was no significant difference between FMS and FMD $(\mathrm{P}=0.58, \mathrm{MD} 0.17 \mathrm{~mm}, 95 \% \mathrm{CI}-0.43 \mathrm{~mm}$ to 0.77 $\mathrm{mm})$.

\section{Single-rooted teeth (Table 8)}

One study (Swierkot 2009) at high risk of bias was included in the analysis for single-rooted teeth alone after $3 / 4$ months. There was a significant difference found for moderate pockets in favour of FMS (P value < 0.00001 , MD $0.95 \mathrm{~mm}, 95 \%$ CI 0.65 to 1.25 ); data for deep pockets were not provided. We included three studies (Koshy 2005; Quirynen 2006; Swierkot 2009), one at high, one at unclear, and one at low risk of bias, in the meta-analysis after $6 / 8$ months for single-rooted teeth. There were no significant differences for moderate $(\mathrm{P}$ value $=0.52, \mathrm{MD}-0.10 \mathrm{~mm}, 95 \% \mathrm{CI}-0.40$ to 0.20$)$ or deep pockets ( $\mathrm{P}$ value $=0.88, \mathrm{MD}-0.03 \mathrm{~mm}, 95 \% \mathrm{CI}-0.48$ to 0.41 , with a high degree of heterogeneity for moderate pockets.

\section{Multi-rooted teeth (Table 8)}

The same three studies provided data for multi-rooted teeth. After $3 / 4$ months moderate pockets showed a significant difference in favour of FMS (Swierkot 2009; P value < 0.00001, MD $1.37 \mathrm{~mm}$, 95\% CI 0.81 to 1.93 ); no data were available for deep pockets. We included three studies (Koshy 2005; Quirynen 2006; Swierkot 2009), one at high, one at unclear and one at low risk of bias, in the meta-analysis for multi-rooted teeth alone after $6 / 8$ months. There was no significant difference for moderate $(\mathrm{P}$ value $=0.68$, MD $0.04 \mathrm{~mm}, 95 \% \mathrm{CI}-0.16$ to 0.26 ; $\mathrm{Chi}^{2}=0.94,2 \mathrm{df}, \mathrm{P}=0.63$, $\mathrm{I}^{2}=0 \%$ ) or deep pockets (P value $=0.83$, MD $0.05 \mathrm{~mm}, 95 \% \mathrm{CI}$ -0.38 to $0.47 ; \mathrm{Chi}^{2}=1.10,1 \mathrm{df}, \mathrm{P}_{h e t}=0.29, \mathrm{I}^{2}=9 \%$ ).

\section{Sensitivity analysis}

We undertook a sensitivity analysis for low risk trials only for PPD at $6 / 8$ months. The MD was 0.01 ( -0.43 to 0.45 ; one trial), which is consistent with the overall finding of no evidence of a difference.

\section{FMS versus FMD: CAL}

Whole-mouth data are shown in a forest plot (Analysis 3.2) and other data in Table 9.

We included two studies in the meta-analysis for whole-mouth scores in single- and multi-rooted teeth after 3/4 months (Swierkot 2009; Zanatta 2006), one at high and one at unclear risk of bias. One study was included in the analysis for moderate pockets (Zanatta 2006) and both were included for deep pockets in single- and multi-rooted teeth (Swierkot 2009; Zanatta 2006). A significant difference between FMS and FMD was found for whole mouth in favour of FMD (P value $=0.006, \mathrm{MD}-0.25 \mathrm{~mm}, 95 \%$ CI -0.42 to -0.07 ; $\left.\mathrm{Chi}^{2}=0.92,1 \mathrm{df}, \mathrm{P}=0.34, \mathrm{I}^{2}=0 \%\right)$. No significant differences were found for moderate pockets $(\mathrm{P}$ value $=0.83$, $\mathrm{MD}-0.05 \mathrm{~mm}, 95 \% \mathrm{CI}-0.50$ to 0.40 ) or for deep pockets (P value $=0.35, \mathrm{MD} 0.41 \mathrm{~mm}, 95 \% \mathrm{CI}-0.45$ to 1.27$)$. There was evidence of heterogeneity for the deep pockets. We included two studies in the meta-analysis for whole-mouth scores in single- and multirooted teeth after 6/8 months (Koshy 2005; Swierkot 2009), one at high and one at low risk of bias. No studies provided data for moderate pockets and only one study was included in the analysis for deep pockets in single- and multi-rooted teeth (Swierkot 2009). No significant differences between FMS and FMD were found for whole-mouth (P value $=0.13, \mathrm{MD}-0.02 \mathrm{~mm}, 95 \% \mathrm{CI}$ -0.32 to 0.27 ) or for deep pockets (P value $=0.17, \mathrm{MD}-0.51 \mathrm{~mm}$, $95 \%$ CI -1.24 to 0.22 ). There was evidence of heterogeneity.

\section{Single-rooted teeth (Table 9)}

One study (Swierkot 2009) with high risk of bias provided data after 3/4 months for single-rooted teeth alone. A significant difference was observed for moderate pockets in favour of FMS (P value $=0.0005, \mathrm{MD} 0.71 \mathrm{~mm} ; 95 \% \mathrm{CI} 0.31$ to 1.11$)$; no data were available for deep pockets. Two studies (Koshy 2005; Swierkot 2009), one at high and one at low risk of bias, provided data after $6 / 8$ months for single-rooted teeth. No significant difference was observed for moderate pockets $(\mathrm{P}$ value $=0.38, \mathrm{MD}-0.09 \mathrm{~mm}$; $95 \% \mathrm{CI}-0.30$ to 0.11 ) or deep pockets ( $\mathrm{P}$ value $=0.24$, MD 0.56 $\mathrm{mm} ; 95 \% \mathrm{CI}-0.37$ to 1.49$)$.

\section{Multi-rooted teeth (Table 9)}

One study (Swierkot 2009) with a high risk of bias provided data after 3/4 months for multi-rooted teeth. A significant difference was observed for moderate pockets in favour of FMS (P value < $0.00001, \mathrm{MD} 1.53 \mathrm{~mm}$; $95 \%$ CI 0.89 to 2.17 ); no data were available for deep pockets. Two studies (Koshy 2005; Swierkot 2009), one at high and one at low risk of bias, provided data after $6 / 8$ months for multi-rooted teeth. No significant difference was 
found for moderate pockets (P value $=0.93, \mathrm{MD}-0.02 \mathrm{~mm} ; 95 \%$ CI -0.53 to 0.49 ); for deep pockets a significant difference was found in favour of FMS (P value $=0.01$, MD $0.74 \mathrm{~mm}$; 95\% CI 0.17 to 1.31 ) in one study (Koshy 2005).

\section{FMS versus FMD: BOP}

Whole-mouth data are shown in a forest plot (Analysis 3.3) and other data in Table 10.

We included two studies in the meta-analysis after $3 / 4$ months for single- and multi-rooted teeth combined (Swierkot 2009; Zanatta 2006), one at high and one at unclear risk of bias. There was no significant difference between FMS and FMD for the wholemouth evaluation $(\mathrm{P}$ value $=0.85, \mathrm{MD}-1.59 \%, 95 \% \mathrm{CI}-9.97$ to 6.80$)$. For deep pockets a significant difference was shown in one study (Swierkot 2009) in favour of FMS (P value $=0.04$, MD $7.00 \%, 95 \%$ CI 0.43 to 13.57$)$. No data were available for moderate pockets. We included two studies in the meta-analysis after $6 / 8$ months for single- and multi-rooted teeth combined (Koshy 2005; Swierkot 2009), one at high and one at low risk of bias. There was no significant difference between FMS and FMD for the whole-mouth evaluation ( $\mathrm{P}$ value $=0.15$, MD $-0.20 \%$, 95\% CI -13.27 to 12.87 ). For deep pockets one study showed significance in favour of FMS (P value = 0.02, MD 8.00\%, 95\% CI 1.18 to 14.82 ; Swierkot 2009). No data were provided for moderate pockets. There was evidence of heterogeneity for the whole-mouth findings.

\section{Single-rooted teeth (Table 10)}

Only one study (Swierkot 2009) with high risk of bias provided data after 3/4 months for single-rooted teeth. No significant difference for moderate pockets was found ( $\mathrm{P}$ value $=0.46$, MD 2.00\%, $95 \%$ CI -3.27 to 7.27 ); no data were available for deep pockets. Two studies (Quirynen 2006; Swierkot 2009), one at high and one at unclear risk of bias, provided data after $6 / 8$ months for single-rooted teeth. A significant difference for moderate pockets was found in favour of FMD (P value = 0.02, MD -6.69\%, 95\% $\mathrm{CI}-12.18 \%$ to $\left.-1.19 \%, \mathrm{Chi}^{2}=0.38,1 \mathrm{df}, \mathrm{P}=0.54, \mathrm{I}^{2}=0 \%\right)$. For deep pockets, a significant difference in favour of FMD was found $(\mathrm{P}=0.006$, mean difference $-18.00 \%, 95 \% \mathrm{CI}-30.83$ to 5.17) in one study (Quirynen 2006).

\section{Multi-rooted teeth (Table 10)}

One study (Swierkot 2009) at high risk of bias provided data after $3 / 4$ months for multi-rooted teeth. A significant difference for moderate pockets was found in favour of FMS (P value $<0.00001$, MD 5.00\%, 95\% CI 2.93 to 7.07). No data were available for deep pockets. Two studies (Quirynen 2006; Swierkot 2009), one at high and one at unclear risk of bias, provided data after $6 / 8$ months for multi-rooted teeth. We found no significant difference for moderate pockets $(\mathrm{P}$ value $=0.07, \mathrm{MD}-4.16 \%, 95 \% \mathrm{CI}-8.72$ to 0.39 ) in two studies (Quirynen 2006; Swierkot 2009) or deep pockets ( $\mathrm{P}$ value $=0.65$, MD $4.00 \%, 95 \% \mathrm{CI}-13.37$ to 21.37 ) in one study (Quirynen 2006). 
A D D I TIONALS UMMARYOF F INDINGS [Explanation]

FMD versus control for the treatment of adult chronic periodontitis

Patient or population: adults with chronic periodontitis

Settings: university dental departments

Intervention: FMD versus control

\begin{tabular}{|c|c|c|c|c|c|c|}
\hline \multirow[t]{3}{*}{ Outcomes } & \multicolumn{2}{|c|}{ Illustrative comparative risks* $(95 \% \mathrm{CI})$} & \multirow{3}{*}{$\begin{array}{l}\text { Relative effect } \\
(95 \% \text { CI })\end{array}$} & \multirow{3}{*}{$\begin{array}{l}\text { No of Participants } \\
\text { (studies) }\end{array}$} & \multirow{3}{*}{$\begin{array}{l}\text { Quality of the evidence } \\
\text { (GRADE) }\end{array}$} & \multirow[t]{3}{*}{ Comments } \\
\hline & Assumed risk & Corresponding risk & & & & \\
\hline & Control & FMD versus control & & & & \\
\hline Tooth loss & & & & & & $\begin{array}{l}\text { Not reported in any of the } \\
\text { trials. }\end{array}$ \\
\hline $\begin{array}{l}\text { Change in PPD; single- } \\
\text { and multi-rooted teeth - } \\
\text { Whole mouth } \\
\text { Follow-up: } 3-4 \text { months }\end{array}$ & $\begin{array}{l}\text { The mean change in PPD; } \\
\text { single- and multi-rooted } \\
\text { teeth - whole mouth } \\
\text { ranged across control } \\
\text { groups from } \\
\mathbf{0 . 6 9} \text { to } 2.51 \mathrm{~mm}\end{array}$ & $\begin{array}{l}\text { The mean change in PPD; } \\
\text { single- and multi-rooted } \\
\text { teeth - whole mouth in the } \\
\text { intervention groups was } \\
\mathbf{0 . 1 3} \text { higher } \\
(0.09 \text { lower to } 0.34 \\
\text { higher) }\end{array}$ & & $\begin{array}{l}44 \\
\text { (2 studies) }\end{array}$ & $\begin{array}{l}\oplus \oplus \bigcirc \bigcirc \\
\mathbf{l}_{\mathbf{0}} \mathbf{w}^{1}\end{array}$ & $\begin{array}{l}\text { Similar result was found } \\
\text { for the longer follow-up of } \\
6 \text { to } 8 \text { months } \\
\text { Subgroup analyses were } \\
\text { undertaken for 1) single- } \\
\text { and multi-rooted teeth } \\
\text { separately, and 2) for } \\
\text { teeth with initial moderate } \\
(5-6 \mathrm{~mm} \text { ) or high (>6 } \\
\text { mm) levels of PPD } \\
\text { There was no consistent } \\
\text { evidence of a benefit for } \\
\text { FMD. }\end{array}$ \\
\hline
\end{tabular}

Change in CAL; single- The mean change in CAL; The mean change in CAL; and multi-rooted teeth - single- and multi-rooted single- and multi-rooted Whole mouth

Follow-up: 3-4 months teeth - whole mouth teeth - whole mouth in the ranged across control intervention groups was groups from 0.04 highe 0.81 to $1.87 \mathrm{~mm}$ (0.25 lower to 0.33
(2 studies) $\oplus \oplus \bigcirc \bigcirc$

low
Similar result was found for the longer follow-up of 6 to 8 months

Subgroup analyses were undertaken for 1) singleand multi-rooted teeth 
higher)

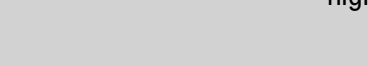

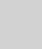

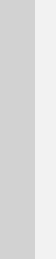

Change in BOP; single- The mean change in BOP; The mean change in BOP;

and multi-rooted teeth - single- and multi-rooted single- and multi-rooted

Whole mouth

probe

Follow-up: 3-4 months teeth - whole mouth teeth - whole mouth in the ranged across control intervention groups was

\section{groups from $\quad 12.59$ higher}

18 to 31 percent $\quad(8.58$ lower to 33.77

higher)

separately, and 2) for teeth with initial moderate

(5-6 mm) or high $(>6$ $\mathrm{mm}$ ) levels of PPD

There was no consistent evidence of a benefit for FMD.

68

(3 studies) $\oplus \oplus \oplus \bigcirc$

low $^{2}$

Similar result was found for the longer follow-up of 6 to 8 months

Subgroup analyses were undertaken for 1) singleand multi-rooted teeth separately, and 2) for teeth with initial moderate (5-6 $\mathrm{mm})$ or high $(>6$ $\mathrm{mm}$ ) levels of PPD

There was no consistent evidence of a benefit for FMD.

*The basis for the assumed risk (e.g. the median control group risk across studies) is provided in footnotes. The corresponding risk (and its $95 \%$ confidence interval) is based on the assumed risk in the comparison group and the relative effect of the intervention (and its $95 \% \mathrm{Cl}$ ).

CI: confidence interval; FMD: full mouth disinfection; PPD: probing pocket depth; CAL: clinical attachment level; BOP: bleeding on probing (BOP)

\section{GRADE Working Group grades of evidence}

High quality: Further research is very unlikely to change our confidence in the estimate of effect.

Moderate quality: Further research is likely to have an important impact on our confidence in the estimate of effect and may change the estimate.

Low quality: Further research is very likely to have an important impact on our confidence in the estimate of effect and is likely to change the estimate.

Very low quality: We are very uncertain about the estimate.

${ }^{1}$ One trial at high and one at unclear risk of bias. Small number of trials and participants. Downgraded two levels for design limitations and imprecision.

${ }^{2}$ One trial at high and two at unclear risk of bias. Small number of trials and participants. Downgraded two levels for design limitations and imprecision. 
FMS versus FMD for the treatment of adult chronic periodontitis

Patient or population: adults with chronic periodontitis

Settings: university dental departments

Intervention: FMS versus FMD

\begin{tabular}{|c|c|c|c|c|c|c|}
\hline \multirow[t]{3}{*}{ Outcomes } & \multicolumn{2}{|c|}{ Illustrative comparative risks* $(95 \% \mathrm{Cl})$} & \multirow{3}{*}{$\begin{array}{l}\text { Relative effect } \\
(95 \% \mathrm{Cl})\end{array}$} & \multirow{3}{*}{$\begin{array}{l}\text { No of Participants } \\
\text { (studies) }\end{array}$} & \multirow{3}{*}{$\begin{array}{l}\text { Quality of the evidence } \\
\text { (GRADE) }\end{array}$} & \multirow[t]{3}{*}{ Comments } \\
\hline & Assumed risk & Corresponding risk & & & & \\
\hline & FMD & FMS & & & & \\
\hline Tooth loss & & & & & & $\begin{array}{l}\text { Not reported in any of the } \\
\text { trials. }\end{array}$ \\
\hline $\begin{array}{l}\text { Change in PPD; single- } \\
\text { and multi-rooted teeth - } \\
\text { Whole mouth } \\
\text { probe } \\
\text { Follow-up: } 3-4 \text { months }\end{array}$ & $\begin{array}{l}\text { The mean change in } \\
\text { PPD; single- and multi- } \\
\text { rooted teeth - whole } \\
\text { mouth ranged across } \\
\text { FMS groups from } \\
\mathbf{0 . 6 9} \text { to } 2.58 \mathrm{~mm}\end{array}$ & $\begin{array}{l}\text { The mean change in PPD; } \\
\text { single- and multi-rooted } \\
\text { teeth - whole mouth in the } \\
\text { intervention groups was } \\
\text { 0.11 lower } \\
\text { ( } 0.34 \text { lower to } 0.12 \\
\text { higher) }\end{array}$ & & $\begin{array}{l}45 \\
\text { (2 studies) }\end{array}$ & $\begin{array}{l}\oplus \oplus \bigcirc \bigcirc \\
\text { low }^{1}\end{array}$ & $\begin{array}{l}\text { Similar result was found } \\
\text { for the longer follow-up of } \\
6 \text { to } 8 \text { months } \\
\text { Subgroup analyses were } \\
\text { undertaken for } 1) \text { single- } \\
\text { and multi-rooted teeth } \\
\text { separately, and 2) for } \\
\text { teeth with initial moderate } \\
(5-6 \mathrm{~mm}) \text { or high ( }>6 \\
\mathrm{~mm}) \text { levels of PPD }\end{array}$ \\
\hline
\end{tabular}

Change in CAL; single- The mean change in The mean change in CAL; and multi-rooted teeth - CAL; single- and multi- single- and multi-rooted Whole mouth rooted teeth - whole teeth-whole-mouth in the

Follow-up: 3-4 months mouth ranged across intervention groups was

$$
\begin{array}{ll}
\text { FMS groups from } & \mathbf{0 . 2 5} \text { lower } \\
\mathbf{0 . 5 6}-\mathbf{1 . 9 9} \mathrm{mm} & \text { (0.42 lower to } 0.07 \\
& \text { lower) }
\end{array}
$$

45

(2 studies) $\oplus \oplus \bigcirc \bigcirc$

Iow ${ }^{1}$
The result for the 6 to

8 month follow-up was not significant and did not indicate a benefit for FMS

Subgroup analyses were undertaken for 1) singleand multi-rooted teeth separately, and 2) for teeth with initial moderate 
$(5-6 \mathrm{~mm})$ or high $(>6$ $\mathrm{mm}$ ) levels of PPD

There was no consistent evidence of a benefit for either intervention

Change in BOP; single- The mean change in The mean change in BOP

and multi-rooted teeth - BOP; single- and multi- single- and multi-rooted

Whole mouth

probe

Follow-up: 3-4 months

rooted teeth - whole teeth - whole mouth in the

mouth ranged across intervention groups was

\section{FMS groups from $\quad 1.59$ lower}

22 to 23 percent $\quad(9.97$ lower to 6.80

higher)
45

(2 studies)

The result for the 6 to

8 month follow-up had a smaller treatment effect and also did not indicate a benefit for either intervention

Subgroup analyses were undertaken for 1) singleand multi-rooted teeth separately, and 2) for teeth with initial moderate (5-6 mm) or high (> 6 $\mathrm{mm}$ ) levels of PPD

There was no consistent evidence of a benefit for either intervention

*The basis for the assumed risk (e.g. the median control group risk across studies) is provided in footnotes. The corresponding risk (and its $95 \%$ confidence interval) is based on the assumed risk in the comparison group and the relative effect of the intervention (and its $95 \% \mathrm{CI}$ ).

Cl: confidence interval; FMD: full mouth disinfection; FMS: full mouth scaling; PPD: probing pocket depth; CAL: clinical attachment level; BOP: bleeding on probing (BOP)

GRADE Working Group grades of evidence

High quality: Further research is very unlikely to change our confidence in the estimate of effect.

Moderate quality: Further research is likely to have an important impact on our confidence in the estimate of effect and may change the estimate.

Low quality: Further research is very likely to have an important impact on our confidence in the estimate of effect and is likely to change the estimate.

Very low quality: We are very uncertain about the estimate.

One trial at high and one at unclear risk of bias. Small number of trials and participants. Downgraded two levels for design limitations

and imprecision. 


\section{DISCUSSION}

\section{Summary of main results}

In this review, we included 12 trials that assessed the effects of full-mouth treatment modalities within 24 hours with or without adjunctive antiseptics compared to the conventional quadrant approach. We assessed the quality of the body of evidence using GRADE criteria (Schünemann 2011), and our assessment is presented in the Summary of findings for the main comparison.

None of the trials reported data on our primary outcome, tooth loss.

There is low quality evidence from the analyses for all teeth at two time points that neither FMS or FMD were more beneficial than conventional SRP for the other primary outcome, probing pocket depth (PPD), nor for gain in probing attachment (CAL) or bleeding on probing (BOP). The low quality evidence available for FMS versus FMD suggests there is no difference in their effects on PPD and BOP. FMD seemed to improve CAL more than FMS at $3 / 4$ months but not at $6 / 8$ months.

We conducted various meta-analyses for single- and multi-rooted teeth, and teeth at different initial levels of PPD with some inconsistent findings.

Harms and adverse events were reported in eight studies. The most important harm identified was an increased body temperature after FMS or FMD treatments.

\section{Overall completeness and applicability of evidence}

The objectives of this review were to assess the effects of three treatment modalities of chronic periodontitis for the clinical outcomes tooth loss, PPD reduction, CAL gain and BOP reduction. Aggressive periodontitis was excluded due to its low incidence and the application of systemic antibiotics during therapy. Overall, there was insufficient evidence to claim or refute a benefit for one of the three investigated treatment modalities for the treatment of chronic periodontitis. None of the trials reported the primary outcome tooth loss. This is unsurprising as they were conducted over relatively short time periods from 3 to 12 months. Longer studies would be needed to look at tooth loss.

Study participants were aged between 27 and 78 years, and overall equal numbers of males and females (54.7\% males) took part in the studies.

Although economic costs and patient burdens may be important for any treatment comparison, they could not be addressed in this review because of lack of data. There is a paucity of studies of long duration because supportive periodontal therapy begins 6 to 12 weeks after treatment. Therefore effects due to different treatment modalities may be lost after longer observation periods.
Readers of this review are likely to be interested in the safety of treatment modalities; however, it was not possible to assess this in the long term, as RCTs are not appropriate study designs to assess the possible systemic effects related to safety. In the short term, eight studies reported adverse systemic effects.

\section{Quality of the evidence}

The body of evidence for FMS versus control at both 3 to 4 and 6 to 8 months was assessed as being of low quality for PPD, CAL and BOP. This was downgraded two levels from 'high' due to some studies being at high or unclear risk of bias and there being a small number of trials and participants. There was no evidence of any heterogeneity.

The body of evidence comparing FMD with control for both time periods was also assessed as low quality for the same reasons.

For the comparison between FMD and control there was considerable heterogeneity in the meta-analyses for PPD reduction, CAL gain and BOP reduction, possibly due to differences in the time point of probing in relation to subgingival instrumentation and the type of probe used, as well as the instruments used for root treatment, i.e. manual or powered or a combination of both. Differences also existed for the use of chlorhexidine (or other antiseptic) and the time schedule for full-mouth approaches, which ranged from 12 to 24 hours. More discrepancies might have resulted from the fact that not every group included oral hygiene instructions before baseline. Furthermore, even though all studies included minimal observation periods of 3 months, re-evaluation was conducted at varying time points 3 to 12 months after treatment.

The body of evidence comparing FMS with FMD was assessed as low quality due to the small number of trials and patients and the risk of bias in the studies. Only one of the three studies included in this comparison had a low risk of bias. The other two studies were at moderate or high risk of bias.

\section{Potential biases in the review process}

We conducted a sensitive search of multiple databases to identify suitable studies for this review, with no restrictions on language or publication status. We attempted to contact some study authors for missing information, but we were not able to include all missing data. We recognise that some deviations from protocol may have introduced bias in the review process. However, we have clearly reported the reasoning behind our judgements and we have tried to be consistent.

\section{Agreements and disagreements with other studies or reviews}


Following completion and publication of the first version of this Cochrane systematic review (Eberhard 2008a), another systematic review originating from the $6^{\text {th }}$ European Workshops on Periodontology was published with confirmatory data and conclusions (Lang 2008). Additionally, the authors attempted to perform a meta-analysis of the microbiological results of the included studies; however, no conclusions could be drawn, mainly due to the differences in the microbiological techniques utilised. Another review published in the British Dental Journal suggested that both the traditional quadrant approach and the newer full-mouth debridement could be equally effective as treatments for chronic periodontitis (Farman 2008). Most recently, a review focusing on treatment time and oral hygiene in combination with different treatment modalities found no differences between full and partial mouth treatment modalities (Tomasi 2009). It was concluded that long-term treatment success mainly depends on the quality of patients' oral hygiene and instrumentation and less on the choice of treatment protocol or time spent for subgingival instrumentation. At the same time, another review article was published by the advocates of the full-mouth treatment concept (Teughels 2009). Conclusions drawn by Teughels et al were merely based on a literature overview without statistical evaluation, in contrast to our current systematic review, which is based on several meta analyses of 12 RCTs. In their opinion, the one-stage, full-mouth disinfection concept results in significant additional clinical and microbiological improvements in non-surgical periodontal therapy, which is in contrast to our findings and those of other groups (Eberhard 2008a; Farman 2008; Lang 2008; Tomasi 2009).

\section{AUTHORS' CONCLUSIONS}

\section{Implications for practice}

The inclusion of five additional randomised controlled trials in this updated review comparing the clinical effects of conventional mechanical treatment with full-mouth scaling (FMS) and full-mouth disinfection (FMD) approaches for the treatment of chronic periodontitis has not changed the conclusions of the original review. From the twelve included trials there is no clear evidence that FMS or FMD is more beneficial than conventional scaling and root planing (SRP). In practice, the decision to select one approach to non-surgical periodontal therapy over another can include patient preference and the convenience of the treatment schedule.

\section{Implications for research}

There is low quality evidence for the three comparisons (FMS vs. SRP, FMD VS. SRP and FMS vs. FMD), which means it is likely further research could change findings. To increase the quality of the evidence base, studies with low risk of bias are warranted, with attention paid to allocation concealment, complete outcome data reporting and blinding of outcome assessments. However, outcome assessment blinding can be compromised by participant awareness of differences between interventions and visible signs of differences in intervention groups, if, for example not all debridement has been completed in comparison groups to FMS or FMD. Objective outcomes such as tooth loss might be less amenable to bias although their value is limited by the duration of follow-up needed (likely three to five years).

Future studies should address economic costs and patient burden. Authors should follow the CONSORT statement and ensure means and standard deviations are reported for all continuous outcomes.

\section{ACKNOWLEDGEMENTS}

We appreciate the excellent support from Luisa Fernandez Mauleffinch, Anne-Marie Glenny, Anne Littlewood, Philip Riley, Helen Wakeford and Laura MacDonald (Cochrane Oral Health Group) during the update of this review. We also acknowledge the external referees Esmonde Corbet and Bruce Pihlstrom.

\section{RE F E R E N C E S}

\section{References to studies included in this review}

Apatzidou 2004 \{published data only\}

Apatzidou DA, Kinane DF. Quadrant root planing versus same-day full-mouth root planing. I. Clinical findings. Journal of Clinical Periodontology 2004;31(2):132-40.

Del Peloso 2008 \{published data only\}

Del Peloso RE, Bittencourt S, Sallum ER, Nociti FH Jr, Goncalves RB, Casati MZ. Periodontal debridement as a therapeutic approach for severe chronic periodontitis: a clinical, microbiological and immunological study. Journal of Clinical Periodontology 2008;35:789-98.
Jervøe-Storm 2006 \{published data only\}

Jervøe-Storm PM, Semaan E, AlAhdab H, Engel S,

Fimmers R, Jepsen S. Clinical outcomes of quadrant root planing versus full-mouth root planing. Journal of Clinical Periodontology 2006;33(3):209-15.

Knöfler 2007 \{published data only\} Knöfler GU, Purschwtz RE, Jentsch HFR. Clinical evaluation of partial- and full-mouth scaling in the treatment of chronic periodontitis. Journal of Periodontology 2007;78:2135-42.

Full-mouth treatment modalities (within 24 hours) for chronic periodontitis in adults (Review) 
Koshy 2005 \{published data only\}

Koshy G, Kawashima Y, Kiji M, Nitta H, Umeda M, Nagasawa T, et al. Effects of single-visit full-mouth ultrasonic debridement versus quadrant-wise ultrasonic debridement. Journal of Clinical Periodontology 2005;32(7): $734-43$.

Mongardini 1999 \{published data only\}

* Mongardini C, van Steenberghe D, Dekeyser C, Quirynen $\mathrm{M}$. One stage full- versus partial-mouth disinfection in the treatment of chronic adult or generalized early-onset periodontitis. I. Long-term clinical observations. Journal of Periodontology 1999;70(6):632-45.

Quirynen M, Mongardini C, de Soete M, Pauwels M, Coucke W, van Eldere J, et al. The role of chlorhexidine in the one-stage full-mouth disinfection treatment of patients with advanced adult periodontitis. Long-term clinical and microbiological observations. Journal of Clinical Periodontology 2000;27(8):578-89.

Quirynen 2006 \{published data only\}

Quirynen M, De Soete M, Boschmans G, Pauwels M, Coucke W, Teughels W, et al. Benefit of "one-stage fullmouth disinfection" is explained by disinfection and root planing within 24 hours: a randomized controlled trial. Journal of Clinical Periodontology 2006;33(9):639-47.

Swierkot 2009 \{published data only\} Swierkot K, Nonnenmacher CL, Mutters R, Flores-deJacoby L, Mengel R. One-stage full-mouth disinfection versus quadrant and full-mouth root planing. Journal of Clinical Periodontology 2009;36:240-9.

Vandekerckhove 1996 \{published data only\} Vandekerckhove BN, Bollen CM, Dekeyser C, Darius P, Quirynen M. Full- versus partial-mouth disinfection in the treatment of periodontal infections. Long-term clinical observations of a pilot study. Journal of Periodontology 1996; 67(12):1251-9.

Wennström 2005 \{published data only\} Wennström JL, Tomasi C, Bertelle A, Dellasega E. Fullmouth ultrasonic debridement versus quadrant scaling and root planing as an initial approach in the treatment of chronic periodontitis. Journal of Clinical Periodontology 2005;32(8):851-9.

Zanatta 2006 \{published data only\} Zanatta GM, Bittencourt S, Nociti FH Jr, Sallum EA, Sallum AW, Casati MZ. Periodontal debridement with povidone-iodine in periodontal treatment: shortterm clinical and biochemical observations. Journal of Periodontology 2006;77(3):498-505.

Zijnge 2010 \{published data only\} Zijnge V, Meijer HF, Lie MA, Tromp JAH, Degener JE, Harmsen HJM, et al. The recolonization hypothesis in a full-mouth or multiple-session treatment protocol: a blinded, randomized clinical trial. Journal of Clinical Periodontology 2010;37:518-25.

\section{References to studies excluded from this review}

Bollen 1998 \{published data only\}

Bollen CM, Mongardini C, Papaioannou W, van Steenbergh D, Quirynen M. The effect of a one-stage full-mouth disinfection on different intra-oral niches. Clinical and microbiological observations. Journal of Clinical Periodontology 1998;25(1):56-66.

Eren 2002 \{published data only\}

Eren KS, Gurgan CA, Bostanci HS. Evaluation of nonsurgical periodontal treatment using 2 time intervals. Journal of Periodontology 2002;73(9):1015-9.

Jothi 2009 \{published data only\}

Jothi MV, Bhat KM, Prathiba PK, Bhat GS. The evaluation of a biodegradable dental chip containing chlorhexidine in chitosan base as a targeted drug delivery in the management of chronic periodontitis in patients. Drug Development Research 2009;70:395-401.

Loggner Graff 2009 \{published data only\}

Loggner Graff I, Asklöw B, Thorstensson H. Full-mouth versus quadrant-wise scaling - clinical outcome efficiency and treatment discomfort. Swedish Dental Journal 2009;33: $105-13$.

Meulman 2013 \{published data only\}

Meulman T, Oliveira Giorgetti AP, Gimenes J, Casarin RCV, Peruzzo DC, Nociti Jr FH. One stage, full-mouth ultrasonic debridement in the treatment of severe chronic periodontitis in smokers: A preliminary blind and randomized clinical trial. Journal of the International Academy of Periodontology 2013;15:83-90.

Preus 2013 \{published data only\}

Faveri M, Figueiredo LC, Feres M. [Treatment of chronic periodontitis may be improved by the adjunctive use of systemic metronidazole]. Journal of Evidence-based Dental Practice June 2014;14(2):70-2.

* Preus HR, Gunleiksrud TM, Sandvik L, Gjermo P, Baelum V. A randomized, double-masked clinical trial comparing four periodontitis treatment strategies: 1-year clinical results. Journal of Periodontology August 2013;84 (8):1075-86.

Quirynen 1995 \{published data only\} Quirynen M, Bollen CM, Vandekerckhove BN, Dekeyser C, Papaioannou W, Eyssen H. Full- vs. partial-mouth disinfection in the treatment of periodontal infections: short-term clinical and microbiological observations. Journal of Dental Research 1995;74(8):1459-67.

Serrano 2011 \{published data only\} Serrano C, Torres N, Bejarano A, Caviedes M, Castellanos ME. Clinical and microbiological comparison of three non-surgical protocols for the initial treatment of chronic periodontitis. Journal of the International Academy of Periodontology 2011;13:17-26.

Tomasi 2006 \{published data only\} Tomasi C, Bertelle A, Dellasega E, Wennström JL. Fullmouth ultrasonic debridement and risk of disease recurrence: a 1-year follow-up. Journal of Clinical Periodontology 2006; 33:626-31. 
Ushida 2008 \{published data only\}

Ushida Y, Koshy G, Kawashima Y, Kiji M, Umeda M, Nitta $\mathrm{H}$, et al. Changes in serum interleukin-6, C-reactive protein and thrombomodulin levels under periodontal ultrasonic debridement. Journal of Clinical Periodontology 2008;35: 969-75.

\section{References to studies awaiting assessment}

\section{Zhao 2005 \{published data only\}}

Zhao N, Ge SH, Yang PS. The clinical effect of full-mouth scaling and root planning on chronic periodontitis: a preliminary report. Shanghai Kou Qiang Yi Xue 2005;14 (4):341-4.

\section{Additional references}

\section{AAP 2005}

American Academy of Periodontology. Epidemiology of the periodontal diseases. Journal of Periodontology 2005;76: 1406-19.

Armitage 1999

Armitage GC. Development of a classification system for periodontal diseases and conditions. Annals of Periodontology 1999;4(1):1-6.

Beikler 2004

Beikler T, Abdeen G, Schnitzer S, Sälzer S, Ehmke B, Heinecke A, et al. Microbiological shifts in intra- and extraoral habitats following mechanical periodontal therapy. Journal of Clinical Periodontology 2004;31(9):777-83.

\section{Eberhard 2008a}

Eberhard J, Jepsen S, Jervøe-Storm P-M, Needleman I, Worthington HV. Full-mouth disinfection for the treatment of adult chronic periodontitis (Review). Cochrane Database of Systematic Reviews 2008;23(1):CD004622.

\section{Eberhard 2008b}

Eberhard J, Jervøe-Storm P-M, Needleman I, Worthington H, Jepsen S. Full-mouth treatment concepts for chronic periodontitis: a systematic review. Journal of Clinical Periodontology 2008;35:591-604.

\section{Farman 2008}

Farman M, Joshi RI. Full-mouth treatment versus quadrant root surface debridement in the treatment of chronic periodontitis: a systematic review. British Dental Journal 2008;205:496-7.

\section{Heitz-Mayfield 2002}

Heitz-Mayfield LJ, Trombelli L, Heitz F, Needleman I, Moles D. A systematic review of the effect of surgical debridement vs non-surgical debridement for the treatment of chronic periodontitis. Journal of Clinical Periodontology 2002;29 Suppl 3:92-102.

\section{Higgins 2011}

Higgins JPT, Green S, editors. Cochrane Handbook for Systematic Reviews of Interventions 5.1.0 [updated March 2011]. The Cochrane Library. Chichester, UK: John Wiley \& Sons, Ltd, 2011.

\section{Lang 2008}

Lang NP, Tan WC, Krähenmann MA, Zwahlen M. A systematic review of the effects of full-mouth debridement with and without antiseptics in patients with chronic periodontitis.. Journal of Clinical Periodontology 2008;38, Suppl. 8:8-21.

Oliver 1991

Oliver RC, Brown LJ, Loe H. Variations in the prevalence and extent of periodontitis. Journal of the American Dental Association 1991;122(6):43-8.

\section{Quirynen 2000}

Quirynen M, Mongardini C, de Soete M, Pauwels M, Coucke W, van Eldere J, et al. The role of chlorhexidine in the one-stage full-mouth disinfection treatment of patients with advanced adult periodontitis. Long-term clinical and microbiological observations. Journal of Clinical Periodontology 2000;27(8):578-89.

\section{Schünemann 2011}

Schünemann HJ, Oxman AD, Higgins JPT, Vist GE, Glasziou P, Guyatt GH. Chapter 11: Presenting results and 'Summary of findings' tables. In: Higgins JPT, Green $S$ (editors), Cochrane Handbook for Systematic Reviews of Interventions. The Cochrane Collaboration, 2011. Available from www.cochrane-handbook.org, Version 5.1.0 (updated March 2011).

Teughels 2009

Teughels W, DeKeyser C, van Essche M, Quirynen M. One-stage, full-mouth disinfection: fiction or reality?. Periodontology 2000 2009;50:39-51.

\section{Tomasi 2009}

Tomasi C, Wennström JL. Full-mouth treatment vs. the conventional staged approach for periodontal infection control. Periodontology 2000 2009;51:45-62.

\section{Van der Weijden 2002}

Van der Weijden U, Timmerman MF. A systematic review on the clinical efficacy of subgingival debridement in the treatment of chronic periodontitis. Journal of Clinical Periodontology 2002;29 Suppl 3:55-71.

* Indicates the major publication for the study 


\section{CHARACTERISTICS OF STUDIES}

\section{Characteristics of included studies [ordered by study ID]}

\section{Apatzidou 2004}

Methods

Recruitment period: Unclear
Setting: University Dental Hospital, Scotland
Number of centres: One
Funding source: Unclear

Participants
Inclusion criteria: Diagnosis: Chronic periodontitis - with PD of $>5 \mathrm{~mm}$

Exclusion criteria: Systemic disease or on antibiotics from 3 months before or during study

Age: 31 to 70

Gender: $17 \mathrm{~F}$ and $23 \mathrm{M}$

Smokers: 15

Number randomised: 40 (20/20), 2 Asian (1 in each group), 38 Caucasian

Number evaluated: $40(20 / 20)$

\section{Comparison: FMS vs control}

Test group: (FM-SRP): FMS 2 sessions same day

Control group: (Q-SRP): QRP 4 sessions - 2-weekly intervals

OHI before study start: Unknown

Instruments used: Hand and US instruments

Time per Q: 1 hour

Maintenance: At 7 weeks (FMS) or 13 weeks (QRP) and 6 months from baseline (both groups)

Retreatment: None

Duration of study: 6 months

Outcomes

Primary outcome: PPD (6 sites per tooth)

Secondary outcomes: CAL/RAL, BOP (6 sites per tooth)

Teeth: Whole-mouth recordings with manual probe, moderate and deep PD at baseline Pocket depth at baseline: Moderate $(>5$ and $<7 \mathrm{~mm})$, deep $(>7 \mathrm{~mm})$, for selected sites (deepest site per quadrant)

Outcome time reported: 6-month data used. Baseline, 6-week re-assessment after last instrumentation (FM-SRP: 7 weeks; Q-SRP: 13 weeks from baseline), 25 weeks. Computer-assisted disk probe for selected sites

Other outcomes: MGI, PI, SUP (selected site clinical analysis = 1 deepest pocket per quadrant). Average pain VAS score (0 to 10), body temperature, number of analgesics, cold sores or oral ulcers

Notes

Risk of bias

Bias

Authors' judgement

Support for judgement

Full-mouth treatment modalities (within 24 hours) for chronic periodontitis in adults (Review) 
Apatzidou 2004 (Continued)

\begin{tabular}{|c|c|c|}
\hline $\begin{array}{l}\text { Random sequence generation (selection } \\
\text { bias) }\end{array}$ & Unclear risk & $\begin{array}{l}\text { "Subjects were randomised into two } \\
\text { groups" }\end{array}$ \\
\hline Allocation concealment (selection bias) & Unclear risk & Not mentioned \\
\hline $\begin{array}{l}\text { Incomplete outcome data (attrition bias) } \\
\text { All outcomes }\end{array}$ & Low risk & All patients completed study \\
\hline $\begin{array}{l}\text { Blinding of outcome assessment (detection } \\
\text { bias) } \\
\text { All outcomes }\end{array}$ & High risk & $\begin{array}{l}\text { "Clinical measurements were collected by } \\
\text { a calibrated single examiner (D. A. A.) and } \\
\text { unbiased data collection was assured by } \\
\text { having no access to recordings of previous } \\
\text { visits" } \\
\text { Comment: Blinding at high risk of bias as } \\
\text { the same person undertook the interven- } \\
\text { tions and the outcome assessments }\end{array}$ \\
\hline Selective reporting (reporting bias) & Low risk & $\begin{array}{l}\text { Data reported on all primary and secondary } \\
\text { outcomes }\end{array}$ \\
\hline Other bias & Low risk & $\begin{array}{l}\text { Baseline balance good for smokers and } \\
\text { pocket depth. No apparent other biases }\end{array}$ \\
\hline
\end{tabular}

\section{Del Peloso 2008}

Methods

Recruitment period: July 2005 - June 2006
Setting: University Dental Hospital, Brazil
Number of centres: One
Funding source: Unclear

Participants

Interventions
Inclusion criteria: Diagnosis: Severe chronic periodontitis - with PD of $>5 \mathrm{~mm}$ and BOP positive

Exclusion criteria: Medical disorders, SRP in past 6 months or on antibiotics from 6 months before or during study, smokers, pregnancy

Age: 30 to 66

Gender: 18 F (9/9) and 7 M (4/3)

Smokers: 0

Number randomised: 25 (?/?)

Number evaluated: $25(13 / 12)$

\section{Comparison: FMS vs control}

Test group: (FMS) One session within 45 minutes

Control group: (SRP): QRP 4 sessions at 1-week intervals

OHI before study start: Yes

Instruments used: Hand and US instruments

Time per Q: 45 minutes for test group

Maintenance: Every month 
Del Peloso 2008 (Continued)

Retreatment: After 3 months (PPD $\geq 5 \mathrm{~mm}$ )

Duration of study: 6 months

$\begin{array}{ll}\text { Putcomes } & \text { Primary outcome: PPD (6 sites per tooth) } \\ \text { Secondary outcomes: RAL, BOP }(6 \text { sites per tooth) } \\ \text { Teeth: Whole-mouth recordings with manual probe, moderate and severe PD at baseline } \\ \text { Pocket depth at baseline: Moderate }(5 \text { and } 6 \mathrm{~mm}) \text {, deep }(>7 \mathrm{~mm}) \text { (authors' information) } \\ \text {. Manual probe with stent } \\ \text { Outcome time reported: } 3 \text { months used, } 6 \text { months also reported. } \\ \text { Other outcomes: Plaque score, Gingival Bleeding Index, recession }(6 \text { sites per tooth), } \\ \text { body temperature, VAS scales for patient, visual plaque index after initial prophylaxis, } \\ 30 \% \text { in test and } 40 \% \text { in control group }\end{array}$

Notes Starting quadrant of SRP unclear

On request only BOP for sites $>4 \mathrm{~mm}$; not for subgroups

Risk of bias

\begin{tabular}{|c|c|c|}
\hline Bias & Authors' judgement & Support for judgement \\
\hline $\begin{array}{l}\text { Random sequence generation (selection } \\
\text { bias) }\end{array}$ & Low risk & $\begin{array}{l}\text { Quote: "Patients were randomised into two } \\
\text { groups according to a computer-generated } \\
\text { list" }\end{array}$ \\
\hline
\end{tabular}

Allocation concealment (selection bias) Low risk

Quote: "The allocation concealment was secured by having a person not involved in the study performing the randomisation. This person was different from the one responsible for the treatment (S. B.) and different from the examiner (E. D. P. R.). The randomisation code was not broken until all data had been collected. Thus, the treatment group was not revealed to the clinical examiner or to the statistician"

Incomplete outcome data (attrition bias) Low risk

All patients completed study

All outcomes

Blinding of outcome assessment (detection Low risk

bias)

Treatment and examination by two independent persons

All outcomes

Selective reporting (reporting bias) Low risk

Data reported on all primary and secondary outcomes

Other bias

Low risk

Baseline balance good for pocket depth. No apparent other biases 
Funding source: Unclear

Inclusion criteria: Diagnosis: Chronic periodontitis - with PD of $>5 \mathrm{~mm}$ and BOP positive. All patients were in good general health

Exclusion criteria: SRP in past 6 months or on antibiotics from 6 months before or during study, pregnancy

Age: $53.1+/-10.2$

Gender: $11 \mathrm{~F}$ (5/6) and $9 \mathrm{M}$ (5/4)

Smokers: 2 (1 in each group) (smoking at least 10 cigarettes per day)

Number randomised: 20

Number evaluated: $20(10 / 10)$ all Caucasian

Comparison: FMS vs control
Test group: (FM-RP): FMS 2 sessions within 24 hours on 2 consecutive days
Control group: (QRP): QRP 4 sessions - 1-week intervals
OHI before study start: yes
Instruments used: Hand and US instruments
Time per Q: 1 hour
Maintenance: Every month after 3 months
Retreatment: None
Duration of study: 6 months

Outcomes

Primary outcome: PPD (6 sites per tooth)

Secondary outcomes: RAL, BOP (only for PPD > $4 \mathrm{~mm}$ ) (6 sites per tooth)

Teeth: Whole-mouth recordings with computer-assisted probe with stent for all measurements, moderate and severe PD at baseline

Pocket depth at baseline: Moderate $(>5-<7 \mathrm{~mm})$, deep (> $7 \mathrm{~mm})$

Outcome time reported: 3 months used, 6 months also reported

Other outcomes: Data from first quadrant

Notes

Risk of bias

\begin{tabular}{|c|c|c|}
\hline Bias & Authors' judgement & Support for judgement \\
\hline $\begin{array}{l}\text { Random sequence generation (selection } \\
\text { bias) }\end{array}$ & Low risk & $\begin{array}{l}\text { "Patients were randomised into two groups } \\
\text { according to a computer generated list pro- } \\
\text { vided by an external agent" }\end{array}$ \\
\hline
\end{tabular}

Allocation concealment (selection bias) Low risk

Not mentioned in report of trial but author states "treatment was concealed for all participants until first intervention. The randomisation was first made, when the patient was sitting in the office and treat- 
ment began. An independent person gave the treatment-mode to the therapist"

\begin{tabular}{ll|l} 
Incomplete outcome data (attrition bias) Low risk & All patients completed study
\end{tabular} All outcomes

Blinding of outcome assessment (detection Low risk bias)

"All measurements were performed by one blinded examiner"

All outcomes

Selective reporting (reporting bias) Low risk

Data reported on all primary and secondary outcomes

Other bias

Low risk

Baseline balance good for pocket depth. No apparent other biases

Knöfler 2007

Methods

Participants
Study design: RCT with 2-arm parallel design

Recruitment period: September 2002 - September 2003

Setting: University Dental Hospital, Leipzig, Germany

Number of centres: One

Funding source: Unclear

Inclusion criteria: Diagnosis: Chronic periodontitis - with PD of $>5 \mathrm{~mm}$ and BOP positive. All patients were in good general health

Exclusion criteria: SRP in past 2 years or on antibiotics from 4 months before or during study, pregnancy, removable dentures, orthodontic therapy

Age: 37 to 65

Gender: 26 F (11/15) and $11 \mathrm{M}(6 / 5)$

Smokers: unclear

Number randomised: 42 Caucasian, 21 in each group on enrolment

Number evaluated: 37 (17/20) all Caucasian

\section{Comparison: FMD vs control}

Test group: (FMS): One session hand plus US instruments. Subgingival irrigation with $1 \% \mathrm{CHX}$ gel three times within $10 \mathrm{~min}$ after scaling. Patients rinsing with $0.2 \% \mathrm{CHX}$ twice a day for two weeks, tongue brushing

Control group: (SRP): Sites $\geq 3 \mathrm{~mm}$ within 4 to 5 weeks in two sessions, always starting 1 and 4 quadrant

OHI before study start: yes

Instruments used: Hand and US instruments

Time per Q: Unclear

Maintenance: every 3 months

Retreatment: Retreatment at sites positive for BOP and PD $\geq 5 \mathrm{~mm}$ at 6 months

Duration of study: 12 months 
Knöfler 2007 (Continued)

\begin{tabular}{ll}
\hline Outcomes & Primary outcome: PPD (6 sites per tooth) \\
& Secondary outcomes: CAL, BOP $(6$ sites per tooth) \\
Teeth: Data split in total molar/premolar recordings and initial moderate pockets (4-6 \\
mm). Exclusion of incisors, canine and third molars \\
Pocket depth at baseline: Moderate $(>5-<7 \mathrm{~mm})$, deep $(>7 \mathrm{~mm})$ \\
Outcome time reported: 6 months used, 12 months also reported \\
Other outcomes: Flat surface sites versus furcation areas
\end{tabular}

Risk of bias

\begin{tabular}{|c|c|c|}
\hline Bias & Authors' judgement & Support for judgement \\
\hline $\begin{array}{l}\text { Random sequence generation (selection } \\
\text { bias) }\end{array}$ & Low risk & $\begin{array}{l}\text { "At the baseline visit, patients were assigned } \\
\text { randomly to one of two treatment groups } \\
\text { by the toss of a coin" }\end{array}$ \\
\hline
\end{tabular}

Allocation concealment (selection bias) Unclear risk

"The three experienced examiners were trained to adequate levels of accuracy and reproducibility for the

clinical variables CAL and PD.Operators and examiners were the same persons"

Incomplete outcome data (attrition bias) Low risk All outcomes

42 enrolled, 37 completed. Clear description of drop-outs in each group (from author)

Blinding of outcome assessment (detection Low risk bias)

All outcomes

"The three experienced examiners were trained to adequate levels of accuracy and reproducibility for the clinical variables CAL and PD. Operators and examiners were the same persons"

From authors: "There were 3 investigators. Clinical parameters at 6 and 12 months visits were always recorded by the same investigator in one patient

Examinations were performed by one of the 3 investigators not performing the treatment"

\begin{tabular}{|c|c|c|}
\hline Selective reporting (reporting bias) & Low risk & $\begin{array}{l}\text { Data reported on all primary and secondary } \\
\text { outcomes }\end{array}$ \\
\hline
\end{tabular}

Other bias

Unclear risk

Baseline balance good for pocket depth, however smoking unclear. No apparent other biases 
Koshy 2005

\begin{tabular}{|c|c|}
\hline Methods & $\begin{array}{l}\text { Study design: RCT with 3-arm parallel design } \\
\text { Recruitment period: unclear } \\
\text { Setting: University Dental Clinic, Japan } \\
\text { Number of centres: One } \\
\text { Funding source: Grant from Scientific Society }\end{array}$ \\
\hline Participants & $\begin{array}{l}\text { Inclusion criteria: Diagnosis: Chronic periodontitis - with PD of }>5 \mathrm{~mm} \text {. All patients } \\
\text { were in good general health } \\
\text { Exclusion criteria: SRP in past } 6 \text { months or on antibiotics from } 6 \text { months before or } \\
\text { during study, smokers, pregnancy, allergic to iodine } \\
\text { Age: } 34 \text { to } 66 \\
\text { Gender: } 23 \mathrm{~F} \text { (FMD/FMS/control } 8 / 7 / 8) \text { and } 13 \mathrm{M}(4 / 5 / 4) \\
\text { Smokers: } 0 \\
\text { Number randomised: } 36 \text { all Japanese, } 12 \text { individuals in each group } \\
\text { Number evaluated: } 36(12 / 12 / 12)\end{array}$ \\
\hline
\end{tabular}

Interventions

Comparison: FMS vs control: FMD vs control: FMS vs FMD

Test group 1: (FMD + water): FMS 1 session US scaling with water (duration 2 to 2.5 hours)

Test group 2: (FMD + povidone): FMS 1 session US scaling with $1 \%$ povidone iodine (duration 2-2.5 hours), patients rinsing with $0.05 \%$ CHX twice a day for 1 month, tongue brushing

Control group: (QMD): QRP 4 sessions US scaling with water - 1-week intervals (duration 40-50 min each)

OHI before study start: Yes

Instruments used: US instruments

Time per Q: Unclear

Maintenance: Every month

Retreatment: None

Duration of study: 6 months

Primary outcome: PPD (6 sites per tooth)

Secondary outcomes: RAL, BOP (6 sites per tooth). Manual probe with stent for all measurements

Teeth: Whole-mouth recordings (baseline, 1, 3 and 6 months). Data split in single-/ multi-rooted teeth and initial moderate (PPD 5 to $6 \mathrm{~mm}$ ) and deep pockets (PPD $>6$ $\mathrm{mm}$ )

Pocket depth at baseline: moderate $(>5$ to $<7 \mathrm{~mm}$ ), deep $(>7 \mathrm{~mm})$

Outcome time reported: 6 months used.

Other outcomes: PI, average pain VAS score (0 to 10$)$, body temperature, number of analgesics, microbiology

PAL is equal to RAL

\section{Risk of bias}


Koshy 2005 (Continued)

\begin{tabular}{|c|c|c|}
\hline $\begin{array}{l}\text { Random sequence generation (selection } \\
\text { bias) }\end{array}$ & Low risk & $\begin{array}{l}\text { "They were then randomly allocated to } \\
\text { three groups based on the treatment pro- } \\
\text { tocol and the examiner was blinded to the } \\
\text { allocation. The random sequence was com- } \\
\text { puter generated, with no stratification or } \\
\text { balancing of factors" }\end{array}$ \\
\hline Allocation concealment (selection bias) & Low risk & $\begin{array}{l}\text { "The subjects chose a sequentially num- } \\
\text { bered opaque, sealed envelope, which en- } \\
\text { closed the code for the treatment protocol } \\
\text { they were to receive. The number of en- } \\
\text { velopes was same as the number of subjects" }\end{array}$ \\
\hline $\begin{array}{l}\text { Incomplete outcome data (attrition bias) } \\
\text { All outcomes }\end{array}$ & Low risk & All patients completed study \\
\hline $\begin{array}{l}\text { Blinding of outcome assessment (detection } \\
\text { bias) } \\
\text { All outcomes }\end{array}$ & Low risk & $\begin{array}{l}\text { "The treatment groups were coded so that } \\
\text { only the operator was aware of the pro- } \\
\text { tocol and the examiner remained blinded } \\
\text { throughout the study" }\end{array}$ \\
\hline Selective reporting (reporting bias) & Low risk & $\begin{array}{l}\text { Data reported on all primary and secondary } \\
\text { outcomes }\end{array}$ \\
\hline Other bias & Low risk & $\begin{array}{l}\text { Baseline balance good for pocket depth. No } \\
\text { apparent other biases }\end{array}$ \\
\hline
\end{tabular}

\section{Mongardini 1999}

$\begin{array}{ll}\text { Methods } & \text { Study design: RCT with 2-arm parallel design } \\ \text { Recruitment period: Unclear } \\ \text { Setting: University Dental Hospital, Belgium } \\ \text { Number of centres: One } \\ \text { Funding source: Supported by University }\end{array}$

Participants

Inclusion criteria: Diagnosis: Chronic periodontitis - with PD of $>7 \mathrm{~mm}$ and BOP (aggressive periodontitis patients also included). All patients were in good general health Exclusion criteria: antibiotics from 4 months before or during study, smokers

Age: 23 to 69 (based on all 40)

Gender: $9 \mathrm{~F}(7 / 2)$ and $15 \mathrm{M}(5 / 10)$

Smokers: 8 (3/5) (smoking at least 10 cigarettes per day)

Number randomised: 24 (40 including aggressive periodontitis)

Number evaluated: $24(12 / 12)$

\section{Comparison: FMD vs control}

Test group: 2 sessions scaling within 24 hours, after instrumentation: ; tongue brushing: $\mathrm{CHX}=1 \%, 1 \mathrm{~min}$; rinse: $\mathrm{CHX}=0.2 \%, 1 \mathrm{~min}$; spray pharynx: $\mathrm{CHX}=0.2 \%$; subgingival:

$\mathrm{CHX}=1 \%, 3$ times within $10 \mathrm{~min}$, repeat subgingival after 8 days. Home: rinse CHX 
$=0.2 \%, 1 \mathrm{~min}, 2 \mathrm{x}$ day, 2 months; spray: $\mathrm{CHX}=0.2 \%, 2 \mathrm{x}$ day, 2 months

Control group: SRP 4 sessions 2 weekly intervals

OHI before study start: no

Instruments used: Hand instruments

Time per Q: Unclear

Maintenance: After 1, 2 and 4 months

Retreatment: None

Duration of study: 8 months

Primary outcome: PPD (4 sites per tooth)
Secondary outcomes: CAL, BOP (4 sites per tooth). Manual probe for all measurements
Teeth: Only recording of first quadrant. Data split in single-/multi-rooted teeth and
initial moderate (PPD 4.5 to $6.5 \mathrm{~mm}$ ) and deep pockets $(\mathrm{PPD}>7 \mathrm{~mm})$
Pocket depth at baseline: moderate (PPD 4.5 to $6.5 \mathrm{~mm})$ and deep pockets (PPD $>7$
mm)
Outcome time reported: 4 months used, $1,2,4,8$ months measured.
Other outcomes: SPI, Plaque extent

Notes

Only data from patients with chronic periodontitis (CP) were included in the metaanalysis

\section{Risk of bias}

\begin{tabular}{|c|c|c|}
\hline Bias & Authors' judgement & Support for judgement \\
\hline $\begin{array}{l}\text { Random sequence generation (selection } \\
\text { bias) }\end{array}$ & Low risk & $\begin{array}{l}\text { "...the participants signed an informed } \\
\text { consent form and were randomly dis- } \\
\text { tributed between test and control groups } \\
\text { by coin toss..." }\end{array}$ \\
\hline Allocation concealment (selection bias) & Unclear risk & Unclear \\
\hline $\begin{array}{l}\text { Incomplete outcome data (attrition bias) } \\
\text { All outcomes }\end{array}$ & Low risk & All patients completed study \\
\hline $\begin{array}{l}\text { Blinding of outcome assessment (detection } \\
\text { bias) } \\
\text { All outcomes }\end{array}$ & Low risk & $\begin{array}{l}\text { "As such the chlorhexidine staining in the } \\
\text { test group could be eliminated, in order to } \\
\text { allow blind clinical measurements" }\end{array}$ \\
\hline Selective reporting (reporting bias) & Low risk & $\begin{array}{l}\text { Data reported on all primary and secondary } \\
\text { outcomes }\end{array}$ \\
\hline Other bias & Low risk & $\begin{array}{l}\text { Baseline balance good for pocket depth and } \\
\text { smoking. No apparent other biases }\end{array}$ \\
\hline
\end{tabular}


Recruitment period: unclear

Setting: University Dental Hospital, Belgium

Number of centres: One

Funding Source: supported by University

Inclusion criteria: Diagnosis: Chronic periodontitis - with PD of $>6 \mathrm{~mm}$. All patients were in good general health

Exclusion criteria: SRP in past 12 months or antibiotics from 4 months before or during study, compromised medical condition, pregnancy

Age: 31 to 75 . All Caucasian

Gender: 19 F (FMS/FMD/control 10/4/5) and $24 \mathrm{M}(4 / 10 / 10)$

Smokers: $11(3 / 3 / 5)$

Number randomised: 85 in 5 arms

Number evaluated: 43 in 3 arms (14/14/15) (71 in 5 arms) tongue brushing: $\mathrm{CHX}=1 \%, 1 \mathrm{~min}$; rinse: $\mathrm{CHX}=0.2 \%, 2 \times 1 \mathrm{~min}$; spray pharynx: $\mathrm{CHX}=0.2 \%$; subgingival: $\mathrm{CHX}=1 \%, 3$ times within $10 \mathrm{~min}$. Home: rinse $\mathrm{CHX}=0$. $2 \%, 1$ min, $2 \mathrm{x}$ day, 2 months

Control group: (NC): QRP 4 sessions scaling - 2-week intervals, no antiseptics

OHI before study start: No

Instruments used: Hand instruments

Time per Q: Unclear

Maintenance: 1, 2, 4 months

Retreatment: None

Duration of study: 8 months

Primary outcome: PPD (6 sites per tooth)

Secondary outcomes: CAL (as sum of PPD and gingival recession), BOP (6 sites per tooth). Manual probe for all measurements

Teeth: First quadrant recordings (baseline, 2, 4 and 8 months). Data split in single-/ multi-rooted teeth and initial medium (PPD 4 to $5.5 \mathrm{~mm}$ ) and deep pockets (PPD > 5 $\mathrm{mm}$ )

Pocket depth at baseline: moderate (PPD 4.5 to $6.5 \mathrm{~mm}$ ) and deep pockets (PPD > 7 $\mathrm{mm})$

Outcome time reported: 4 months used, 1, 2, 4, 8 months measured

Other outcomes: SBI, PI, GR (6 sites per tooth)

Drop-outs: 85 enrolled, 71 completed the study. Time point for drop-outs unclear. Only 3 arms of trial included

Authors could not provide data for 4 months evaluation on request 


\section{Quirynen 2006 (Continued)}

\begin{tabular}{|c|c|c|}
\hline $\begin{array}{l}\text { Random sequence generation (selection } \\
\text { bias) }\end{array}$ & Low risk & $\begin{array}{l}\text { "A clinician who was informed about the } \\
\text { baseline clinical data (but not about the } \\
\text { content of the treatment strategies) ran- } \\
\text { domly } \\
\text { allocated (via a random-number table) the } \\
\text { consecutive participants (if fulfilling crite- } \\
\text { ria) to one of the following groups" }\end{array}$ \\
\hline Allocation concealment (selection bias) & Low risk & $\begin{array}{l}\text { "A clinician who was informed about the } \\
\text { baseline clinical data (but not about the } \\
\text { content of the treatment strategies) ran- } \\
\text { domly } \\
\text { allocated (via a random-number table) the } \\
\text { consecutive participants (if fulfilling crite- } \\
\text { ria) to one of the following groups" }\end{array}$ \\
\hline $\begin{array}{l}\text { Incomplete outcome data (attrition bias) } \\
\text { All outcomes }\end{array}$ & Unclear risk & $\begin{array}{l}\text { Drop-outs } 14 / 85 \text {; unclear reasons or tim- } \\
\text { ing of drop-outs }\end{array}$ \\
\hline $\begin{array}{l}\text { Blinding of outcome assessment (detection } \\
\text { bias) } \\
\text { All outcomes }\end{array}$ & Low risk & $\begin{array}{l}\text { Treatment and examination by two inde- } \\
\text { pendent persons }\end{array}$ \\
\hline Selective reporting (reporting bias) & Low risk & $\begin{array}{l}\text { Data reported on all primary and secondary } \\
\text { outcomes }\end{array}$ \\
\hline Other bias & Low risk & $\begin{array}{l}\text { Baseline balance good for pocket depth and } \\
\text { smoking. No apparent other biases }\end{array}$ \\
\hline
\end{tabular}

\section{Swierkot 2009}

Methods

Study design: RCT with 3-arm parallel design

Recruitment period: Unclear

Setting: University Dental Department, Marburg, Germany

Number of centres: One

Funding Source: Supported by University

Participants

Inclusion criteria: Diagnosis: Chronic periodontitis - with PD of $>5 \mathrm{~mm}$ and BOP. All patients were in good general health

Exclusion criteria: antibiotics from 6 months before or during study, history of systemic disease, orthodontic patients, pregnancy

Age: 28 to 63 years

Gender: $20 \mathrm{~F}$ (FMS/FMD/control 7/7/6) and $5 \mathrm{M}(2 / 2 / 1)$

Smokers: $5(3 / 1 / 1)$ (smoking at least 10 cigarettes per day)

Number randomised: $25(9 / 9 / 7)$

Number evaluated: $25(9 / 9 / 7)$ 


\begin{tabular}{|c|c|}
\hline Interventions & $\begin{array}{l}\text { Comparison: FMS vs control: FMD vs control: FMS vs FMD } \\
\text { Test group 1: (FM-SRP): } 2 \text { sessions within } 24 \text { hours } \\
\text { Test group 2: (FMD): } 2 \text { sessions scaling within } 24 \text { hours; after instrumentation: tongue } \\
\text { brushing: } \mathrm{CHX}=1 \%, 1 \mathrm{~min} \text {; rinse: } \mathrm{CHX}=0.2 \% \text {, twice for } 1 \mathrm{~min} \text {; spray pharynx: CHX } \\
\text { = } 0.2 \% 4 \mathrm{x} \text { each, subgingival: } \mathrm{CHX}=1 \% \text {. Home: rinse } \mathrm{CHX}=0.2 \%, 1 \mathrm{~min}, 2 \mathrm{x} \text { day, } \\
14 \text { days; spray tonsils: CHX }=0.2 \%, 1 \mathrm{x} \text { day, } 14 \text { days } \\
\text { Control group: (Q-SRP): } 4 \text { sessions quadrant wise, } 1 \text { week interval starting first quad- } \\
\text { rant, hand and US instruments } \\
\text { OHI before study start: Yes } \\
\text { Instruments used: Hand and US instruments } \\
\text { Time per Q: Unclear } \\
\text { Maintenance: } 1,2,4 \text { and } 8 \text { months } \\
\text { Retreatment: None } \\
\text { Duration of study: } 8 \text { months }\end{array}$ \\
\hline
\end{tabular}

Primary outcome: PPD (4 sites per tooth)

Secondary outcomes: CAL, BOP ( 4 sites per tooth). Manual probe for all measurements Teeth: Whole-mouth recordings (baseline, 1, 2, 4, and 8 months). Data split in singleand multi-rooted teeth for moderate $(4-6 \mathrm{~mm})$ pockets and whole-mouth recordings for deep ( $\geq 7 \mathrm{~mm}$ ) pockets

Pocket depth at baseline: moderate (PPD $4-6 \mathrm{~mm}$ ) and deep pockets (PPD $>7 \mathrm{~mm}$ ) Outcome time reported: 4 months used. 1, 2, 4, 8 months measured.

Other outcomes: PLI, API, microbiology

\begin{tabular}{|c|c|c|}
\hline Bias & Authors' judgement & Support for judgement \\
\hline $\begin{array}{l}\text { Random sequence generation (selection } \\
\text { bias) }\end{array}$ & Low risk & $\begin{array}{l}\text { "The randomisation was performed with a } \\
\text { combination of coin toss and drawing of } \\
\text { lots by a second person not involved in the } \\
\text { study to assign the patients into the follow- } \\
\text { ing groups: full mouth disinfection (FMD) } \\
\text {, FM-SRP and Q-SRP" }\end{array}$ \\
\hline
\end{tabular}

Allocation concealment (selection bias) Low risk

Incomplete outcome data (attrition bias) Low risk All outcomes
"The sequence was concealed until interventions were assigned"

"One patient in every group was excluded from the study due to prescribed antibiotics because of sinusitis maxillaris. The patient of the FM-SRP group dropped out 2 months after treatment and the two patients of the other two groups dropped out 4 months after treatment. Their data were 
Swierkot 2009 (Continued)

not included into the statistical analysis"

\begin{tabular}{|c|c|c|}
\hline $\begin{array}{l}\text { Blinding of outcome assessment (detection } \\
\text { bias) } \\
\text { All outcomes }\end{array}$ & High risk & $\begin{array}{l}\text { "The treatment and reassessment were per- } \\
\text { formed by one periodontist who had been } \\
\text { trained and tested previously for his repro- } \\
\text { ducibility" }\end{array}$ \\
\hline Selective reporting (reporting bias) & Low risk & $\begin{array}{l}\text { Data reported on all primary and secondary } \\
\text { outcomes. }\end{array}$ \\
\hline Other bias & Low risk & $\begin{array}{l}\text { Baseline balance good for pocket depth and } \\
\text { smoking. No apparent other biases }\end{array}$ \\
\hline
\end{tabular}

Vandekerckhove 1996

Methods
Study design: RCT with 2-arm parallel design

Recruitment period: unclear

Setting: University Dental Hospital, Belgium

Number of centres: One

Funding Source: supported by University

Participants

Inclusion criteria: Diagnosis: Chronic periodontitis - with PD of $>7 \mathrm{~mm}$ and BOP. All patients were in good general health

Exclusion criteria: no antibiotics from 4 months before or during study,

Age: $39-62$

Gender: 8 F (4/4) and $2 \mathrm{M}(1 / 1)$

Smokers: $3(1 / 2)$ (smoking at least 10 cigarettes per day)

Number randomised: 10

Number evaluated: $10(5 / 5)$

Interventions

Comparison: FMD vs control

Test group: 2 sessions scaling within 24 hours, after instrumentation: tongue brushing: $\mathrm{CHX}=1 \%, 1 \mathrm{~min}$; rinse: $\mathrm{CHX}=0.2 \%, 2 \times 1 \mathrm{~min}$ + gargle the last 10 seconds; subgingival: $\mathrm{CHX}=1 \%, 3$ times within $10 \mathrm{~min}$. Home: rinse $\mathrm{CHX}=0.2 \%, 1 \mathrm{~min}, 2 \mathrm{x}$ day, 2 weeks Control group: SRP 4 sessions 2 weekly intervals

OHI before study start: no

Instruments used: Hand instruments

Time per Q: 1 hour

Maintenance: none

Retreatment: none

Duration of study: 8 months

Outcomes

Primary outcome: PPD (6 sites per tooth) (data in graph)

Secondary outcomes: CAL, BOP (6 sites per tooth). Manual probe for all measurements Teeth: Only recording of first quadrant. Data split in single-/multi-rooted teeth and initial moderate (PPD 5 to $6 \mathrm{~mm}$ ) and deep pockets (PPD $>7 \mathrm{~mm}$ )

Pocket depth at baseline: moderate (PPD 5-6 mm) and deep pockets (PPD $>7 \mathrm{~mm}$ )

Outcome time reported: 4 months used. 1, 2, 4, 8 months measured. 
Other outcomes: Recession, GI, PI

\begin{tabular}{|c|c|c|}
\hline Notes & \multicolumn{2}{|c|}{$\begin{array}{l}\text { Data extracted from graphs } \\
\text { No supplementary data (CAL, BOP) available on request. }\end{array}$} \\
\hline \multicolumn{3}{|l|}{ Risk of bias } \\
\hline Bias & Authors' judgement & Support for judgement \\
\hline $\begin{array}{l}\text { Random sequence generation (selection } \\
\text { bias) }\end{array}$ & Unclear risk & $\begin{array}{l}\text { "subjects randomly distributed between the } \\
\text { two treatment groups" } \\
\text { unclear }\end{array}$ \\
\hline Allocation concealment (selection bias) & Unclear risk & Unclear \\
\hline $\begin{array}{l}\text { Incomplete outcome data (attrition bias) } \\
\text { All outcomes }\end{array}$ & Low risk & No drop-outs \\
\hline $\begin{array}{l}\text { Blinding of outcome assessment (detection } \\
\text { bias) } \\
\text { All outcomes }\end{array}$ & High risk & $\begin{array}{l}\text { "The clinical parameters were recorded by } \\
\text { the same periodontist ..." } \\
\text { Although blinded at } 8 \text { months, } 4 \text { months } \\
\text { assessment was not blinded }\end{array}$ \\
\hline Selective reporting (reporting bias) & Low risk & $\begin{array}{l}\text { Data reported on all primary and secondary } \\
\text { outcomes. }\end{array}$ \\
\hline Other bias & Low risk & $\begin{array}{l}\text { Baseline balance good for pocket depth and } \\
\text { smoking. No apparent other biases }\end{array}$ \\
\hline
\end{tabular}

Wennström 2005

\begin{tabular}{|c|c|}
\hline Methods & $\begin{array}{l}\text { Study design: RCT with } 2 \text {-arm parallel design } \\
\text { Recruitment period: during } 2002 \\
\text { Setting: University Dental Hospital (Sweden), private dental office (Italy) } \\
\text { Number of centres: Two } \\
\text { Funding Source: Industry funding }\end{array}$ \\
\hline Participants & $\begin{array}{l}\text { Inclusion criteria: Diagnosis: Chronic periodontitis- with PD of }>5 \mathrm{~mm} \text { and BOP. All } \\
\text { patients were in good general health } \\
\text { Exclusion criteria: SRP over last } 12 \text { months, antibiotics from } 3 \text { months before or during } \\
\text { study, pregnant } \\
\text { Age: } 25 \text { to } 75 \\
\text { Gender: } 19 \mathrm{~F}(8 / 11) \text { and } 22 \mathrm{M}(12 / 10) \\
\text { Smokers: } 20(9 / 11) \\
\text { Number randomised: } 42 \\
\text { Number evaluated: } 41(20 / 21)\end{array}$ \\
\hline
\end{tabular}


Wennström 2005 (Continued)

Comparison: FMS vs control
Test group: (FM-UD-test): FMS 1-h session ultrasonic scaling with water, re-instru-
mentation after 3 months in PPD > $4 \mathrm{~mm}$
Control group: (Q-SRP-control): QRP 4 sessions hand instrumentation - 1-week in-
tervals (time recorded, no time restriction), re-instrumentation after 3 months in PPD
$>4 \mathrm{~mm}$
OHI before study start: yes
Instruments used: Hand and US instruments
Time per Q: 1 hour
Maintenance: 1 month following completion of instrumentation (both groups)
Retreatment: at 3 months
Duration of study: 6 months

Outcomes

Primary outcome: PPD (6 sites per tooth)

Secondary outcomes: CAL, BOP ( 6 sites per tooth). Manual probe for all measurements Teeth: Whole-mouth recordings (baseline, 3 and 6 months). Data split in initial moderate (PPD 5 to $6 \mathrm{~mm}$ ) and deep pockets (PPD $>6 \mathrm{~mm}$ )

Pocket depth at baseline: moderate (PPD 5-6 mm) and deep pockets (PPD $>7 \mathrm{~mm}$ )

Outcome time reported: 3 months used. 3 and 6 months measured.

Other outcomes: PI, Average pain VAS score (100 mm scale)

$\begin{array}{lll}\text { Notes } & \text { For BOP: Data supplemented by authors }\end{array}$

Risk of bias

\begin{tabular}{|c|c|c|}
\hline Bias & Authors' judgement & Support for judgement \\
\hline $\begin{array}{l}\text { Random sequence generation (selection } \\
\text { bias) }\end{array}$ & Low risk & $\begin{array}{l}\text { "Within each of these subgroups, a random } \\
\text { assignment to the two treatment protocols } \\
\text { (Fig. 1) was subsequently performed by the } \\
\text { use of } \\
\text { computer-generated tables". }\end{array}$ \\
\hline Allocation concealment (selection bias) & Low risk & $\begin{array}{l}\text { "Allocation concealment was secured by (i) } \\
\text { having a person not otherwise involved in } \\
\text { the study performing the randomisation } \\
\text { and (ii) providing the centres (the dental } \\
\text { hygienists) with sealed envelopes contain- } \\
\text { ing only the assignment for the individual } \\
\text { subject" }\end{array}$ \\
\hline
\end{tabular}

Incomplete outcome data (attrition bias) Low risk All outcomes

Blinding of outcome assessment (detection Low risk bias)

All outcomes
Comment: 42 enrolled, 41 randomised, and 41 present at 6 months

"One examiner (a periodontist), who was masked with respect to the treatment assignments, performed all examinations" 
Wennström 2005 (Continued)

\begin{tabular}{|c|c|c|}
\hline Selective reporting (reporting bias) & Low risk & $\begin{array}{l}\text { Data reported on all primary and secondary } \\
\text { outcomes. }\end{array}$ \\
\hline Other bias & Low risk & $\begin{array}{l}\text { Baseline balance good for pocket depth and } \\
\text { smoking. No apparent other biases }\end{array}$ \\
\hline
\end{tabular}

Zanatta 2006

\begin{tabular}{|c|c|}
\hline Methods & $\begin{array}{l}\text { Study design: RCT with 3-arm parallel design } \\
\text { Recruitment period: Treatment between March } 2004 \text { and July } 2004 \\
\text { Setting: University Dental Clinic, Brazil } \\
\text { Number of centres: One } \\
\text { Funding Source: unclear }\end{array}$ \\
\hline Participants & $\begin{array}{l}\text { Inclusion criteria: Diagnosis: Chronic periodontitis - with PD of }>5 \mathrm{~mm} \text { and BOP. All } \\
\text { patients were in good general health } \\
\text { Exclusion criteria: SRP in past } 6 \text { months or on antibiotics from } 6 \text { months before or } \\
\text { during study, pregnancy, allergic to iodine } \\
\text { Age: } 27-72 \\
\text { Gender: } 18 \mathrm{~F} \text { and } 27 \mathrm{M} \\
\text { Smokers: unclear } \\
\text { Number randomised: } 45(15 / 15 / 15) \\
\text { Number evaluated: } 40(12 / 15 / 13)\end{array}$ \\
\hline Interventions & $\begin{array}{l}\text { Comparison: FMS vs control: FMD vs control: FMS vs FMD } \\
\text { Test group 1: (PDG): FMS } 1 \text { session ultrasonic scaling with } 0.9 \% \mathrm{NaCl} \text { (duration } 45 \\
\text { min) } \\
\text { Test group 2: (PD-PIG): FMS } 1 \text { session ultrasonic scaling with } 0.5 \% \text { povidone iodine } \\
\text { (duration } 45 \text { min) } \\
\text { Control group: (CG): QRP } 4 \text { sessions ultrasonic scaling with water - 1-week intervals } \\
\text { (duration unclear) } \\
\text { OHI before study start: yes } \\
\text { Instruments used: US instruments } \\
\text { Time per Q: unclear } \\
\text { Maintenance: twice weekly from baseline } \\
\text { Retreatment: none } \\
\text { Duration of study: } 3 \text { months }\end{array}$ \\
\hline
\end{tabular}

Outcomes

Primary outcome: PPD (6 sites per tooth)

Secondary outcomes: CAL, BOP (6 sites per tooth). Computerised probe with stent for all measurements

Teeth: Whole-mouth recordings (baseline, 1 and 3 months). Data split initial moderate (PPD 5 to $6 \mathrm{~mm}$ ) and deep pockets (PPD $>6 \mathrm{~mm}$ )

Pocket depth at baseline: moderate $(5$ to $6 \mathrm{~mm}$ ), deep (> $6 \mathrm{~mm}$ ).

Outcome time reported: 3 months used.

Other outcomes: PI, GR

Full-mouth treatment modalities (within 24 hours) for chronic periodontitis in adults (Review) 


\section{Risk of bias}

\begin{tabular}{|c|c|c|}
\hline Bias & Authors' judgement & Support for judgement \\
\hline $\begin{array}{l}\text { Random sequence generation (selection } \\
\text { bias) }\end{array}$ & Unclear risk & $\begin{array}{l}\text { "Patients were randomly assigned to one of } \\
\text { the following treatment groups:..." } \\
\text { Unclear }\end{array}$ \\
\hline Allocation concealment (selection bias) & Unclear risk & Unclear \\
\hline $\begin{array}{l}\text { Incomplete outcome data (attrition bias) } \\
\text { All outcomes }\end{array}$ & Unclear risk & $\begin{array}{l}\text { Low drop-out } 5 / 45 \text { and numbers by group } \\
\text { given but reasons not given }\end{array}$ \\
\hline $\begin{array}{l}\text { Blinding of outcome assessment (detection } \\
\text { bias) } \\
\text { All outcomes }\end{array}$ & Low risk & $\begin{array}{l}\text { "A previously calibrated examiner, masked } \\
\text { to the type of treatment, performed all clin- } \\
\text { ical assessments" }\end{array}$ \\
\hline Selective reporting (reporting bias) & Low risk & $\begin{array}{l}\text { Data reported on all primary and secondary } \\
\text { outcomes. }\end{array}$ \\
\hline Other bias & Unclear risk & $\begin{array}{l}\text { Baseline balance good for pocket depth but } \\
\text { smoking is unclear. No apparent other bi- } \\
\text { ases }\end{array}$ \\
\hline
\end{tabular}

Zijnge 2010

Methods

Study design: RCT with 2-arm parallel design
Recruitment period: September 2007 - December 2008
Setting: Private clinic, The Netherlands
Number of centres: One
Funding Source: University funding

Participants
Inclusion criteria: Diagnosis: Chronic periodontitis - with PD of $>6 \mathrm{~mm}$ at $>10 \%$ sites. All patients were in good general health

Exclusion criteria: SRP over last 5 years, antibiotics from 3 months before or during study, pregnant, smokers, removable denture

Age: 25 to 75

Gender: 16 F (8/8) and $22 \mathrm{M}(10 / 12)$

Smokers: 0

Number randomised: $39(19 / 20)$

Number evaluated: $38(18 / 20)$

Interventions

\section{Comparison: FMS vs control}

Test group: (FM-SRP): One 3-hour session

Control group: (MS-SRP): 3 sessions quadrant wise, 1 hour duration per session, 1 
week interval starting first quadrant, hand instruments

OHI before study start: no

Instruments used: Hand instruments

Time per Q: 1 hour

Maintenance: 1,2 week

Retreatment: none

Duration of study: 3 months

Primary outcome: PPD (6 sites per tooth)

Secondary outcomes: BOP (6 sites per tooth). Manual probe for all measurements

Teeth: Whole-mouth recordings as well as Test-quadrant (1st quadrant). Data split in moderate (4 to $6 \mathrm{~mm}$ ) and deep ( $\geq 7 \mathrm{~mm}$ ) pockets

Pocket depth at baseline: moderate (PPD 4 to $6 \mathrm{~mm}$ ) and deep pockets (PPD $>7 \mathrm{~mm}$ )

Outcome time reported: 3 months

Other outcomes: PI, microbiology

Notes

Plaque index at baseline is unclear

Pockets $<3 \mathrm{~mm}$ were not recorded. No data for CAL on request

\section{Risk of bias}

\begin{tabular}{|c|}
\hline Bias \\
\hline
\end{tabular}

Random sequence generation (selection Low risk bias)
Quote: “a second independent person informed them whether they had to continue the treatment in the other quadrants (FMSRP) or continue treatment in another session (MS-SRP), based on a computer-generated randomisation table"

Allocation concealment (selection bias) Low risk

Quote: “All study personnel was blinded to treatment assignment for the duration of the study"

Incomplete outcome data (attrition bias) Low risk All outcomes

Comment: 44 attended baseline exam but not clear if they were randomised. One patient dropped out of FM-SPR group. Probably low risk of bias

Blinding of outcome assessment (detection Low risk bias)

All outcomes

Quote: "After 3 months the patients were examined by a periodontist. All study personnel was blinded to treatment assignment for the duration of the study"

\begin{tabular}{|c|c|c|}
\hline Selective reporting (reporting bias) & Unclear risk & Data not reported on CAL \\
\hline
\end{tabular}

Other bias

Low risk
Baseline balance good for pocket depth. No apparent other biases 
API: approximal plaque index

BOP: bleeding on probing

CAL: clinical attachment level

CHX: chlorhexidine gluconate

FMD: full-mouth disinfection $=$ full-mouth subgingival scaling and root planing with use of antiseptics

FMS: full-mouth scaling = full-mouth subgingival scaling and root planing

GI: gingival index

GR: gingival recession

MGI: modified gingival index

OHI: oral hygiene instruction

PD: probing depth

PI: plaque index

PLI: Plaque index

PPD: probing pocket depth

Q: quadrant

QRP: quadrant wise subgingival scaling and root planing, clockwise in 4 sessions

RAL: relative attachment level

RCT: randomised controlled trial

SBI: sulcus bleeding index

SI: staining index

SRP: scaling and root planing

SUP: suppuration

US: ultrasonic

VAS: visual analogue scale

Characteristics of excluded studies [ordered by study ID]

\begin{tabular}{l|l}
\hline Study & Reason for exclusion \\
\hline Bollen 1998 & $\begin{array}{l}\text { 6 out of 16 patients suffering from aggressive periodontitis. Data not shown separately for aggressive and } \\
\text { chronic periodontitis }\end{array}$ \\
\hline Eren 2002 & Patients in the intervention arm received FMS for 4 consecutive days (over 24 hours) \\
\hline Jothi 2009 & No QRP control group \\
\hline Loggner Graff 2009 & Retreatment of patients after 3 months in study prior to outcome assessment at 6 months \\
\hline Meulman 2013 & Data only available as figures. No reply from authors to request for supplemental data \\
\hline Preus 2013 & Participants in all arms received a chlorhexidine rinse \\
\hline Quirynen 1995 & 2-months data only \\
\hline Serrano 2011 & 4 to 6 weeks data only
\end{tabular}

Full-mouth treatment modalities (within 24 hours) for chronic periodontitis in adults (Review)

Copyright @ 2015 The Cochrane Collaboration. Published by John Wiley \& Sons, Ltd. 
(Continued)

Tomasi 2006 18-month evaluation after baseline but all patients had several retreatments. These were the same patients as Wennström 2005 but it was an observational follow-up of the trial

Ushida $2008 \quad$ Immunology study with no clinical data

FMS: full-mouth scaling

QRP: quadrant wise scaling 
DATA AND ANALYSES

\section{Comparison 1. FMS versus control}

\begin{tabular}{|c|c|c|c|c|}
\hline Outcome or subgroup title & $\begin{array}{l}\text { No. of } \\
\text { studies }\end{array}$ & $\begin{array}{c}\text { No. of } \\
\text { participants }\end{array}$ & Statistical method & Effect size \\
\hline $\begin{array}{l}1 \text { Change in PPD: whole mouth, } \\
\text { single-rooted teeth and } \\
\text { multi-rooted teeth }\end{array}$ & 6 & & Mean Difference (IV, Random, 95\% CI) & Subtotals only \\
\hline $1.13 / 4$ months & 3 & 82 & Mean Difference (IV, Random, 95\% CI) & $0.01[-0.17,0.19]$ \\
\hline $1.26 / 8$ months & 4 & 117 & Mean Difference (IV, Random, 95\% CI) & $0.03[-0.12,0.17]$ \\
\hline $\begin{array}{l}2 \text { Change in CAL: whole mouth, } \\
\text { single- and multi-rooted teeth }\end{array}$ & 6 & & Mean Difference (IV, Random, 95\% CI) & Subtotals only \\
\hline $2.13 / 4$ months & 3 & 82 & Mean Difference (IV, Random, 95\% CI) & $-0.02[-0.26,0.22]$ \\
\hline $2.26 / 8$ months & 4 & 117 & Mean Difference (IV, Random, 95\% CI) & $0.05[-0.11,0.22]$ \\
\hline $\begin{array}{l}3 \text { Change in BOP: whole mouth, } \\
\text { single- and multi-rooted teeth }\end{array}$ & 7 & & Mean Difference (IV, Random, 95\% CI) & Subtotals only \\
\hline $3.13 / 4$ months & 4 & 120 & Mean Difference (IV, Random, 95\% CI) & $-2.86[-7.65,1.93]$ \\
\hline $3.26 / 8$ months & 4 & 117 & Mean Difference (IV, Random, 95\% CI) & $1.98[-5.23,9.20]$ \\
\hline
\end{tabular}

Comparison 2. FMD versus control

\begin{tabular}{|c|c|c|c|c|}
\hline Outcome or subgroup title & $\begin{array}{l}\text { No. of } \\
\text { studies }\end{array}$ & $\begin{array}{c}\text { No. of } \\
\text { participants }\end{array}$ & Statistical method & Effect size \\
\hline $\begin{array}{l}1 \text { Change in PPD: whole mouth, } \\
\text { single- and multi-rooted teeth }\end{array}$ & 3 & & Mean Difference (IV, Random, 95\% CI) & Subtotals only \\
\hline $1.13 / 4$ months & 2 & 44 & Mean Difference (IV, Random, 95\% CI) & $0.13[-0.09,0.34]$ \\
\hline $1.2 \mathrm{6} / 8$ months & 2 & 40 & Mean Difference (IV, Random, 95\% CI) & $0.14[-0.19,0.46]$ \\
\hline $\begin{array}{l}2 \text { Change in CAL: whole mouth, } \\
\text { single- and multi-rooted teeth }\end{array}$ & 3 & & Mean Difference (IV, Random, 95\% CI) & Subtotals only \\
\hline $2.13 / 4$ months & 2 & 44 & Mean Difference (IV, Random, 95\% CI) & $0.04[-0.25,0.33]$ \\
\hline $2.26 / 8$ months & 2 & 40 & Mean Difference (IV, Random, 95\% CI) & $0.03[-0.20,0.26]$ \\
\hline $\begin{array}{l}3 \text { Change in BOP: whole mouth, } \\
\text { single- and multi-rooted teeth }\end{array}$ & 4 & & Mean Difference (IV, Random, 95\% CI) & Subtotals only \\
\hline $3.13 / 4$ months & 3 & 68 & Mean Difference (IV, Random, 95\% CI) & $12.59[-8.58,33.77]$ \\
\hline $3.26 / 8$ months & 3 & 64 & Mean Difference (IV, Random, 95\% CI) & $12.56[-4.01,29.13]$ \\
\hline
\end{tabular}




\begin{tabular}{|c|c|c|c|c|}
\hline Outcome or subgroup title & $\begin{array}{l}\text { No. of } \\
\text { studies }\end{array}$ & $\begin{array}{c}\text { No. of } \\
\text { participants }\end{array}$ & Statistical method & Effect size \\
\hline $\begin{array}{l}1 \text { Change in PPD: whole mouth, } \\
\text { single- and multi-rooted teeth }\end{array}$ & 3 & & Mean Difference (IV, Random, 95\% CI) & Subtotals only \\
\hline $1.13 / 4$ months & 2 & 45 & Mean Difference (IV, Random, 95\% CI) & $-0.11[-0.34,0.12]$ \\
\hline $1.26 / 8$ months & 2 & 42 & Mean Difference (IV, Random, 95\% CI) & $0.00[-0.28,0.29]$ \\
\hline $\begin{array}{l}2 \text { Change in CAL: whole mouth, } \\
\text { single- and multi-rooted teeth }\end{array}$ & 3 & & Mean Difference (IV, Random, 95\% CI) & Subtotals only \\
\hline $2.13 / 4$ months & 2 & 45 & Mean Difference (IV, Random, 95\% CI) & $-0.25[-0.42,-0.07]$ \\
\hline $2.26 / 8$ months & 2 & 42 & Mean Difference (IV, Random, 95\% CI) & $-0.02[-0.32,0.27]$ \\
\hline $\begin{array}{l}3 \text { Change in BOP: whole mouth, } \\
\text { single- and multi-rooted teeth }\end{array}$ & 3 & & Mean Difference (IV, Random, 95\% CI) & Subtotals only \\
\hline $3.13 / 4$ months & 2 & 45 & Mean Difference (IV, Random, 95\% CI) & $-1.59[-9.97,6.80]$ \\
\hline $3.26 / 8$ months & 2 & 42 & Mean Difference (IV, Random, 95\% CI) & $\begin{array}{l}-0.20[-13.27,12 . \\
87]\end{array}$ \\
\hline
\end{tabular}

\section{Analysis I.I. Comparison I FMS versus control, Outcome I Change in PPD: whole mouth, single-rooted teeth and multi-rooted teeth.}

Review: Full-mouth treatment modalities (within 24 hours) for chronic periodontitis in adults

Comparison: I FMS versus control

Outcome: I Change in PPD: whole mouth, single-rooted teeth and multi-rooted teeth

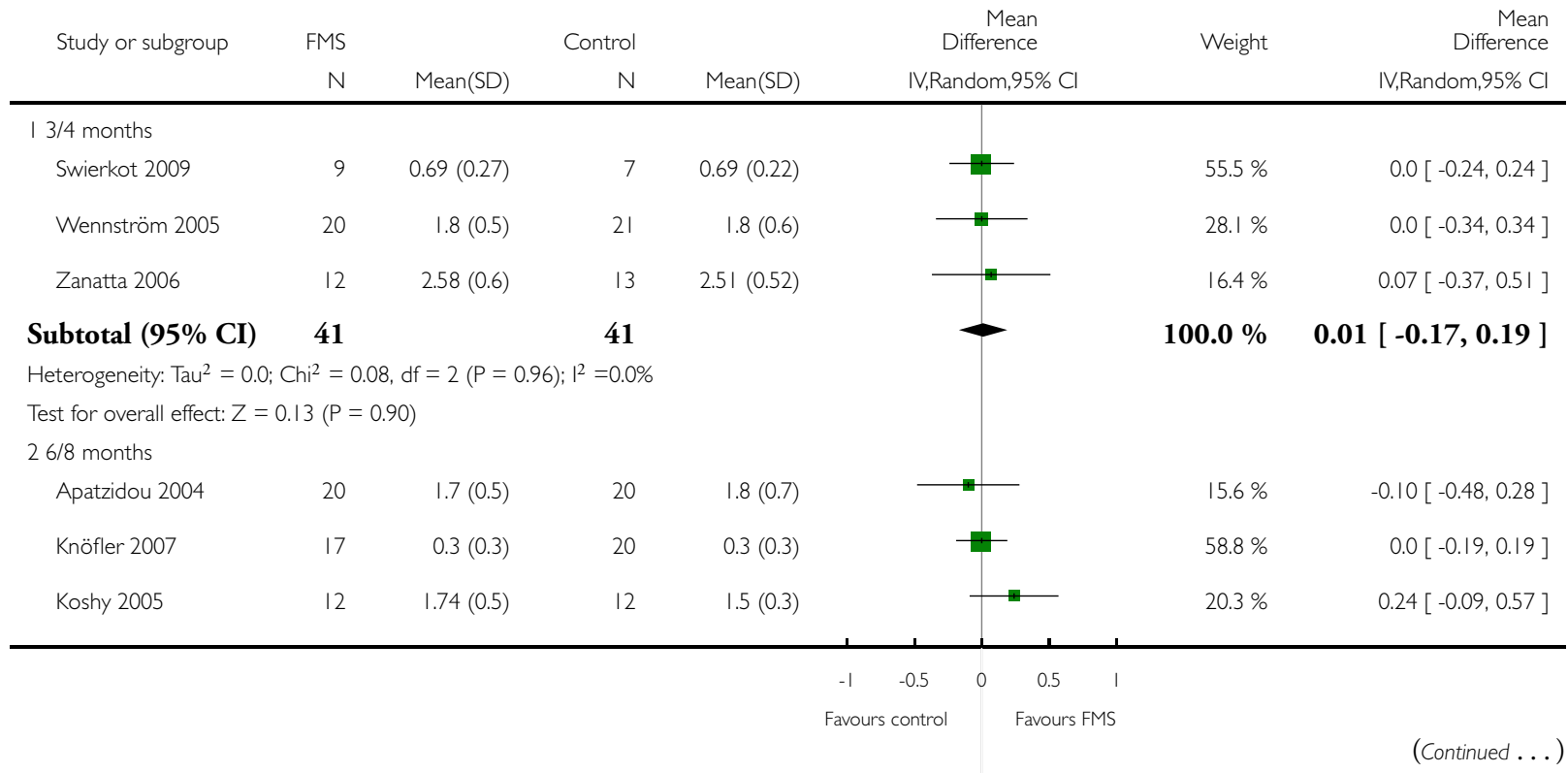

Full-mouth treatment modalities (within 24 hours) for chronic periodontitis in adults (Review) 


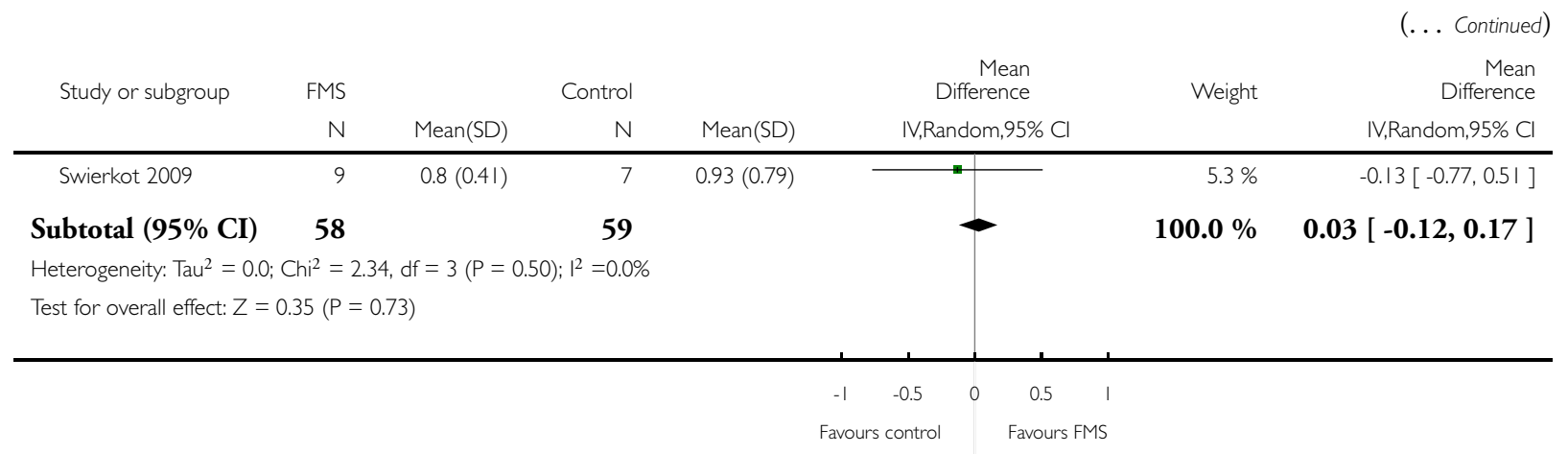

\section{Analysis I.2. Comparison I FMS versus control, Outcome 2 Change in CAL: whole mouth, single- and} multi-rooted teeth.

Review: Full-mouth treatment modalities (within 24 hours) for chronic periodontitis in adults

Comparison: I FMS versus control

Outcome: 2 Change in CAL: whole mouth, single- and multi-rooted teeth

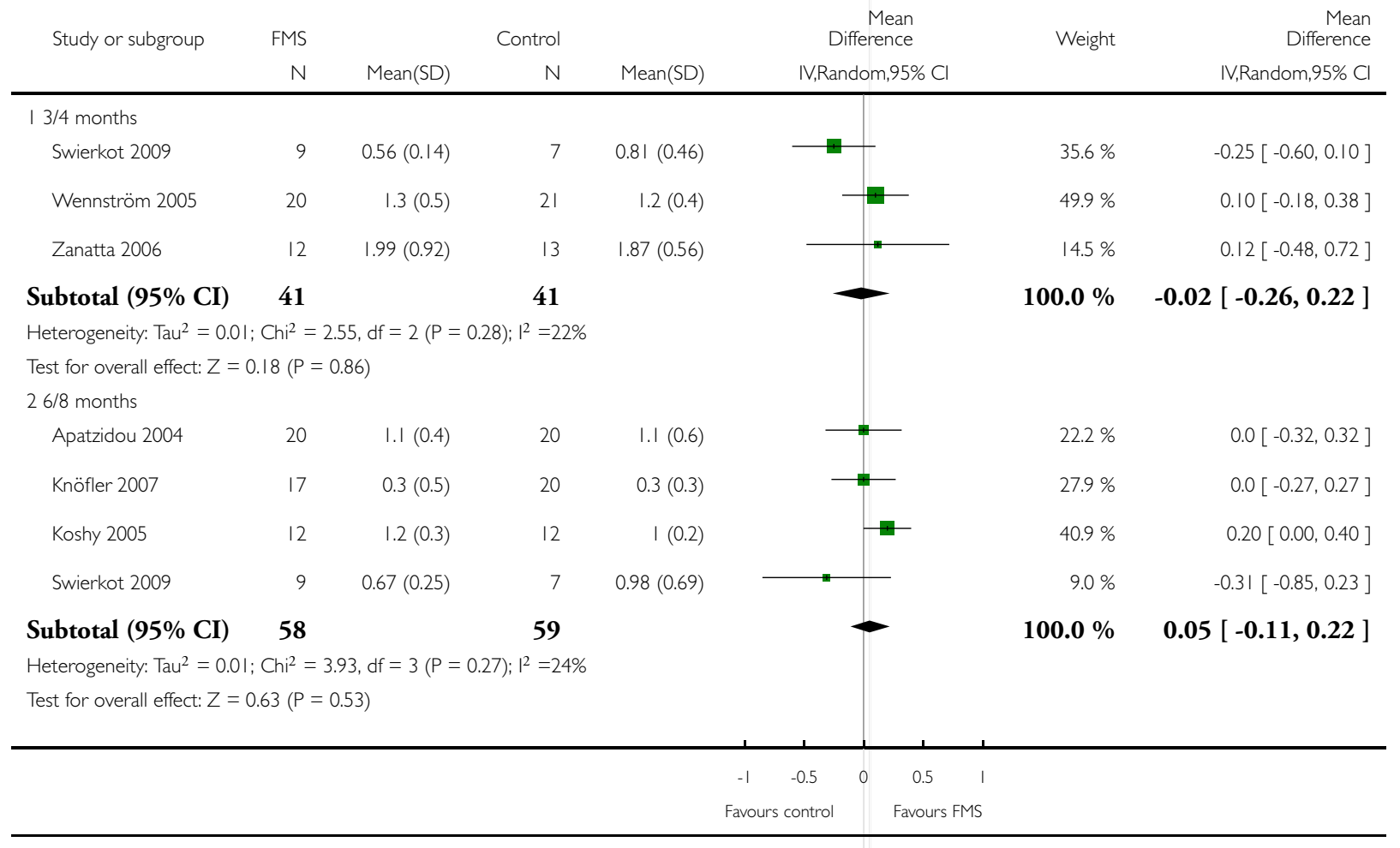

Full-mouth treatment modalities (within 24 hours) for chronic periodontitis in adults (Review) 
Analysis I.3. Comparison I FMS versus control, Outcome 3 Change in BOP: whole mouth, single- and multi-rooted teeth.

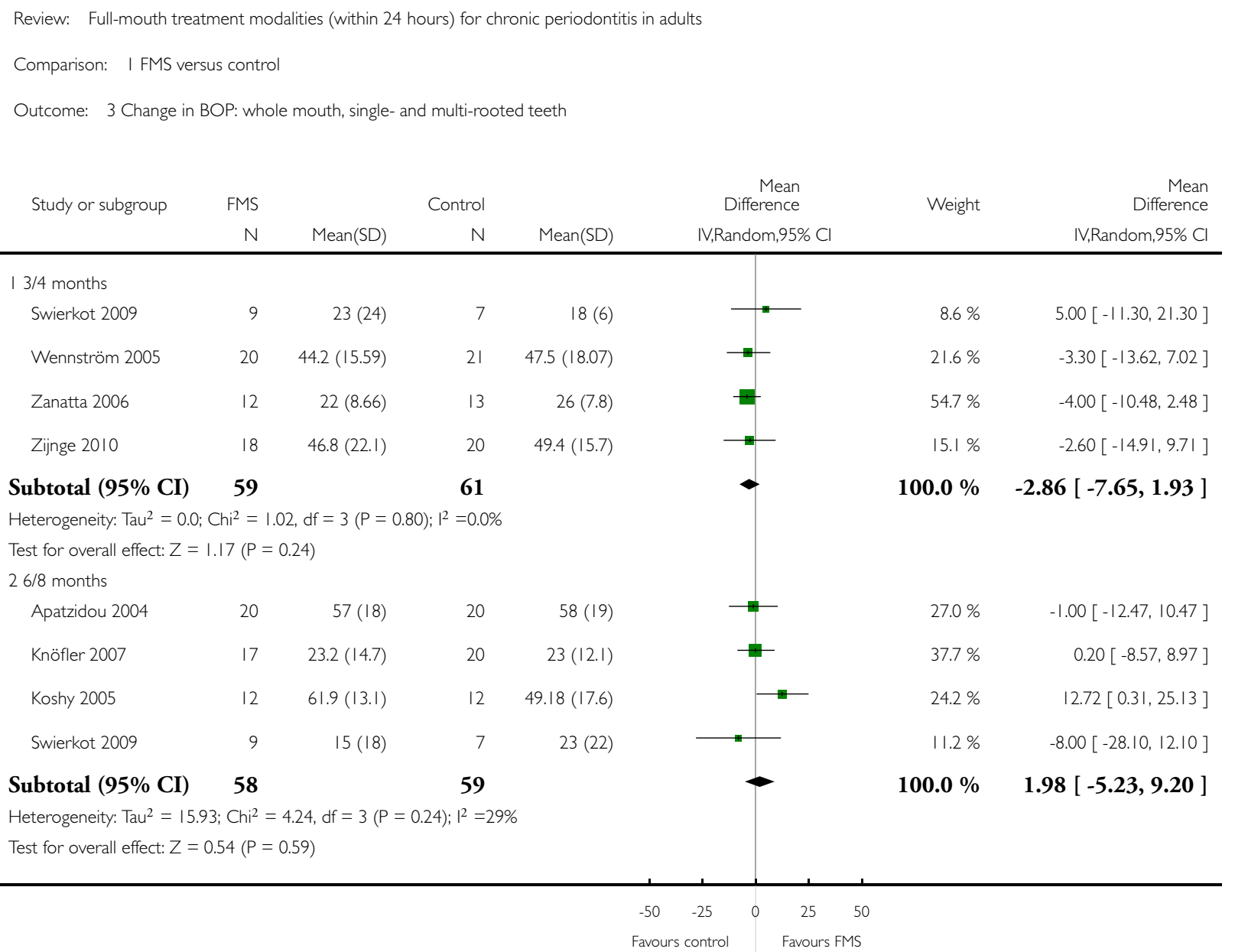


Analysis 2.I. Comparison 2 FMD versus control, Outcome I Change in PPD: whole mouth, single- and multi-rooted teeth.

Review: Full-mouth treatment modalities (within 24 hours) for chronic periodontitis in adults

Comparison: 2 FMD versus control

Outcome: I Change in PPD: whole mouth, single- and multi-rooted teeth

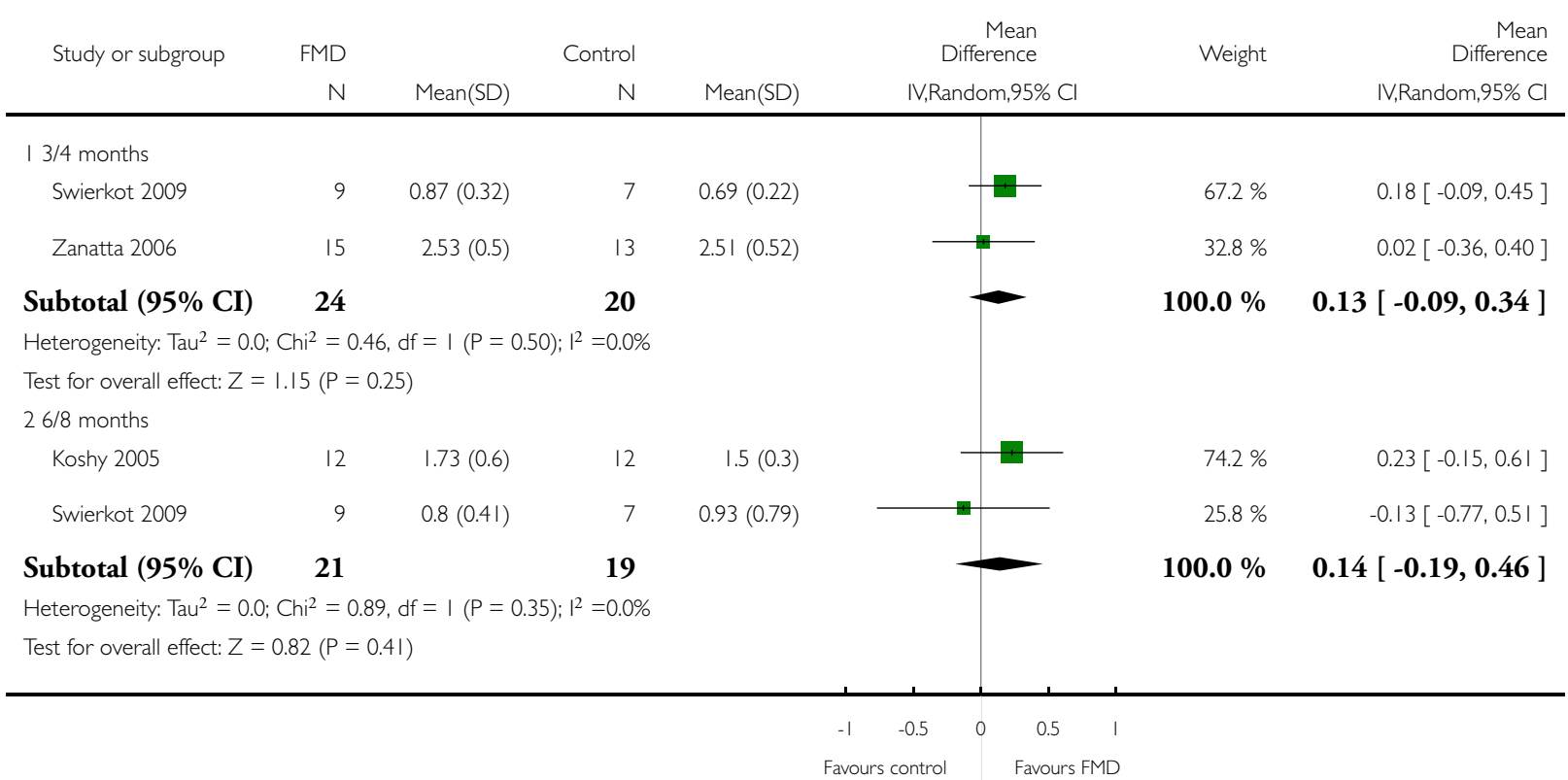


Analysis 2.2. Comparison 2 FMD versus control, Outcome 2 Change in CAL: whole mouth, single- and multi-rooted teeth.

Review: Full-mouth treatment modalities (within 24 hours) for chronic periodontitis in adults

Comparison: 2 FMD versus control

Outcome: 2 Change in CAL: whole mouth, single- and multi-rooted teeth

\begin{tabular}{|c|c|c|c|c|c|c|c|c|}
\hline \multirow[t]{2}{*}{ Study or subgroup } & \multirow{2}{*}{$\begin{array}{r}\text { FMD } \\
N\end{array}$} & \multicolumn{3}{|c|}{ Control } & \multirow{2}{*}{\multicolumn{2}{|c|}{$\begin{array}{c}\text { Mean } \\
\text { Difference } \\
\text { IV,Random,95\% Cl }\end{array}$}} & \multirow[t]{2}{*}{ Weight } & \multirow{2}{*}{$\begin{array}{r}\text { Mean } \\
\text { Difference } \\
\text { IV,Random,95\% Cl }\end{array}$} \\
\hline & & Mean(SD) & $N$ & Mean(SD) & & & & \\
\hline \multicolumn{9}{|l|}{ I $3 / 4$ months } \\
\hline Swierkot 2009 & 9 & $0.83(0.24)$ & 7 & $0.81(0.46)$ & & & $60.8 \%$ & $0.02[-0.36,0.40]$ \\
\hline Zanatta 2006 & 15 & $1.94(0.7)$ & 13 & $1.87(0.56)$ & & & $39.2 \%$ & $0.07[-0.40,0.54]$ \\
\hline Subtotal (95\% CI) & 24 & & 20 & & & & $100.0 \%$ & $0.04[-0.25,0.33]$ \\
\hline \multicolumn{9}{|c|}{ Heterogeneity: $\mathrm{Tau}^{2}=0.0 ; \mathrm{Chi}^{2}=0.03, \mathrm{df}=\mathrm{I}(\mathrm{P}=0.87) ; \mathrm{I}^{2}=0.0 \%$} \\
\hline \multicolumn{9}{|c|}{ Test for overall effect: $Z=0.27(P=0.79)$} \\
\hline \multicolumn{9}{|l|}{$26 / 8$ months } \\
\hline Koshy 2005 & 12 & $1.07(0.4)$ & 12 & I $(0.2)$ & & & $82.6 \%$ & $0.07[-0.18,0.32]$ \\
\hline Swierkot 2009 & 9 & $0.84(0.32)$ & 7 & $0.98(0.69)$ & & 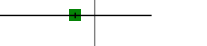 & $17.4 \%$ & $-0.14[-0.69,0.41]$ \\
\hline Subtotal (95\% CI) & 21 & & 19 & & & & $100.0 \%$ & $0.03[-0.20,0.26]$ \\
\hline \multicolumn{9}{|c|}{ Heterogeneity: $\operatorname{Tau}^{2}=0.0 ; \mathrm{Chi}^{2}=0.46, \mathrm{df}=\mathrm{I}(\mathrm{P}=0.50) ;\left.\right|^{2}=0.0 \%$} \\
\hline \multicolumn{9}{|c|}{ Test for overall effect: $Z=0.29(P=0.77)$} \\
\hline & & & & & -1 & -0.5 & 1 & \\
\hline & & & & & Favou & Favours $F$ & & \\
\hline
\end{tabular}


Analysis 2.3. Comparison 2 FMD versus control, Outcome 3 Change in BOP: whole mouth, single- and multi-rooted teeth.

Review: Full-mouth treatment modalities (within 24 hours) for chronic periodontitis in adults

Comparison: 2 FMD versus control

Outcome: 3 Change in BOP: whole mouth, single- and multi-rooted teeth

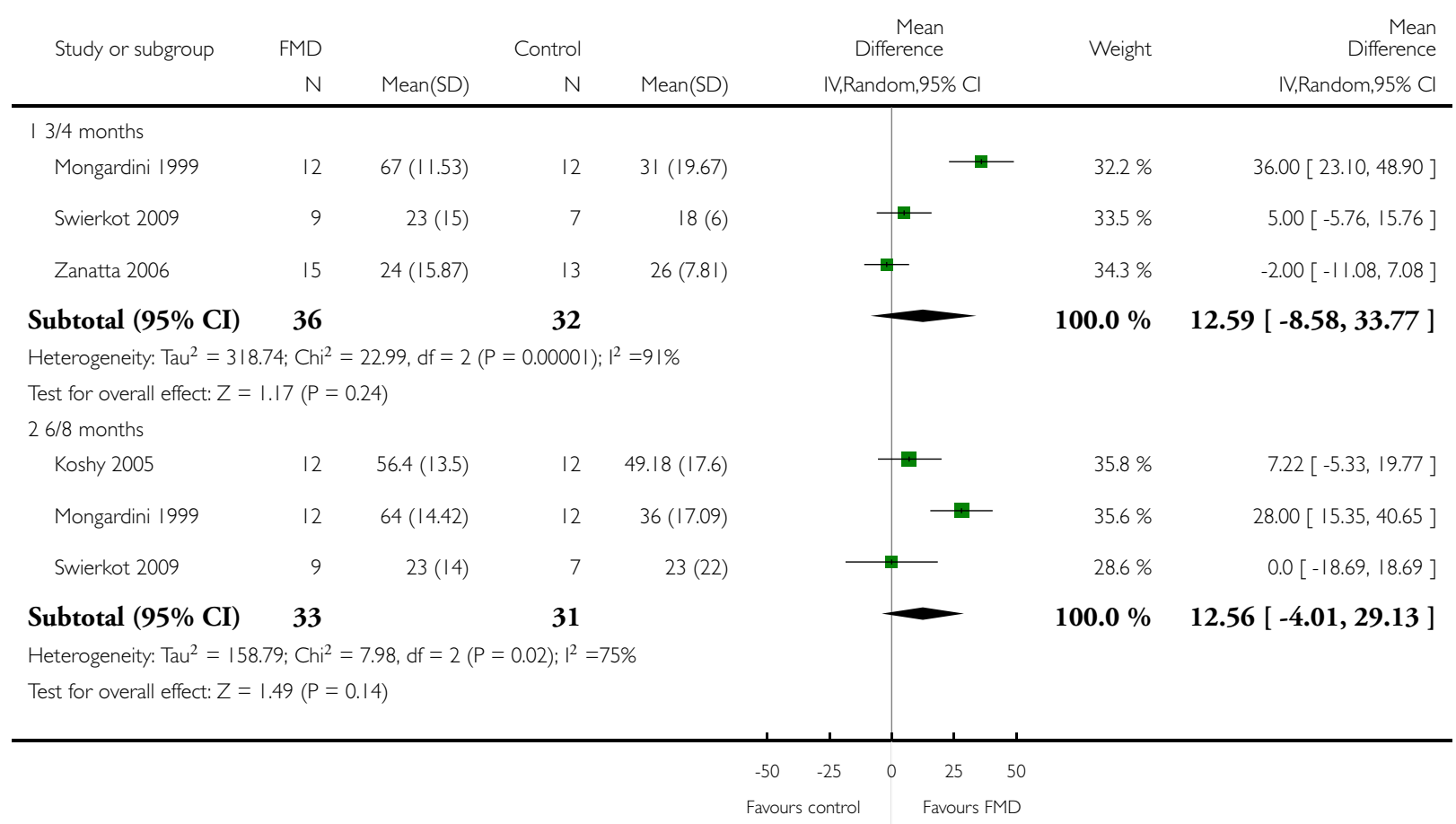


Analysis 3.I. Comparison 3 FMS versus FMD, Outcome I Change in PPD: whole mouth, single- and multirooted teeth.

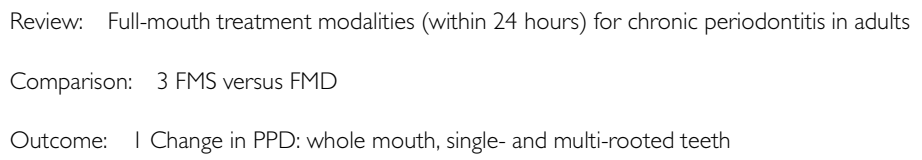

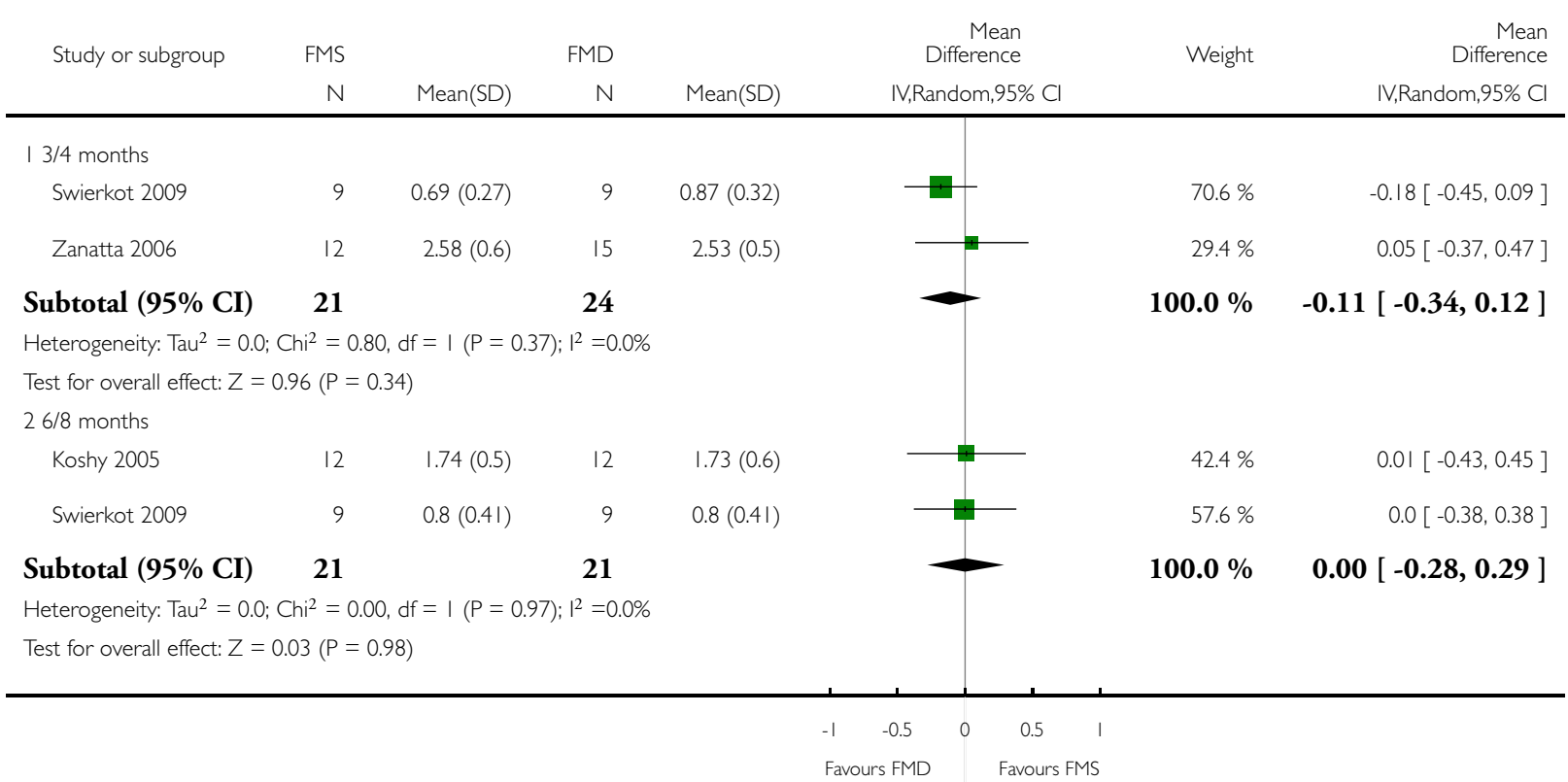


Analysis 3.2. Comparison 3 FMS versus FMD, Outcome 2 Change in CAL: whole mouth, single- and multirooted teeth.

Review: Full-mouth treatment modalities (within 24 hours) for chronic periodontitis in adults

Comparison: 3 FMS versus FMD

Outcome: 2 Change in CAL: whole mouth, single- and multi-rooted teeth

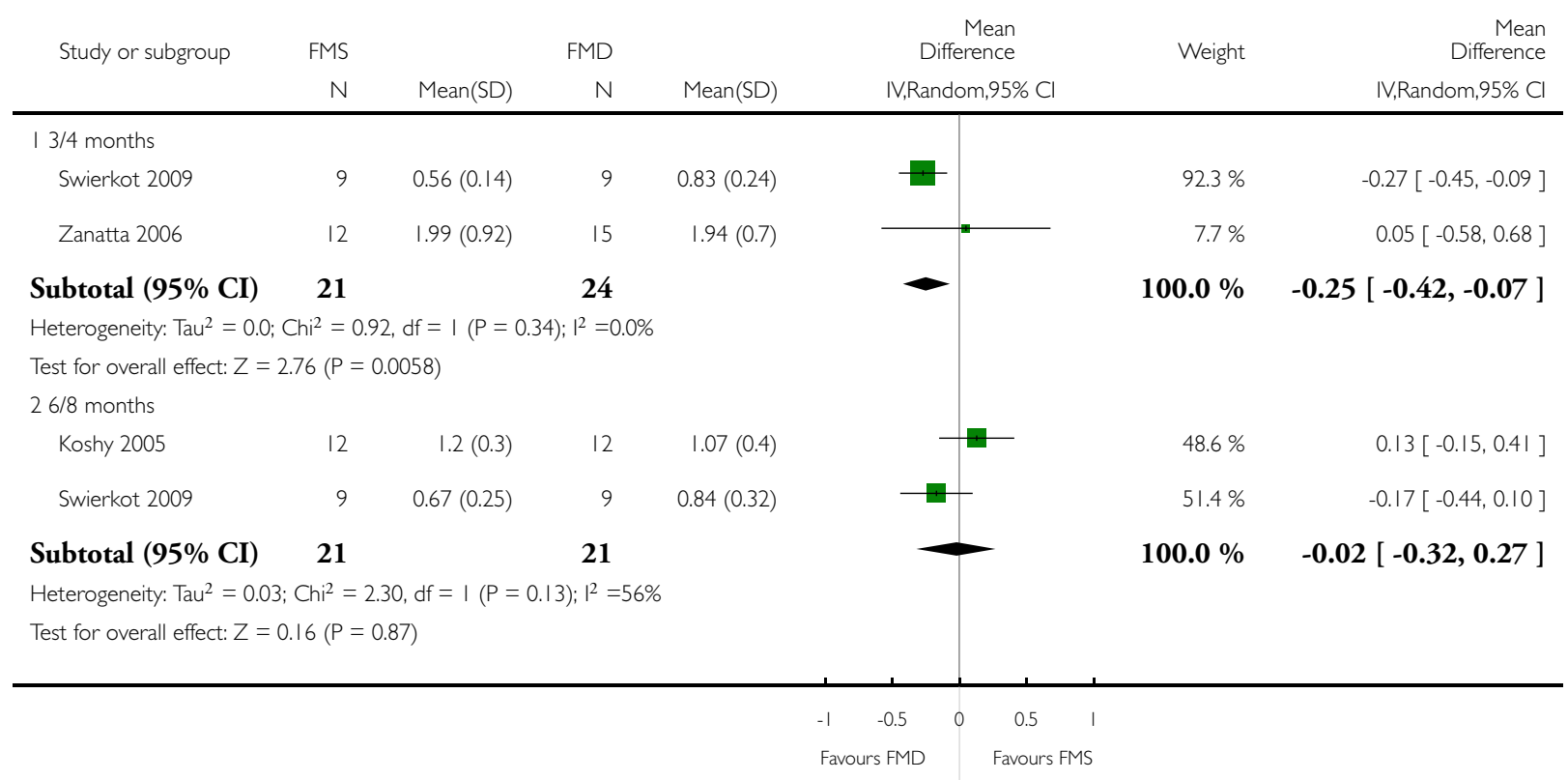




\section{Analysis 3.3. Comparison 3 FMS versus FMD, Outcome 3 Change in BOP: whole mouth, single- and multi- rooted teeth.}

Review: Full-mouth treatment modalities (within 24 hours) for chronic periodontitis in adults

Comparison: 3 FMS versus FMD

Outcome: 3 Change in BOP: whole mouth, single- and multi-rooted teeth

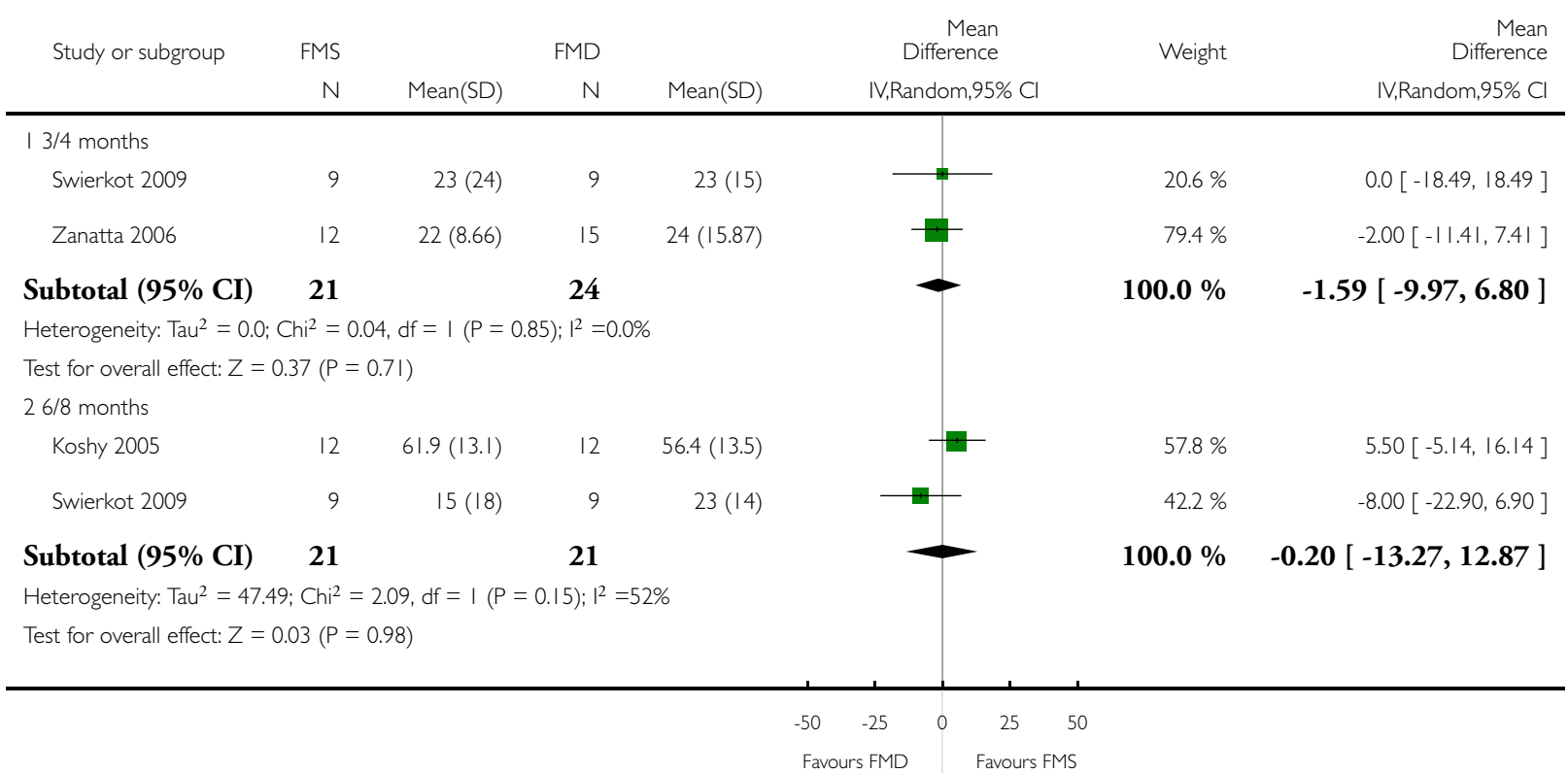

\section{ADDITIONAL TABLES}

Table 1. Adverse events and patient-reported outcomes

\begin{tabular}{ll}
\hline Study & Outcome \\
\hline Apatzidou 2004 & $\begin{array}{l}\text { Visual analogue scale }(0-10) \text { of pain, percentage of patients taking analgesics, number of analgesics, body } \\
\text { temperature (axilla) all recorded after } 24 \text { and } 48 \text { hours. Occurence of labial herpes or oral ulcers recorded } \\
\text { after } 2 \text { weeks }\end{array}$ \\
\hline Del Peloso 2008 & $\begin{array}{l}\text { Body temperature (axilla), visual analogue scale }(0-10) \text { of pain, reports of analgesics, reports of oral } \\
\text { ulcerations or other adverse effects }\end{array}$ \\
\hline Jervøe-Storm 2006 & Not reported \\
\hline Knöfler 2007 & Not reported
\end{tabular}


Table 1. Adverse events and patient-reported outcomes (Continued)

\begin{tabular}{l|l} 
Koshy 2005 & $\begin{array}{l}\text { Visual analogue scale }(1-10) \text { of pain, number of painkillers, body temperature (axilla) all recorded after } \\
\text { treatment same day and next day }\end{array}$ \\
\hline Mongardini 1999 & $\begin{array}{l}\text { Visual analogue scale of pain on a } 10 \mathrm{~cm} \text { scale, number of analgesics, body temperature (axilla) all recorded } \\
\text { same and next day. Occurence of labial herpes or oral ulcers recorded during the first week }\end{array}$ \\
\hline Quirynen 2006 & Not reported \\
\hline Swierkot 2009 & Adverse events or side effects (none reported) \\
\hline Vandekerckhove 1996 & $\begin{array}{l}\text { Questionnaire of pain, number of analgesics, body temperature all recorded after the first session of treatment. } \\
\text { Occurence of labial herpes }\end{array}$ \\
\hline Wennström 2005 & Overall degree of treatment discomfort on a 100 mm visual analogue scale \\
\hline Zanatta 2006 & Not reported \\
\hline Zijnge 2010 & Adverse events or severe side effects (none reported) \\
\hline
\end{tabular}

Table 2. FMS versus control: change in PPD

\begin{tabular}{|c|c|c|c|c|c|}
\hline $\begin{array}{l}\text { Tooth type: } \\
\text { Single-rooted, } \\
\text { Multi-rooted, } \\
\text { or Both }\end{array}$ & $\begin{array}{l}\text { Baseline pocket } \\
\text { depth }(\mathrm{mm})\end{array}$ & $\begin{array}{l}\text { Time } \\
\text { (Months) }\end{array}$ & $\begin{array}{l}\text { Number of studies } \\
\text { (Participants) }\end{array}$ & $\begin{array}{l}\text { Mean difference } \\
\text { (Random-effects } \\
\text { meta-analysis) }\end{array}$ & $\begin{array}{l}\text { Heterogeneity } \\
\left(\mathrm{P} \text { value; } \mathrm{I}^{2}\right)\end{array}$ \\
\hline Both & $5-6$ & $3 / 4$ & $5(149)$ & $\begin{array}{l}-0.05 \quad[-0.19,0.09] \\
(P=0.46)\end{array}$ & $(\mathrm{P}=0.94) ; \mathrm{I}^{2}=0 \%$ \\
\hline Both & $>6$ & $3 / 4$ & $6(165)$ & $\begin{array}{l}-0.05 \quad\left[\begin{array}{ll}-0.31, & 0.21] \\
(P=0.69)\end{array}\right.\end{array}$ & $(\mathrm{P}=0.57) ; \mathrm{I}^{2}=0 \%$ \\
\hline Both & $5-6$ & $6 / 8$ & $3(97)$ & $\begin{array}{l}-0.13[-0.35,0.08] \\
(P=0.23)\end{array}$ & $(\mathrm{P}=0.91) ; \mathrm{I}^{2}=0 \%$ \\
\hline Both & $>6$ & $6 / 8$ & $3(76)$ & $\begin{array}{l}0.00[-0.48,0.48] ;(P \\
=1.00)\end{array}$ & $(\mathrm{P}=0.81) ; \mathrm{I}^{2}=0 \%$ \\
\hline Single-rooted & $5-6$ & $3 / 4$ & $1(16)$ & $\begin{array}{l}0.63[0.29,0.97] ;(P \\
=0.0002)\end{array}$ & Not applicable \\
\hline Single-rooted & $>6$ & $3 / 4$ & $0(0)$ & Not estimable & Not applicable \\
\hline Single-rooted & $5-6$ & $6 / 8$ & $3(69)$ & $\begin{array}{l}0.16[-0.01,0.32] ;(P \\
=0.06)\end{array}$ & $(\mathrm{P}=0.89) ; \mathrm{I}^{2}=0 \%$ \\
\hline
\end{tabular}


Table 2. FMS versus control: change in PPD (Continued)

\begin{tabular}{l|l|l|l|l}
\hline Single-rooted & $>6$ & $6 / 8$ & $2(53)$ & $\begin{array}{l}0.26[-0.21,0.73] ;\left(\mathrm{P} \quad(\mathrm{P}=0.64) ; \mathrm{I}^{2}=0 \%\right. \\
=0.27)\end{array}$ \\
\hline Multi-rooted & $5-6$ & $3 / 4$ & $1(16)$ & $\begin{array}{l}1.00[0.41,1.59] ;(\mathrm{P} \\
=0.0008)\end{array}$ \\
\hline Multi-rooted & $>6$ & $3 / 4$ & $0(0)$ & Not applicable \\
\hline Multi-rooted & $5-6$ & $6 / 8$ & $3(69)$ & $\begin{array}{l}0.21[-0.14,0.55] ;\left(\mathrm{P} \quad(\mathrm{P}=0.06) ; \mathrm{I}^{2}=64 \%\right. \\
=0.24)\end{array}$ \\
\hline Multi-rooted & $>6$ & $6 / 8$ & $2(53)$ & $\begin{array}{l}0.18[-0.26,0.62] ;\left(\mathrm{P} \quad(\mathrm{P}=0.42) ; \mathrm{I}^{2}=0 \%\right. \\
=0.42)\end{array}$ \\
\hline
\end{tabular}

Table 3. FMS versus control: change in CAL

\begin{tabular}{|c|c|c|c|c|c|}
\hline $\begin{array}{l}\text { Tooth type: } \\
\text { Single-rooted, } \\
\text { Multi-rooted, } \\
\text { or Both }\end{array}$ & $\begin{array}{l}\text { Baseline pocket } \\
\text { depth }(\mathrm{mm})\end{array}$ & $\begin{array}{l}\text { Time } \\
\text { (Months) }\end{array}$ & $\begin{array}{l}\text { Number } \\
\text { of studies (Partici- } \\
\text { pants) }\end{array}$ & $\begin{array}{l}\text { Mean difference } \\
\text { (Random-effects } \\
\text { meta-analysis) }\end{array}$ & $\begin{array}{l}\text { Heterogeneity } \\
\left(\mathrm{P} \text { value; } \mathrm{I}^{2}\right)\end{array}$ \\
\hline Both & $5-6$ & $3 / 4$ & $4(111)$ & $\begin{array}{l}-0.02 \quad\left[\begin{array}{ll}-0.26, & 0.23\end{array}\right] \\
(P=0.85)\end{array}$ & $(\mathrm{P}=0.90) ; \mathrm{I}^{2}=0 \%$ \\
\hline Both & $>6$ & $3 / 4$ & $5(127)$ & $\begin{array}{l}0.09[-0.22,0.41] ;(\mathrm{P} \\
=0.57)\end{array}$ & $(\mathrm{P}=1.00) ; \mathrm{I}^{2}=0 \%$ \\
\hline Both & $5-6$ & $6 / 8$ & $4(126)$ & $\begin{array}{l}0.09[-0.12,0.30] ;(\mathrm{P} \\
=0.40)\end{array}$ & $(\mathrm{P}=0.47) ; \mathrm{I}^{2}=0 \%$ \\
\hline Both & $>6$ & $6 / 8$ & $4(105)$ & $\begin{array}{l}0.05[-0.64,0.74] ;(\mathrm{P} \\
=0.89)\end{array}$ & $(P=0.005) ; I^{2}=77 \%$ \\
\hline Single-rooted & $5-6$ & $3 / 4$ & $1(16)$ & $\begin{array}{l}0.41[-0.00,0.82] ;(\mathrm{P} \\
=0.05)\end{array}$ & Not applicable \\
\hline Single-rooted & $>6$ & $3 / 4$ & $0(0)$ & Not estimable & Not applicable \\
\hline Single-rooted & $5-6$ & $6 / 8$ & $2(40)$ & $\begin{array}{l}0.04[-0.19,0.27] ;(\mathrm{P} \\
=0.71)\end{array}$ & $(\mathrm{P}=0.50) ; \mathrm{I}^{2}=0 \%$ \\
\hline Single-rooted & $>6$ & $6 / 8$ & $1(24)$ & $\begin{array}{l}0.47[-0.37,1.31] ;(\mathrm{P} \\
=0.27)\end{array}$ & Not applicable \\
\hline Multi-rooted & $5-6$ & $3 / 4$ & $1(16)$ & $\begin{array}{l}1.11[0.45,1.77] ;(\mathrm{P} \\
=0.0009)\end{array}$ & Not applicable \\
\hline
\end{tabular}


Table 3. FMS versus control: change in CAL (Continued)

\begin{tabular}{llllll}
\hline Multi-rooted & $>6$ & $3 / 4$ & $0(0)$ & Not estimable & Not applicable \\
\hline Multi-rooted & $5-6$ & $6 / 8$ & $2(40)$ & $\begin{array}{l}0.00[-0.34,0.34] ;\left(\mathrm{P} \quad(\mathrm{P}=0.19) ; \mathrm{I}^{2}=41 \%\right. \\
=1.00)\end{array}$ \\
\hline Multi-rooted & $>6$ & $6 / 8$ & $1(24)$ & $\begin{array}{l}0.38[-0.28,1.04] ;(\mathrm{P} \quad \text { Not applicable } \\
=0.26)\end{array}$ \\
\hline
\end{tabular}

Table 4. FMS versus control: change in BOP

\begin{tabular}{|c|c|c|c|c|c|}
\hline $\begin{array}{l}\text { Tooth type: } \\
\text { Single-rooted, } \\
\text { Multi-rooted, } \\
\text { or Both }\end{array}$ & $\begin{array}{l}\text { Baseline pocket } \\
\text { depth }(\mathrm{mm})\end{array}$ & $\begin{array}{l}\text { Time } \\
\text { (Months) }\end{array}$ & $\begin{array}{l}\text { Number } \\
\text { of studies (Partici- } \\
\text { pants) }\end{array}$ & $\begin{array}{l}\text { Mean difference } \\
\quad \text { (Random-effects } \\
\text { meta-analysis) }\end{array}$ & $\begin{array}{l}\text { Heterogeneity } \\
\left(\mathrm{P} \text { value; } \mathrm{I}^{2}\right)\end{array}$ \\
\hline Both & $5-6$ & $3 / 4$ & $2(61)$ & $\begin{array}{l}-8.05 \quad[-30.25,14 \\
16] ;(P=0.48)\end{array}$ & $(\mathrm{P}=0.02) ; \mathrm{I}^{2}=80 \%$ \\
\hline Both & $>6$ & $3 / 4$ & $3(77)$ & $\begin{array}{l}-0.33[-7.70,7.04] \\
(P=0.93)\end{array}$ & $(\mathrm{P}=0.51) ; \mathrm{I}^{2}=0 \%$ \\
\hline Both & $5-6$ & $6 / 8$ & $2(57)$ & $\begin{array}{l}-4.94[-16.59,6.72] \\
(P=0.41)\end{array}$ & $(\mathrm{P}=0.87) ; \mathrm{I}^{2}=0 \%$ \\
\hline Both & $>6$ & $6 / 8$ & $2(36)$ & $\begin{array}{l}10.22[-0.59,21.03] \\
(P=0.06)\end{array}$ & $(\mathrm{P}=0.92) ; \mathrm{I}^{2}=0 \%$ \\
\hline Single-rooted & $5-6$ & $3 / 4$ & $1(16)$ & $\begin{array}{l}3.00[-2.43,8.43] ;(\mathrm{P} \\
=0.28)\end{array}$ & Not applicable \\
\hline Single-rooted & $>6$ & $3 / 4$ & $0(0)$ & Not estimable & Not applicable \\
\hline Single-rooted & $5-6$ & $6 / 8$ & $2(45)$ & $\begin{array}{l}-3.06[-10.47,4.35] \\
(P=0.42)\end{array}$ & $(\mathrm{P}=0.27) ; \mathrm{I}^{2}=18 \%$ \\
\hline Single-rooted & $>6$ & $6 / 8$ & $1(29)$ & $\begin{array}{l}-4.00 \quad[-20.17, \quad 12 \\
17] ;(P=0.63)\end{array}$ & Not applicable \\
\hline Multi-rooted & $5-6$ & $3 / 4$ & $1(16)$ & $\begin{array}{l}7.00[4.54,9.46] ;(\mathrm{P} \\
<0.00001)\end{array}$ & Not applicable \\
\hline Multi-rooted & $>6$ & $3 / 4$ & $0(0)$ & Not estimable & Not applicable \\
\hline Multi-rooted & $5-6$ & $6 / 8$ & $2(45)$ & $\begin{array}{l}2.38[-2.95,7.71] ;(\mathrm{P} \\
=0.38)\end{array}$ & $(\mathrm{P}=0.50) ; \mathrm{I}^{2}=0 \%$ \\
\hline
\end{tabular}


Table 4. FMS versus control: change in BOP (Continued)

\begin{tabular}{|c|c|c|c|c|c|}
\hline Multi-rooted & $>6$ & $6 / 8$ & $1(29)$ & $\begin{array}{l}-4.00 \quad[-23.29,15 \\
29] ;(P=0.68)\end{array}$ & Not applicable \\
\hline
\end{tabular}

Table 5. FMD versus control: change in PPD

\begin{tabular}{|c|c|c|c|c|c|}
\hline $\begin{array}{l}\text { Tooth type: } \\
\text { Single-rooted, } \\
\text { multi-rooted, } \\
\text { or both }\end{array}$ & $\begin{array}{l}\text { Baseline pocket } \\
\text { depth }(\mathrm{mm})\end{array}$ & $\begin{array}{l}\text { Time } \\
\text { (Months) }\end{array}$ & $\begin{array}{l}\text { Number of studies } \\
\text { (Participants) }\end{array}$ & $\begin{array}{l}\text { Mean difference } \\
\quad \text { (Random-effects } \\
\text { meta-analysis) }\end{array}$ & $\begin{array}{l}\text { Heterogeneity } \\
\left(\mathrm{P} \text { value; } \mathrm{I}^{2}\right)\end{array}$ \\
\hline Both & $5-6$ & $3 / 4$ & $1(28)$ & $\begin{array}{l}0.12[-0.19,0.43] ;(\mathrm{P} \\
=0.45)\end{array}$ & Not applicable \\
\hline Both & $>6$ & $3 / 4$ & $2(44)$ & $\begin{array}{l}-0.56[-1.10,-0.03] ; \\
(P=0.04)\end{array}$ & $(\mathrm{P}=0.24) ; \mathrm{I}^{2}=29 \%$ \\
\hline Both & $5-6$ & $6 / 8$ & $0(0)$ & Not estimable & Not applicable \\
\hline Both & $>6$ & $6 / 8$ & $1(16)$ & $\begin{array}{l}-0.14 \quad\left[\begin{array}{ll}-0.52, & 0.24\end{array}\right] \\
(\mathrm{P}=0.47)\end{array}$ & Not applicable \\
\hline Single-rooted & $5-6$ & $3 / 4$ & $3(50)$ & $\begin{array}{l}0.28[-0.59,1.15] ;(\mathrm{P} \\
=0.52)\end{array}$ & $\begin{array}{l}(\mathrm{P}=0.0005) ; \mathrm{I}^{2}= \\
87 \%\end{array}$ \\
\hline Single-rooted & $>6$ & $3 / 4$ & $2(34)$ & $\begin{array}{l}1.28[-0.48,3.04] ;(\mathrm{P} \\
=0.15)\end{array}$ & $(\mathrm{P}=0.03) ; \mathrm{I}^{2}=78 \%$ \\
\hline Single-rooted & $5-6$ & $6 / 8$ & $5(103)$ & $\begin{array}{l}0.41[0.11,0.70] ;(\mathrm{P} \\
=0.006)\end{array}$ & $(\mathrm{P}=0.01) ; \mathrm{I}^{2}=70 \%$ \\
\hline Single-rooted & $>6$ & $6 / 8$ & $4(87)$ & $\begin{array}{l}0.78[-0.01,1.57] ;(\mathrm{P} \\
=0.05)\end{array}$ & $(\mathrm{P}=0.03) ; \mathrm{I}^{2}=67 \%$ \\
\hline Multi-rooted & $5-6$ & $3 / 4$ & $3(50)$ & $\begin{array}{l}0.18[-0.79,1.15] ;(\mathrm{P} \\
=0.72)\end{array}$ & $(\mathrm{P}=0.003) ; \mathrm{I}^{2}=83 \%$ \\
\hline Multi-rooted & $>6$ & $3 / 4$ & $2(34)$ & $\begin{array}{l}1.28[0.44,2.11] ;(\mathrm{P} \\
=0.003)\end{array}$ & $(\mathrm{P}=0.92) ; \mathrm{I}^{2}=0 \%$ \\
\hline Multi-rooted & $5-6$ & $6 / 8$ & $5(103)$ & $\begin{array}{l}0.21[-0.12,0.53] ;(\mathrm{P} \\
=0.21)\end{array}$ & $(\mathrm{P}=0.03) ; \mathrm{I}^{2}=62 \%$ \\
\hline Multi-rooted & $>6$ & $6 / 8$ & $4(87)$ & $\begin{array}{l}0.56[-0.23,1.34] ;(\mathrm{P} \\
=0.16)\end{array}$ & $(\mathrm{P}=0.04) ; \mathrm{I}^{2}=65 \%$ \\
\hline
\end{tabular}


Table 6. FMD versus control: change in CAL

\begin{tabular}{|c|c|c|c|c|c|}
\hline $\begin{array}{l}\text { Tooth type: } \\
\text { Single-rooted, } \\
\text { multi-rooted, } \\
\text { or both }\end{array}$ & $\begin{array}{l}\text { Baseline pocket } \\
\text { depth }(\mathrm{mm})\end{array}$ & $\begin{array}{l}\text { Time } \\
\text { (Months) }\end{array}$ & $\begin{array}{l}\text { Number of studies } \\
\text { (Participants) }\end{array}$ & $\begin{array}{l}\text { Mean difference } \\
\text { (Random-effects } \\
\text { meta-analysis) }\end{array}$ & $\begin{array}{l}\text { Heterogeneity } \\
\left(\mathrm{P} \text { value; } \mathrm{I}^{2}\right)\end{array}$ \\
\hline Both & $5-6$ & $3 / 4$ & $1(28)$ & $\begin{array}{l}0.18[-0.21,0.57] ;(P \\
=0.37)\end{array}$ & Not applicable \\
\hline Both & $>6$ & $3 / 4$ & $2(44)$ & $\begin{array}{l}-0.39\left[\begin{array}{ll}-1.32, & 0.54] \\
(P=0.42)\end{array}\right.\end{array}$ & $(\mathrm{P}=0.06) ; \mathrm{I}^{2}=71 \%$ \\
\hline Both & $5-6$ & $6 / 8$ & $0(0)$ & Not estimable & Not applicable \\
\hline Both & $>6$ & $6 / 8$ & $1(16)$ & $\begin{array}{l}-0.16\left[\begin{array}{ll}-0.41, & 0.09] ; \\
(P=0.20)\end{array}\right.\end{array}$ & Not applicable \\
\hline Single-rooted & $5-6$ & $3 / 4$ & $2(40)$ & $\begin{array}{l}0.08[-0.87,1.04] ;(P \\
=0.86)\end{array}$ & $(\mathrm{P}=0.04) ; \mathrm{I}^{2}=75 \%$ \\
\hline Single-rooted & $>6$ & $3 / 4$ & $1(24)$ & $\begin{array}{l}1.90[0.73,3.07] ;(P \\
=0.001)\end{array}$ & Not applicable \\
\hline Single-rooted & $5-6$ & $6 / 8$ & $3(64)$ & $\begin{array}{l}0.14[0.00,0.28] ;(\mathrm{P} \\
=0.05)\end{array}$ & $(\mathrm{P}=0.48) ; \mathrm{I}^{2}=0 \%$ \\
\hline Single-rooted & $>6$ & $6 / 8$ & $2(48)$ & $\begin{array}{l}0.72[-0.94,2.37] ;(P \\
=0.40)\end{array}$ & $(\mathrm{P}=0.03) ; \mathrm{I}^{2}=79 \%$ \\
\hline Multi-rooted & $5-6$ & $3 / 4$ & $2(40)$ & $\begin{array}{l}0.27[-1.21,1.75] ;(\mathrm{P} \\
=0.72)\end{array}$ & $(\mathrm{P}=0.001) ; \mathrm{I}^{2}=90 \%$ \\
\hline Multi-rooted & $>6$ & $3 / 4$ & $1(24)$ & $\begin{array}{l}1.30[0.20,2.40] ;(\mathrm{P} \\
=0.02)\end{array}$ & Not applicable \\
\hline Multi-rooted & $5-6$ & $6 / 8$ & $3(64)$ & $\begin{array}{l}0.12[-0.17,0.41] ;(P \\
=0.43)\end{array}$ & $(\mathrm{P}=0.07) ; \mathrm{I}^{2}=62 \%$ \\
\hline Multi-rooted & $>6$ & $6 / 8$ & $2(48)$ & $\begin{array}{l}0.52[-1.30,2.34] ;(\mathrm{P} \\
=0.57)\end{array}$ & $(\mathrm{P}=0.005) ; \mathrm{I}^{2}=87 \%$ \\
\hline
\end{tabular}

Table 7. FMD versus control: change in BOP

\begin{tabular}{|c|c|c|c|c|c|}
\hline $\begin{array}{l}\text { Tooth type: } \\
\text { Single-rooted, } \\
\text { multi-rooted, } \\
\text { or both }\end{array}$ & $\begin{array}{l}\text { Baseline pocket } \\
\text { depth }(\mathrm{mm})\end{array}$ & $\begin{array}{l}\text { Time } \\
\text { (Months) }\end{array}$ & $\begin{array}{l}\text { Number of studies } \\
\text { (Participants) }\end{array}$ & $\begin{array}{l}\text { Mean difference } \\
\quad \text { (Random-effects } \\
\text { meta-analysis) }\end{array}$ & $\begin{array}{l}\text { Heterogeneity } \\
\left(\mathrm{P} \text { value; } \mathrm{I}^{2}\right)\end{array}$ \\
\hline
\end{tabular}


Table 7. FMD versus control: change in BOP (Continued)

\begin{tabular}{|c|c|c|c|c|c|}
\hline Both & $5-6$ & $3 / 4$ & $0(0)$ & Not estimable & Not applicable \\
\hline Both & $>6$ & $3 / 4$ & $1(16)$ & $\begin{array}{l}-5.00[-11.70,1.70] ; \\
(P=0.14)\end{array}$ & Not applicable \\
\hline Both & $5-6$ & $6 / 8$ & $0(0)$ & Not estimable & Not applicable \\
\hline Both & $>6$ & $6 / 8$ & $1(16)$ & $\begin{array}{l}2.00[-7.83,11.83] ; \\
(\mathrm{P}=0.69)\end{array}$ & Not applicable \\
\hline Single-rooted & $5-6$ & $3 / 4$ & $1(16)$ & $\begin{array}{l}5.00[1.97,8.03] ;(\mathrm{P} \\
=0.001)\end{array}$ & Not applicable \\
\hline Single-rooted & $>6$ & $3 / 4$ & $0(0)$ & Not estimable & Not applicable \\
\hline Single-rooted & $5-6$ & $6 / 8$ & $2(45)$ & $\begin{array}{l}4.83[1.86,7.80] ;(\mathrm{P} \\
=0.001)\end{array}$ & $(\mathrm{P}=0.60) ; \mathrm{I}^{2}=0 \%$ \\
\hline Single-rooted & $>6$ & $6 / 8$ & $1(29)$ & $\begin{array}{l}14.00[-2.17,30.17] ; \\
(P=0.09)\end{array}$ & Not applicable \\
\hline Multi-rooted & $5-6$ & $3 / 4$ & $1(16)$ & $\begin{array}{l}2.00[0.38,3.62] ;(\mathrm{P} \\
=0.02)\end{array}$ & Not applicable \\
\hline Multi-rooted & $>6$ & $3 / 4$ & $0(0)$ & Not estimable & Not applicable \\
\hline Multi-rooted & $5-6$ & $6 / 8$ & $2(45)$ & $\begin{array}{l}8.72[-2.61,20.06] ; \\
(P=0.13)\end{array}$ & $(\mathrm{P}=0.22) ; \mathrm{I}^{2}=34 \%$ \\
\hline Multi-rooted & $>6$ & $6 / 8$ & $1(29)$ & $\begin{array}{l}-8.00[-25.00,9.00] ; \\
(P=0.36)\end{array}$ & Not applicable \\
\hline
\end{tabular}

Table 8. FMS versus FMD: change in PPD

\begin{tabular}{|c|c|c|c|c|c|}
\hline $\begin{array}{l}\text { Tooth type: } \\
\text { Single-rooted, } \\
\text { multi-rooted, } \\
\text { or both }\end{array}$ & $\begin{array}{l}\text { Baseline pocket } \\
\text { depth }(\mathrm{mm})\end{array}$ & $\begin{array}{l}\text { Time } \\
\text { (Months) }\end{array}$ & $\begin{array}{l}\text { Number of studies } \\
\text { (Participants) }\end{array}$ & $\begin{array}{l}\text { Mean difference } \\
\text { (Random-effects } \\
\text { meta-analysis) }\end{array}$ & $\begin{array}{l}\text { Heterogeneity } \\
\left(\mathrm{P} \text { value; } \mathrm{I}^{2}\right)\end{array}$ \\
\hline Both & $5-6$ & $3 / 4$ & $1(27)$ & $\begin{array}{l}-0.13[-0.46,0.20] \\
(P=0.44)\end{array}$ & Not applicable \\
\hline Both & $>6$ & $3 / 4$ & $2(45)$ & $\begin{array}{l}0.95[-0.33,2.23] ;(\mathrm{P} \\
=0.15)\end{array}$ & $(\mathrm{P}=0.007) ; \mathrm{I}^{2}=86 \%$ \\
\hline Both & $5-6$ & $6 / 8$ & $0(0)$ & Not estimable & Not applicable \\
\hline
\end{tabular}


Table 8. FMS versus FMD: change in PPD (Continued)

\begin{tabular}{|c|c|c|c|c|c|}
\hline Both & $>6$ & $6 / 8$ & $1(18)$ & $\begin{array}{l}0.17[-0.43,0.77] ;(P \\
=0.58)\end{array}$ & Not applicable \\
\hline Single-rooted & $5-6$ & $3 / 4$ & $1(18)$ & $\begin{array}{l}0.95[0.65,1.25] ;(P \\
<0.00001)\end{array}$ & Not applicable \\
\hline Single-rooted & $>6$ & $3 / 4$ & $0(0)$ & Not estimable & Not applicable \\
\hline Single-rooted & $5-6$ & $6 / 8$ & $3(70)$ & $\begin{array}{l}-0.10 \quad[-0.40,0.20] ; \\
(P=0.52)\end{array}$ & $(P=0.02) ; I^{2}=76 \%$ \\
\hline Single-rooted & $>6$ & $6 / 8$ & $2(52)$ & $\begin{array}{l}-0.03 \quad[-0.48,0.41] ; \\
(P=0.88)\end{array}$ & $(\mathrm{P}=0.55) ; \mathrm{I}^{2}=0 \%$ \\
\hline Multi-rooted & $5-6$ & $3 / 4$ & $1(18)$ & $\begin{array}{l}1.37[0.81,1.93] ;(\mathrm{P} \\
<0.00001)\end{array}$ & Not applicable \\
\hline Multi-rooted & $>6$ & $3 / 4$ & $0(0)$ & Not estimable & Not applicable \\
\hline Multi-rooted & $5-6$ & $6 / 8$ & $3(70)$ & $\begin{array}{l}0.04[-0.16,0.25] ;(P \\
=0.68)\end{array}$ & $(\mathrm{P}=0.63) ; \mathrm{I}^{2}=0 \%$ \\
\hline Multi-rooted & $>6$ & $6 / 8$ & $2(52)$ & $\begin{array}{l}0.05[-0.38,0.47] ;(P \\
=0.83)\end{array}$ & $(\mathrm{P}=0.29) ; \mathrm{I}^{2}=9 \%$ \\
\hline
\end{tabular}

Table 9. FMS versus FMD: change in CAL

\begin{tabular}{|c|c|c|c|c|c|}
\hline $\begin{array}{l}\text { Tooth type: } \\
\text { Single-rooted, } \\
\text { multi-rooted, } \\
\text { or both }\end{array}$ & $\begin{array}{l}\text { Baseline pocket } \\
\text { depth }(\mathrm{mm})\end{array}$ & $\begin{array}{l}\text { Time } \\
\text { (Months) }\end{array}$ & $\begin{array}{l}\text { Number of studies } \\
\text { (Participants) }\end{array}$ & $\begin{array}{l}\text { Mean difference } \\
\quad \text { (Random-effects } \\
\text { meta-analysis) }\end{array}$ & $\begin{array}{l}\text { Heterogeneity } \\
\left(\mathrm{P} \text { value; } \mathrm{I}^{2}\right)\end{array}$ \\
\hline Both & $5-6$ & $3 / 4$ & $1(27)$ & $\begin{array}{l}-0.05 \quad[-0.50,0.40] \\
(P=0.83)\end{array}$ & Not applicable \\
\hline Both & $>6$ & $3 / 4$ & $2(45)$ & $\begin{array}{l}0.41[-0.45,1.27] ;(\mathrm{P} \\
=0.35)\end{array}$ & $(\mathrm{P}=0.17) ; \mathrm{I}^{2}=47 \%$ \\
\hline Both & $5-6$ & $6 / 8$ & $0(0)$ & Not estimable & Not applicable \\
\hline Both & $>6$ & $6 / 8$ & $1(18)$ & $\begin{array}{l}-0.51 \quad[-1.24,0.22] \\
(P=0.17)\end{array}$ & Not applicable \\
\hline Single-rooted & $5-6$ & $3 / 4$ & $1(18)$ & $\begin{array}{l}0.71[0.31,1.11] ;(\mathrm{P} \\
=0.0005)\end{array}$ & Not applicable \\
\hline Single-rooted & $>6$ & $3 / 4$ & $0(0)$ & Not estimable & Not applicable \\
\hline
\end{tabular}


Table 9. FMS versus FMD: change in CAL (Continued)

\begin{tabular}{|c|c|c|c|c|c|}
\hline Single-rooted & $5-6$ & $6 / 8$ & $2(42)$ & $\begin{array}{l}-0.09 \quad[-0.30,0.11] \\
(P=0.38)\end{array}$ & $(\mathrm{P}=0.44) ; \mathrm{I}^{2}=0 \%$ \\
\hline Single-rooted & $>6$ & $6 / 8$ & $1(24)$ & $\begin{array}{l}0.56[-0.37,1.49] ;(\mathrm{P} \\
=0.24)\end{array}$ & Not applicable \\
\hline Multi-rooted & $5-6$ & $3 / 4$ & $1(18)$ & $\begin{array}{l}1.53[0.89,2.17] ;(\mathrm{P} \\
<0.00001)\end{array}$ & Not applicable \\
\hline Multi-rooted & $>6$ & $3 / 4$ & $0(0)$ & Not estimable & Not applicable \\
\hline Multi-rooted & $5-6$ & $6 / 8$ & $2(42)$ & $\begin{array}{l}-0.02[-0.53,0.49] \\
(P=0.93)\end{array}$ & $(\mathrm{P}=0.06) ; \mathrm{I}^{2}=73 \%$ \\
\hline Multi-rooted & $>6$ & $6 / 8$ & $1(24)$ & $\begin{array}{l}0.74[0.17,1.31] ;(\mathrm{P} \\
=0.01)\end{array}$ & Not applicable \\
\hline
\end{tabular}

Table 10. FMS versus FMD: change in BOP

\begin{tabular}{|c|c|c|c|c|c|}
\hline $\begin{array}{l}\text { Tooth type: } \\
\text { Single-rooted, } \\
\text { multi-rooted, } \\
\text { or both }\end{array}$ & $\begin{array}{l}\text { Baseline pocket } \\
\text { depth }(\mathrm{mm})\end{array}$ & $\begin{array}{l}\text { Time } \\
\text { (Months) }\end{array}$ & $\begin{array}{l}\text { Number of studies } \\
\text { (Participants) }\end{array}$ & $\begin{array}{l}\text { Mean difference } \\
\quad \text { (Random-effects } \\
\text { meta-analysis) }\end{array}$ & $\begin{array}{l}\text { Heterogeneity } \\
\left(\mathrm{P} \text { value; } \mathrm{I}^{2}\right)\end{array}$ \\
\hline Both & $5-6$ & $3 / 4$ & $1(27)$ & $\begin{array}{l}-0.05 \quad[-0.50,0.40] \\
(P=0.83)\end{array}$ & Not applicable \\
\hline Both & $>6$ & $3 / 4$ & $2(45)$ & $\begin{array}{l}0.41[-0.45,1.27] ;(\mathrm{P} \\
=0.35)\end{array}$ & $(\mathrm{P}=0.17) ; \mathrm{I}^{2}=47 \%$ \\
\hline Both & $5-6$ & $6 / 8$ & $0(0)$ & Not estimable & Not applicable \\
\hline Both & $>6$ & $6 / 8$ & $1(18)$ & $\begin{array}{l}-0.51 \quad\left[\begin{array}{ll}-1.24, & 0.22] \\
(\mathrm{P}=0.17)\end{array}\right.\end{array}$ & Not applicable \\
\hline Single-rooted & $5-6$ & $3 / 4$ & $1(18)$ & $\begin{array}{l}0.71[0.31,1.11] ;(\mathrm{P} \\
=0.0005)\end{array}$ & Not applicable \\
\hline Single-rooted & $>6$ & $3 / 4$ & $0(0)$ & Not estimable & Not applicable \\
\hline Single-rooted & $5-6$ & $6 / 8$ & $2(42)$ & $\begin{array}{l}-0.09 \quad[-0.30,0.11] \\
(P=0.38)\end{array}$ & $(\mathrm{P}=0.44) ; \mathrm{I}^{2}=0 \%$ \\
\hline Single-rooted & $>6$ & $6 / 8$ & $1(24)$ & $\begin{array}{l}0.56[-0.37,1.49] ;(\mathrm{P} \\
=0.24)\end{array}$ & Not applicable \\
\hline
\end{tabular}


Table 10. FMS versus FMD: change in BOP (Continued)

\begin{tabular}{|c|c|c|c|c|c|}
\hline Multi-rooted & $5-6$ & $3 / 4$ & $1(18)$ & $\begin{array}{l}1.53[0.89,2.17] ;(P \\
<0.00001)\end{array}$ & Not applicable \\
\hline Multi-rooted & $>6$ & $3 / 4$ & $0(0)$ & Not estimable & Not applicable \\
\hline Multi-rooted & $5-6$ & $6 / 8$ & $2(42)$ & $\begin{array}{l}-0.02[-0.53,0.49] ; \\
(P=0.93)\end{array}$ & $(P=0.06) ; I^{2}=73 \%$ \\
\hline Multi-rooted & $>6$ & $6 / 8$ & $1(24)$ & $\begin{array}{l}0.74[0.17,1.31] ;(\mathrm{P} \\
=0.01)\end{array}$ & Not applicable \\
\hline
\end{tabular}

\section{A P P E N D I CES}

\section{Appendix I. MEDLINE (OVID) search strategy}

1.exp Periodontal Diseases/

2. periodont\$.mp.

3. ((dental adj6 scaling) or (tooth adj6 scaling) or (tooth adj6 scale\$) or (teeth adj6 scaling) or (teeth adj6 scale\$) or (supragingival\$ adj (scaling or scale\$)) or (subgingival\$ adj (scaling or scale\$))).mp.

4. exp Dental Prophylaxis/

5. (dental prophylaxis or oral prophylaxis).mp.

6. ((root adj plane\$) or (root adj6 planing)).mp.

7. ((mechanical\$ adj6 debride\$) or periodontal adj debridem\$).mp.

8. (subgingival adj curettage).mp.

9. exp Subgingival Curettage/

10. (pocket adj6 irrigat\$).mp.

11. CHLORHEXIDINE/

12. chlorhexidine.mp.

13. (Eludril or Chlorohex or corsodyl).mp.

14. or/1-2

15. or $/ 3-13$

16. ((full-mouth adj6 disinfection) or (full mouth adj6 disinfection) or (full mouth adj6 debridement) or (full mouth adj6 debridement) or full mouth scaling or full-mouth scaling).mp.

17. 14 and 15 and 16 


\section{Appendix 2. Cochrane Oral Health Group Trials Register search strategy}

From January 2014, updated searches of the Cochrane Oral Health Group Trials Register were undertaken using the Cochrane Register of Studies and the search strategy below:

1 ((periodont* or "furcation defect" or "intra-bony defect*" or "intra bony defect*" or "infra-bony defect*" or "infra bony defect*”)) AND (INREGISTER)

2 ((scaling or scale or prophylaxis or "root plane*" OR "root planing" or debridem* or curett* or "pocket irrigat*" or chlorhexidine or eludril or chlorohex or corsodyl)) AND (INREGISTER)

3 ((“full-mouth" OR "full mouth")) AND (INREGISTER)

4 (\#1 AND \#2 AND \#3) AND (INREGISTER)

Previous searches of the trials register were undertaken using the Procite software and the following search strategy:

((periodont* or "furcation defect" or "intra-bony defect*" or "intra bony defect*" or "infra-bony defect*" or "infra bony defect*") AND (scaling or scale or prophylaxis or "root plane" ${ }^{*}$ OR "root planing" or debridem* or curett* or "pocket irrigat*" or chlorhexidine or eludril or chlorohex or corsodyl) AND ("full-mouth" OR "full mouth"))

\section{Appendix 3. CENTRAL search strategy}

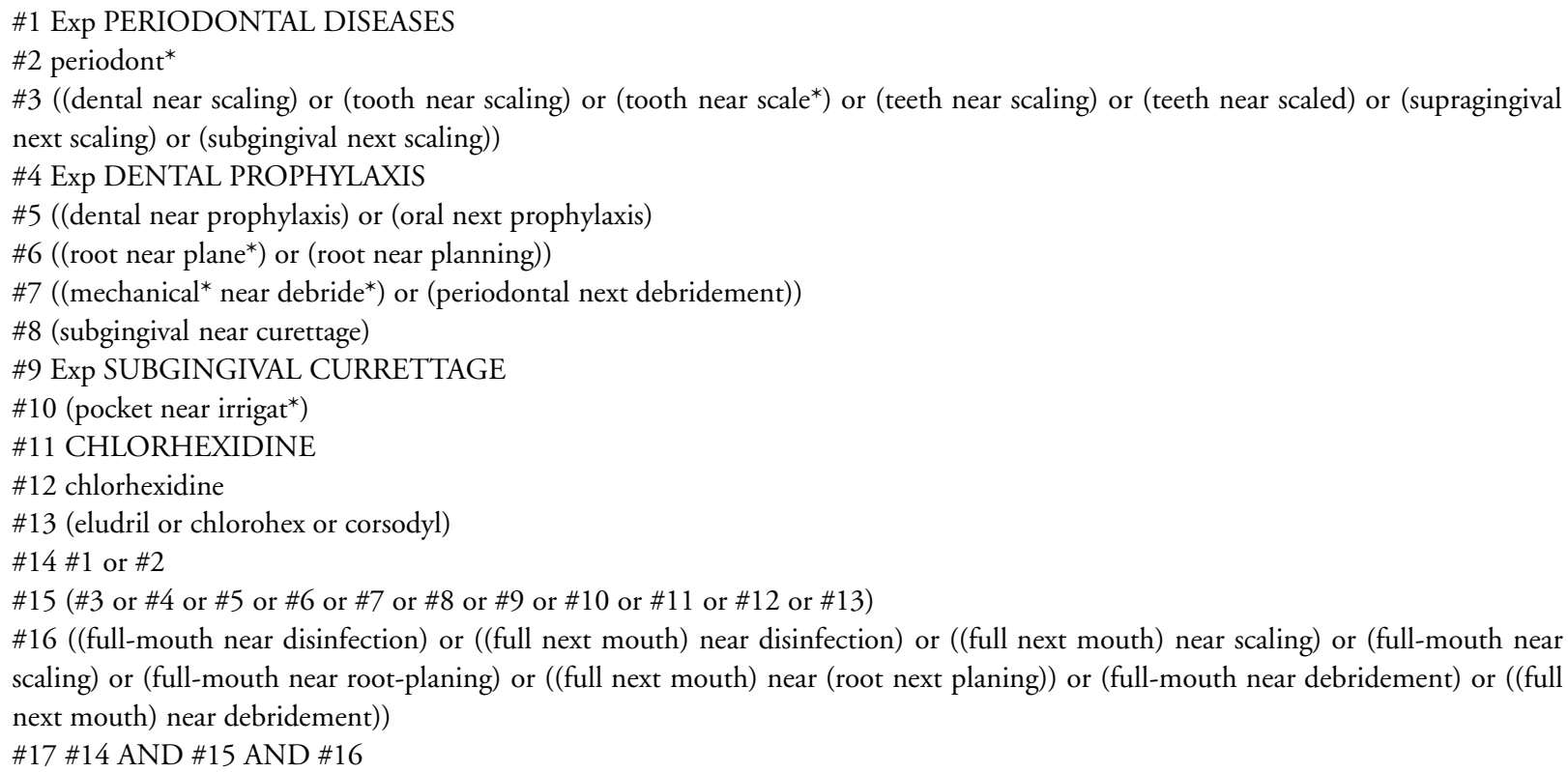

\section{Appendix 4. EMBASE (OVID) search strategy}

1. exp Periodontal Diseases/

2. periodont\$.mp.

3. ((dental adj6 scaling) or (tooth adj6 scaling) or (tooth adj6 scale\$) or (teeth adj6 scaling) or (teeth adj6 scale\$) or (supragingival\$ adj (scaling or scale\$)) or (subgingival\$ adj (scaling or scale\$))).mp.

4. exp Dental Prophylaxis/

5. (dental prophylaxis or oral prophylaxis).mp.

6. ((root adj plane\$) or (root adj6 planing)).mp.

7. ((mechanical\$ adj6 debride\$) or periodontal adj debridem\$).mp.

8. (subgingival adj curettage).mp.

9. exp Subgingival Curettage/

10. (pocket adj6 irrigat\$).mp.

11. CHLORHEXIDINE/

Full-mouth treatment modalities (within 24 hours) for chronic periodontitis in adults (Review) 
12. chlorhexidine.mp.

13. (Eludril or Chlorohex or corsodyl).mp.

14. or/1-2

15. or/3-13

16. ((full-mouth adj6 disinfection) or (full mouth adj6 disinfection) or (full mouth adj6 debridement) or (full mouth adj6 debridement) or full mouth scaling or full-mouth scaling).mp.

17. 14 and 15 and 16

\section{Appendix 5. CINAHL (OVID) search strategy}

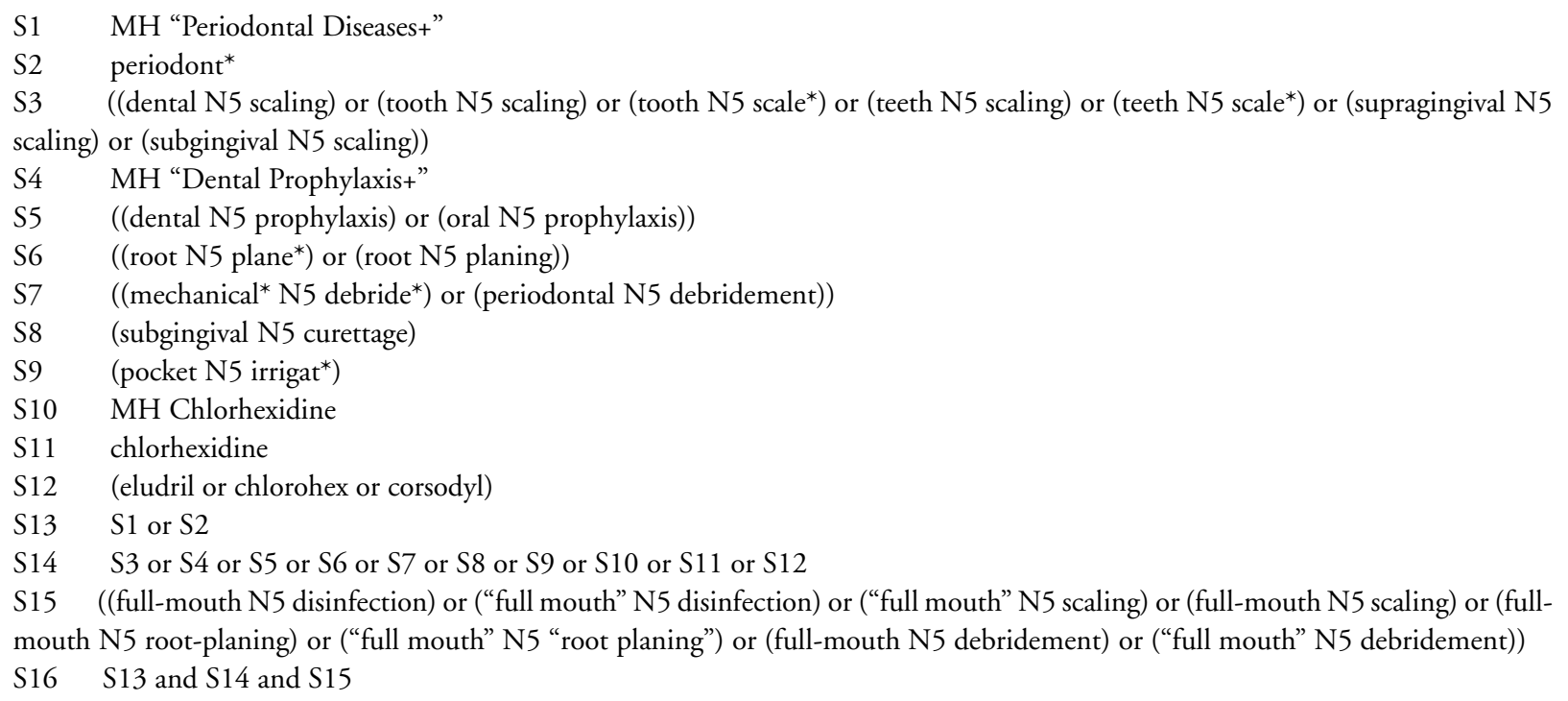

\section{Appendix 6. US National Institutes of Health Trials Register and WHO International Clinical Trials Registry Platform search strategy}

periodontitis AND full mouth

\section{Appendix 7. Assessment of risk of bias in included studies}

Method of randomisation sequence generation was classified as:

-Low risk of bias when random number generation was used such as computer generated schemes;

-High risk of bias when other methods of randomisation were used (such as alternate assignment, hospital number);

-Unclear when method of randomisation was not reported or explained.

Allocation concealment (i.e. how the randomisation sequence was hidden from the examiners) was classified as:

-Low risk of bias when examiners were kept unaware of randomisation sequence (for example, by means of central randomisation, sequentially numbered, opaque envelopes);

-High risk of bias when other methods of allocation concealment were used (such as alternate assignment, hospital number);

-Unclear when method of allocation concealment was not reported or explained.

Blinding of examiners was classified as:

-Low risk of bias when the outcome assessors were blinded to the intervention;

-High risk of bias when the outcome assessors knew which intervention a patient had received;

-Unclear when there was insufficient information to determine if the outcome assessors were blinded or not.

Full-mouth treatment modalities (within 24 hours) for chronic periodontitis in adults (Review)

Copyright @ 2015 The Cochrane Collaboration. Published by John Wiley \& Sons, Ltd. 
Completeness of outcome data was assessed as:

-Low risk of bias if there was no missing data, or missing data was balanced across the groups with similar reasons unlikely to be due to the intervention, or missing data were imputed using appropriate methods;

-High risk of bias if reason for missing data was likely to be related to outcomes, or if there was a large proportion of missing data;

-Unclear when there is insufficient reporting of attrition/exclusions.

Selective outcome reporting was assessed as:

-Low risk of bias if all primary and secondary outcomes were reported;

-High risk of bias if not all of the study's prespecified outcomes (protocol/abstract) were reported;

-Unclear if there was insufficient information on prespecified outcomes.

Other potential threats to validity were assessed as:

-High risk of bias if a potential source of bias was related to a specific study design issue not already covered (high baseline imbalance for periodontal severity and smoking);

-Low risk of bias if there was no evidence of any other biases;

-Unclear if there was insufficient information provided to make decision.

\section{WHAT'S NEW}

Last assessed as up-to-date: 26 March 2015.

\begin{tabular}{lll}
\hline Date & Event & Description \\
\hline 26 March 2015 & New search has been performed & Search updated. \\
\hline 26 March 2015 & New citation required but conclusions have not changed & $\begin{array}{l}\text { Five new trials included, one new trial excluded and one } \\
\text { study awaiting classification } \\
\text { Title changed from 'Full-mouth disinfection for the } \\
\text { treatment of adult chronic periodontitis' to 'Full-mouth } \\
\text { treatment modalities (within 24 hours) for chronic pe- } \\
\text { riodontitis in adults' }\end{array}$ \\
\hline
\end{tabular}

\section{H I S T O R Y}

Protocol first published: Issue 1, 2004

Review first published: Issue 1, 2008

\begin{tabular}{lll}
\hline Date & Event & Description \\
\hline 6 March 2012 & Amended & Additional tables linked to text. \\
\hline 30 July 2008 & Amended & Converted to new review format. \\
\hline
\end{tabular}




\section{CONTRIBUTIONS OFAUTHORS}

Jörg Eberhard: literature search, review of full-text articles, data extraction, composition of the update.

Sören Jepsen: literature search, review of full-text articles, data extraction, composition of the update.

Pia-Merete Jervøe-Storm: data extraction, data input, composition of the update.

Ian Needleman: protocol development, consultant during the review process.

Helen Worthington: statistical analysis, data input, risk of bias, writing of abstract and results section.

\section{DECLARATIONSOF INTEREST}

Joerg Eberhard: none known.

Sören Jepsen: I am an author of one of the included trials but I did not assess the risk of bias for this trial.

Pia-Merete Jervøe-Storm: I am an author of one of the included trials but I did not assess the risk of bias for this trial.

Ian Needleman: I have received funding for lectures and research from industry related to oral hygiene products and prevention of ventilator-associated pneumonia.

Helen V Worthington: none known.

\section{SOURCES OF SUPPORT}

\section{Internal sources}

- School of Dentistry, The University of Manchester, UK.

- University Hospital Schleswig-Holstein, Campus Kiel, Germany.

- University College London, UK.

- University Hospital Bonn, Germany.

\section{External sources}

- National Institute of Health Research, UK.

The NIHR is the largest single funder of the Cochrane Oral Health Group.

Disclaimer:

The views and opinions expressed therein are those of the authors and do not necessarily reflect those of the NIHR, NHS or the Department of Health.

- Cochrane Oral Health Group Global Alliance, Other.

The production of all our reviews is assisted by funding from our Global Alliance partners (http://ohg.cochrane.org/): British Association for the Study of Community Dentistry, UK; British Association of Oral Surgeons, UK; British Orthodontic Society, UK; British Society of Paediatric Dentistry, UK; British Society of Periodontology, UK; Canadian Dental Hygienists Association, Canada; Mayo Clinic, USA; National Center for Dental Hygiene Research \& Practice, USA; New York University College of Dentistry, USA; and Royal College of Surgeons of Edinburgh, UK 


\section{DIFFERENCES BETWEEN PROTOCOLANDREVIEW}

- We changed the title to include all treatment modalities, not just FMD.

- We added an objective to compare FMS with FMD.

- We restructured the presentation of the results by tooth type and justified this in the background.

- We added 3 to 4 months data to the 6 to 8 months data.

- We changed the sensitivity analysis in the methods section to reduce the number of analyses. This now reads: 'We conducted sensitivity analyses by analysing only studies assessed as having low risk of bias, and by excluding unpublished literature'.

\section{NOTES}

None.

\section{N D EX TERMS}

\section{Medical Subject Headings (MeSH)}

Anti-Infective Agents, Local [ ${ }^{*}$ therapeutic use]; Chlorhexidine [ ${ }^{*}$ therapeutic use]; Chronic Periodontitis [* drug therapy]; Dental Scaling [*methods]; Disinfection [methods]; Periodontal Index; Randomized Controlled Trials as Topic; Root Planing [* methods]; Tooth Loss [prevention \& control]

\section{MeSH check words}

Adult; Humans 